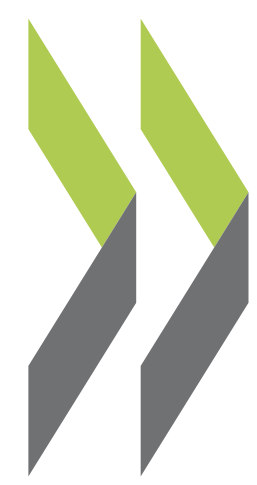

OECD Economics Department Working Papers No. 1583

Who patents, how much is real invention and how relevant? A snapshot of firms and their inventions Margit Molnar, based on the 2016 SIPO China Patent Survey Hui Xu 
ECONOMICS DEPARTMENT

WHO PATENTS, HOW MUCH IS REAL INVENTION AND HOW RELEVANT? - A

SNAPSHOT OF FIRMS AND THEIR INVENTIONS BASED ON THE 2016 SIPO CHINA PATENT SURVEY

ECONOMICS DEPARTMENT WORKING PAPERS No. 1583

By Margit Molnar and Hui Xu

OECD Working Papers should not be reported as representing the official views of the OECD or of its member countries. The opinions expressed and arguments employed are those of the author(s).

Authorised for publication by Isabell Koske, Deputy Director, Country Studies Branch, Economics Department

All Economics Department Working Papers are available at www.oecd.org/eco/workingpapers.

JT03455823 
OECD Working Papers should not be reported as representing the official views of the OECD or of its member countries. The opinions expressed and arguments employed are those of the author(s).

Working Papers describe preliminary results or research in progress by the author(s) and are published to stimulate discussion on a broad range of issues on which the OECD works.

Comments on Working Papers are welcomed, and may be sent to the Economics Department, OECD, 2 rue André-Pascal, 75775 Paris Cedex 16, France, or by e-mail to econ.contact@oecd.org.

All Economics Department Working Papers are available at www.oecd.org/eco/workingpapers.

On 25 May 2018, the OECD Council invited Colombia to become a Member. At the time of preparation the deposit of Colombia's instrument of accession to the OECD Convention was pending and therefore Colombia does not appear in the list of OECD Members and is not included in the OECD zone aggregates.

This document and any map included herein are without prejudice to the status of or sovereignty over any territory, to the delimitation of international frontiers and boundaries and to the name of any territory, city or area.

The statistical data for Israel are supplied by and under the responsibility of the relevant Israeli authorities. The use of such data by the OECD is without prejudice to the status of the Golan Heights, East Jerusalem and Israeli settlements in the West Bank under the terms of international law.

(C) OECD (2019)

You can copy, download or print OECD content for your own use, and you can include excerpts from OECD publications, databases and multimedia products in your own documents, presentations, blogs, websites and teaching materials, provided that suitable acknowledgment of OECD as source and copyright owner is given. All requests for commercial use and translation rights should be submitted to rights@oecd.org 


\section{ABSTRACT / RESUMÉ \\ Who patents, how much is real invention and how relevant? - A snapshot of firms and their inventions based on the 2016 SIPO China Patent Survey}

China has surpassed the United States in patent applications and has become world leader. Strong patenting activity, however, did not lead to strong productivity growth. The delinking of patenting activity from productivity growth could be explained by quality and relevance issues. Although the number of patents has been soaring, few are genuine inventions. Relatively low utilisation rates of patents point to a low degree of relevance. This paper uses a representative survey of Chinese patenting firms to provide a detailed picture of the patenting landscape along the dimensions of geographical areas, detailed industrial sectors, traditional and modern industries as defined by the Chinese government, firm age, size and ownership. It also overviews government subsidies across firms. Transport equipment makers hold most patents per firm, followed by electronics manufacturers. State-owned firms spend more on R\&D per patent, but hold fewer patents per researcher than private or foreign-invested firms. High patenting performance and government support are not necessarily linked to high utilisation of patents. Smaller, younger and private firms expect a higher return on their patents and so do exterior design patent holders. Furthermore, the paper examines what drives patenting activity. Higher R\&D spending by the firm and higher share of researchers in its workforce tend to be associated with higher patents per employee. Smaller and older firms tend to patent more, and government support also appears to matter. Exterior design patents are associated with different firm characteristics: R\&D intensity is lower and government support matters less. Most firms consider IPR protection insufficient and the share of firms having experienced patent infringement is the greatest among the largest firms. Many of them do not do anything once their rights are infringed as they do not expect effective remedy. Instead of patenting, which may not provide sufficient protection from imitators, they adopt other strategies like reaping the first mover advantage to market their goods or sign confidentiality agreements with their staff or contracts on commercial secrets.

This Working Paper relates to the 2019 Economic Survey of China (http://www.oecd.org/economy/chinaeconomic-snapshot/).

JEL codes: O31, O34, O38

Keywords: Chinese patenting, invention patents, firm-level analysis, government subsidies, IPR

Qui dépose des brevets ? Quelle part représentent les véritables inventions ? Dans quelle mesure les brevets sont-ils pertinents ? - Panorama des entreprises et de leurs inventions à partir de l'enquête sur les brevets en Chine réalisée par le Bureau d'État de la propriété intellectuelle de la République Populaire de Chine (BEPIC) en 2016

La Chine dépose désormais plus de demandes de brevet que les États-Unis et occupe la première place au niveau mondial dans ce domaine. Le nombre élevé de dépôts de brevet ne s'est cependant pas traduit par une croissance vigoureuse de productivité. Des problèmes de qualité et de pertinence pourraient expliquer ce découplage. Le nombre de brevets a certes beaucoup augmenté, mais peu de brevets portent sur de véritables inventions. Le taux, relativement faible, d'utilisation des brevets indique que leur degré de pertinence est faible. Cet article s'appuie sur une enquête représentative des entreprises brevetantes chinoises pour brosser un panorama détaillé de l'activité de dépôt de brevet en fonction des zones géographiques, des secteurs industriels précis, de la distinction entre secteurs traditionnels et modernes définie par les autorités chinoises, mais aussi de l'âge, de la taille et du régime de propriété de l'entreprise. II offre également une vue d'ensemble des subventions publiques par entreprise. Les fabricants de matériel de transport détiennent le plus de brevets par entreprise, suivi des fabricants de produits électroniques. Les entreprises publiques dépensent plus en recherche-développement (R-D) par brevet, 


\section{4 | ECO/WKP(2019)53}

mais détiennent moins de brevets par chercheur que les entreprises privées ou celles à capitaux étrangers. Une entreprise peut déposer un nombre important de brevets et bénéficier d'aides publiques sans pour autant avoir un taux élevé d'utilisation de brevets. Les entreprises petites, jeunes et privées cherchent à obtenir un plus haut rendement sur leurs brevets, tout comme les détenteurs de brevets de dessin. Par ailleurs, cet article analyse les déterminants de l'activité de dépôt de brevet. Lorsqu'une entreprise dépense beaucoup en R-D et compte une part importante de chercheurs, elle détient généralement un nombre plus important de brevets par salarié. Les entreprises plus petites et plus anciennes ont tendance à déposer davantage de brevets tout comme celles qui bénéficient d'aides publiques. Les caractéristiques différentes sont différentes dans le cas des brevets de dessin : l'intensité de R-D des entreprises est plus faible et les aides publiques jouent un rôle moins important. La plupart des entreprises estiment que la protection des droits de propriété intellectuelle est insuffisante et les grandes entreprises sont proportionnellement celles qui enregistrent le plus de contrefaçons de produits brevetés. Nombre de ces entreprises n'engagent aucune action, car elles n'espèrent aucune mesure corrective efficace. Au lieu de déposer des brevets, parfois insuffisants pour se protéger contre les imitateurs, elles adoptent d'autres stratégies : maximiser les avantages du précurseur pour commercialiser leurs produits ou signer des accords de confidentialité ou des accords sur le secret des affaires avec les membres de leur personnel, par exemple.

Ce Document de travail se rapporte à l'Étude économique de la Chine 2019 (http://www.oecd.org/fr/economie/chine-en-un-coup-d-oeil/).

Classification JEL: O31, O34, O38

Mots-clés: dépôt de brevet en Chine, brevet d'invention, analyse du niveau entreprise, aide publique, droit de la propriété intellectuelle 


\section{Table of contents}

Who patents, how much is real invention and how relevant? - A snapshot of firms and their inventions based on the 2016 SIPO China Patent Survey

Introduction

Who patents? - A snapshot of patenting firms

Transport equipment and electronics makers hold most manufacturing patents 16

Research firms jointly are the largest patent holders in services $\quad 20$

Most patenters are medium-to large, but giants produce most patents $\quad 22$

$\begin{array}{ll}\text { Most patenters are mature firms with over } 15 \text { years of history } & 27\end{array}$

Eastern provinces and municipalities are home to most patenting firms $\quad 29$

The patent landscape is dominated by SOEs 33

Who are the real inventors? $\quad 36$

Electronics makers lead in invention patents 38

Research firms and telecommunications and trading firms hold most invention patents in
services

Mainly larger firms hold invention patents $\quad 40$

SOEs are the largest invention patenters $\quad 44$

Gauging patent relevance: utilisation rates and expected revenues $\quad 44$

Guangdong is the best utiliser of patents among the largest patenting provinces 44

Transport equipment makers, telecommunications service providers and wholesalers/retailers have the highest utilisation rates 45

Large and medium-size as well as older firms perform better in patent utilisation 45

Utilities, transport firms, micro, young and private firms and those in some Western provinces expect the highest income from patenting 46

$\begin{array}{ll}\text { How different are "super" patenters? } & 47\end{array}$

What drives patenting activity? $\quad 52$

Government subsidies for R\&D and patenting 56

Towards higher productivity through more relevant and higher quality patenting 58

References $\quad 64$

Annex A. Definition of manufacturing sector sub-groups 66

Annex B. Definition of modern and traditional industries 68

\section{Tables}

Table 1. Regression results - What factors determine patenting $\quad 54$

Table 2. Exterior design patenting differs much from invention and utility patenting 55

$\begin{array}{ll}\text { Table A.1. Manufacturing sub-groups } & 66\end{array}$ 


\section{6 | ECO/WKP(2019)53}

Table B.1. New and traditional industries

\section{Figures}

Figure 1. Most manufacturing firms are medium and large size $\quad 9$

Figure 2. Patents are concentrated at very large firms 9

Figure 3. Micro firms hold the most effective patents per researcher and have the highest share of researchers 10

Figure 4. The larger firms collaborate more in research $r$

Figure 5. The larger firms are more likely to collaborate in research in manufacturing sub-industries 12

Figure 6. The largest firms are more likely to collaborate in R\&D in most provinces, though there are exceptions

Figure 7. Some Guangdong electronics firms are very researcher-intensive

Figure 8. In most manufacturing sub-sectors the larger the firm the more it relies on government support 19

Figure 9. Modern industries have higher educated workforce than traditional ones 20

Figure 10. Larger firms in many services industries are reliant on government support 21

Figure 11. Micro firms hold most effective patents per researcher in many provinces 23

Figure 12. The share of researchers decreases with firm size $\quad 26$

Figure 13. Micro and small firms spend a somewhat greater share of their revenue on R\&D 27

Figure 14. Well-established firms are most represented in the survey 28

$\begin{array}{lr}\text { Figure 15. Firm age increases by firm size } & 28\end{array}$

Figure 16. Government support by firm size varies across provinces $\quad 31$

Figure 17. Private firms are well represented but the number of effective patents is higher in SOEs 34

Figure 18. Cooperatives and private firms hold most patents per researcher $\quad 35$

Figure 19. Foreign and private firms have a low share of researchers and employees with tertiary education 35

Figure 20. SOEs spend more than private or foreign firms on R\&D both in absolute terms and per effective patent

Figure 21. Very large firms in modern manufacturing industries tend to have a greater share of invention patents

Figure 22. Resource-processing industries hold the largest share of invention patents among manufacturing industries

Figure 23. Larger firms and modern industries are more likely to hold design patents

Figure 24. The largest firms hold the highest share of invention patents in many provinces 41

Figure 25. Super patenters are also super inventors $\quad 47$

Figure 26. Utility patenting is most common $\quad 48$

Figure 27. Electronics and transport equipment makers lead among super patenters 449

Figure 28. Research and wholesale and retail sales lead among super patenting services firms 50

Figure 29. Most patents are produced by Jiangsu and Guangdong super patenters 51

Figure 30. SOEs lead in invention and utility patenting and private firms in design $\quad 52$

Figure 31. In China direct and indirect subsidies for R\&D are smaller relative to GDP than in many OECD
countries

$\begin{array}{ll}\text { Figure 32. Government budget allocation for R\&D } & 57\end{array}$

Figure 33. Most firms, regardless of firm size, consider IPR protection insufficient 58

Figure 34. Very large firms are more likely to have experienced patent infringement $\quad 59$

Figure 35. Some smaller firms consider IPR protection too high $\quad 60$

$\begin{array}{ll}\text { Figure 36. Several firms prefer not to register patents } & 61\end{array}$

\section{Boxes}

Box 1. Who are the top patenters? 


\section{Who patents, how much is real invention and how relevant? - A snapshot of firms and their inventions based on the 2016 SIPO China Patent Survey}

By Margit Molnar and Hui $\mathrm{Xu}^{1}$

\section{Introduction}

1. China is already the leading patenter in the world, in recent years surpassing the United States in patent applications and catching up with the European Union in terms of R\&D spending relative to GDP. Empirical research, however, shows that the R\&D and patent boom has not translated into rapid productivity growth (Boeing et al., 2016) and in general, stalling productivity growth is a concern when the economy is switching from double-digit to high single-digit growth rates. The disconnect between patenting and productivity growth may be related to quality and relevance issues (OECD, 2019 and 2017).

2. As firms are the largest patenters as well as the largest R\&D dispensers in China, a better understanding of patenting activity at the firm level can contribute to a better design of policies seeking higher productivity growth. Notwithstanding China's rapid catching up with the top innovators on several measures, there is only a single Chinese firm, Huawei, which managed to make its way into the club of top 100 global innovators. ${ }^{2}$ Huawei is also among the top R\&D spenders in the world; in 2016 it spent nearly $15 \%$ of its revenue on R\&D. To get insights into patenting firms' characteristics and the environment for patenting, the 2016 China Patent Survey of patenting firms conducted by the State Intellectual Property Office (SIPO) is exploited in this paper.

3. The 2016 SIPO China Patent Survey represents over $3 \%$ of the roughly 270,000 patenters in China. It was conducted in 2016 and therefore refers to the situation at end-2015. Patenters in 23 provinces

\footnotetext{
${ }^{1}$ Margit Molnár is Head of the China Desk at the OECD Economics Department and Hui Xu is researcher at the Development Research Centre of the State Intellectual Property Office. The authors would like to thank Alvaro Pereira, Patrick Lenain and Balázs Égert from the Economics Department and Yilong Qu from the Directorate for Science, Technology and Innovation for their useful comments and Stephanie Henry for editorial assistance.
}

2“Top $100 \quad$ Global Innovators.” Thomson Reuters. http://top100innovators.stateofinnovation.thomsonreuters.com (accessed Sept. 27, 2017). This index compiled by Clarivate Analytics takes into account not only the volume, but also the influence, success and globalisation of patents. 


\section{8 | ECO/WKP(2019)53}

and province-level municipalities (henceforth provinces) participated in the survey. ${ }^{3}$ Those provinces accommodate most patenters in China. The survey method is stratified sampling ensuring that the share of patenters by the number of patents is the same as in the total patenter population. That is the share of firms holding 1-2, 3-9, 10-29 and 30-99 patents is the same, while all firms with over 100 patents are surveyed. 8,623 firms provided valid answers to the survey covering 764,329 patents.

4. This paper first investigates what types of firms patent along the multiple dimensions of sectoral, size, ${ }^{4}$ age, regional and ownership/registration status of patenting firms, also assessing the extent of concentration along those dimensions. In the second section, the size and share of invention patents is examined and major invention patenter characteristics are identified along the dimensions used earlier. The third section investigates the state and conditions of patent utilisation and expected returns as potential indicators of patent relevance. The last section identifies the profile of super patenters, i.e. those firms holding over 100 patents from the point of view of more "ordinary" patenters.

\section{Who patents? - A snapshot of patenting firms}

5. The universe of the over 8000 patenting firms participating in the survey represents all firm sizes, regions, sectors and ownerships and also has a large variation in terms of firm age. Most patenters are manufacturers with Beijing being the only province-level entity where over half of patenters are services firms. This is attributable to the large share of research firms (firms that belong to the R\&D sub-sector, which is number 73 according to the Chinese National Bureau of Statistics official classification, for details see Annex B) among Beijing patenters and also to a relatively low level of manufacturing activity in the capital. Most firms in the survey are of medium- to large size (between 50 and 999 employees), except in mining, construction and modern services, where most are very large, employing over 1000 people (Figure 1). Most resources, including material and human, are concentrated in very large firms. Such firms invest the most in innovation; not only in absolute terms, but also on average per patent and produce most patents (Figure 2).

\footnotetext{
3 The 23 provinces include: Anhui, Beijing, Chongqing, Fujian, Gansu, Guangdong, Guangxi, Guizhou, Hebei, Heilongjiang, Henan, Hubei, Hunan, Jiangsu, Liaoning, Ningxia, Shandong, Shanghai, Sichuan, Tianjin, Xinjiang, Yunnan and Zhejiang.

${ }^{4}$ For an easier read, the paper uses the international size classification, whereby firms with up to 19 employees are micro firms, 20-49 small, 50-245 medium, 250-999 large and with at least 1000 employees very large firms. Molnar and $\mathrm{Lu}$ (2019) provide a table of the Chinese official classification of firms by size, where the thresholds vary by sector. What complicates the classification is that large, medium and small firms must meet the lower thresholds of all criteria (defined in terms of size of revenues and/or assets and/or number of staff) to qualify, while micro firms at least one.
} 
Figure 1. Most manufacturing firms are medium and large size

Number of firms by size in modern and traditional manufacturing
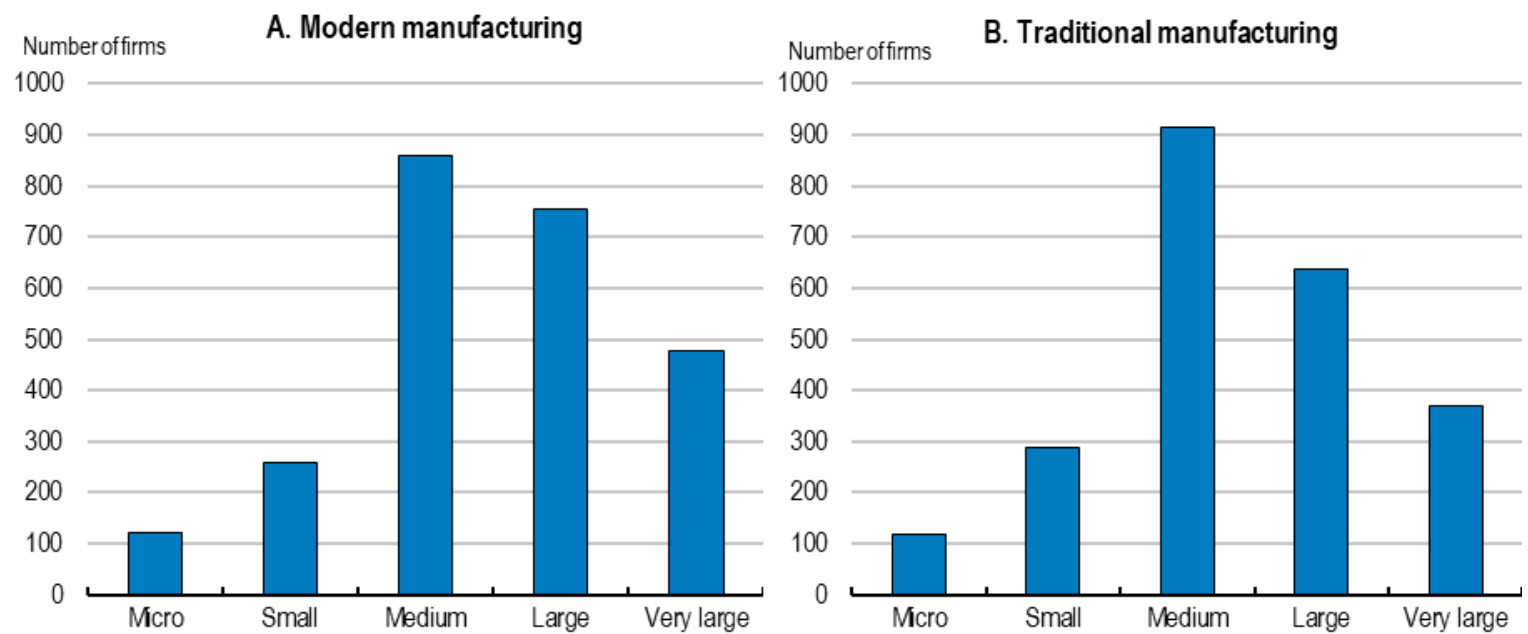

Note: Based on the official classification of industries into new/modern and traditional (National Bureau of Statistics, 2012). Size categories are defined using the definition of up to 19 employees for micro firms, 20-49 for small, 50-245 for medium, 250-999 for large and at least 1000 employees for very large firms.

Source: Authors' calculation based on the 2016 SIPO Patent Survey.

Figure 2. Patents are concentrated at very large firms

Number of patents by firm size
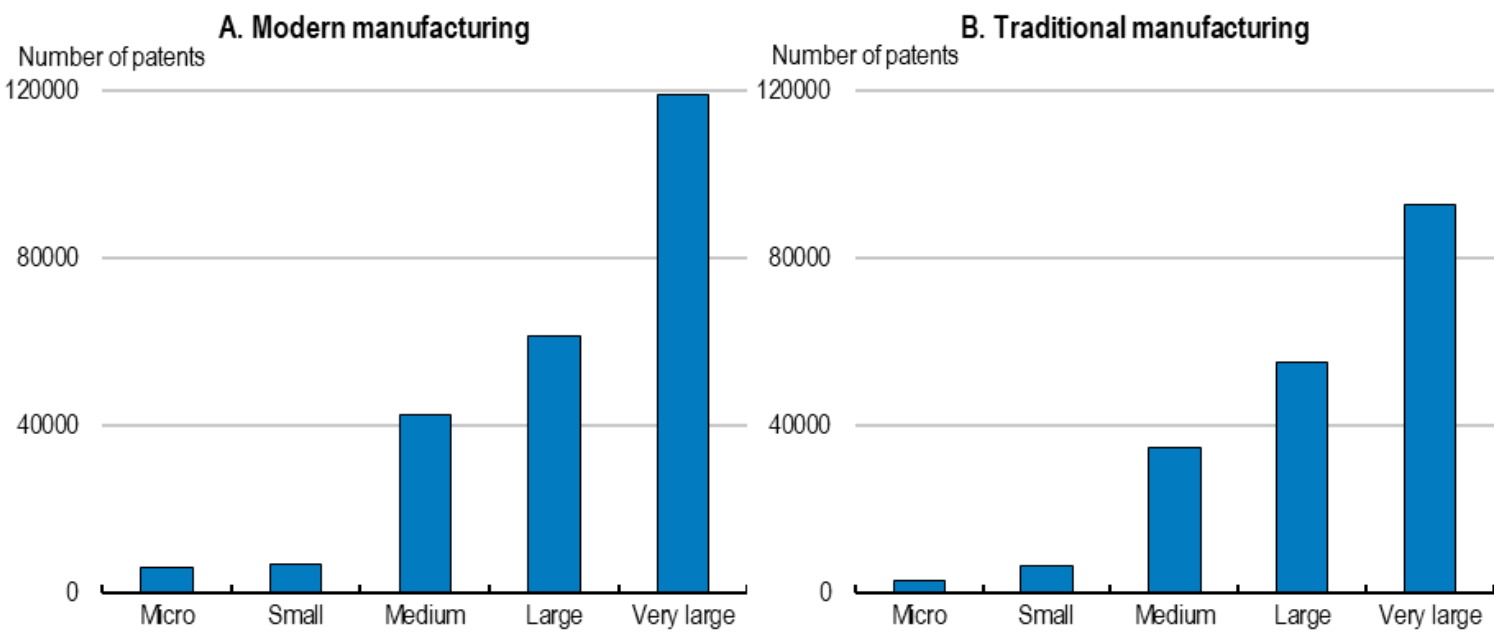

Note: Based on the official classification of industries into new/modern and traditional (National Bureau of Statistics, 2012). Size categories are defined using the definition of up to 19 employees for micro firms, 20-49 for small, 50-245 for medium, 250-999 for large and at least 1000 employees for very large firms.

Source: Authors' calculation based on the 2016 SIPO China Patent Survey.

6. In contrast, micro firms appear to produce the most patents per researcher (Figure 3). They also have the highest share of researchers in total employees among all firm sizes. In modern manufacturing industries, small firms are more important innovators than the large ones. Foreign and private firms are more active in manufacturing, the former more in modern, the latter more in traditional manufacturing industries, while SOEs in services industries, in particular traditional ones. This is not surprising as SOEs dominate many services industries in terms of output and employment (OECD, 2015 and Molnar and Wang, 2015). 
Figure 3. Micro firms hold the most effective patents per researcher and have the highest share of researchers
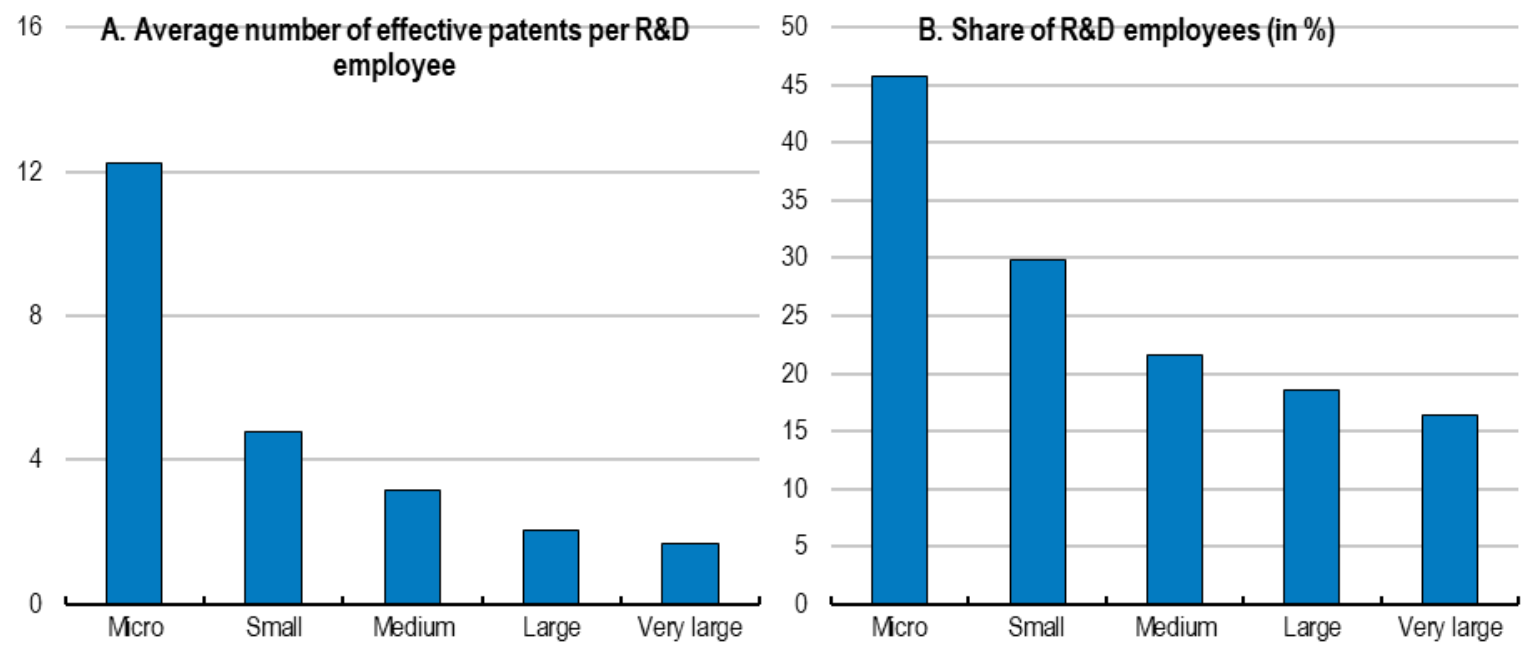

Note: Size categories are defined using the definition of up to 19 employees for micro firms, 20-49 for small, 50-245 for medium, 250-999 for large and at least 1000 employees for very large firms.

Source: Authors' calculation based on the 2016 SIPO Patent Survey.

7. Given the relatively high degree of concentration of patents in very large firms, a closer look at the top 25 patenters provides insights into what the major features of the most successful patenting firms are (Box 1).

\section{Box 1. Who are the top patenters?}

The top 25 firms with the largest number of effective patents jointly own nearly $11 \%$ of all patents, on average nearly 3300 each, the largest owning 7950. On average, they employ 62000 people, are 23 years' old and spent CNY 2.8 billion on R\&D in 2015. A third of them are in the transport equipment manufacturing industry, some in computer, communications and other electronics, ferrous metal smelting and processing, telecommunications and broadcasting and one each in coal mining and dressing, furniture manufacturing, medicine and pharmaceuticals manufacturing, electrical machinery and equipment, wholesale, postal services and commerce. $60 \%$ are located in the Eastern region and $20 \%$ each in the Central and Western. These top 25 inventor firms represent 13 provinces, four of which boast three such firms: Beijing, Shandong, Shanghai and Sichuan. In addition to Beijing and Shanghai, Wuhan, Shenzhen and Suzhou are the other cities where more than one such firm is registered. SOEs dominate the innovation landscape. $32 \%$ of the top 25 patenters are purely state-owned firms, $20 \%$ foreign invested, $4 \%$ purely private and the rest incorporated, limited liability and other firms with unspecified ownership.

Source: Authors' analysis using the 2016 SIPO China Patent Survey. 


\section{Larger firms are more likely to conduct joint research}

8. Patenting worldwide is mainly done as a result of collaborative efforts among firms within the same country or across borders. Given the ever expanding knowledge created, it is increasingly becoming the standard way of research. In China, it is mainly the largest manufacturing firms that collaborate on research projects (Figure 4) and the picture is broadly the same across manufacturing sub-sectors (Figure 5).

Figure 4. The larger firms collaborate more in research

Share of manufacturing firms collaborating in research by firm size

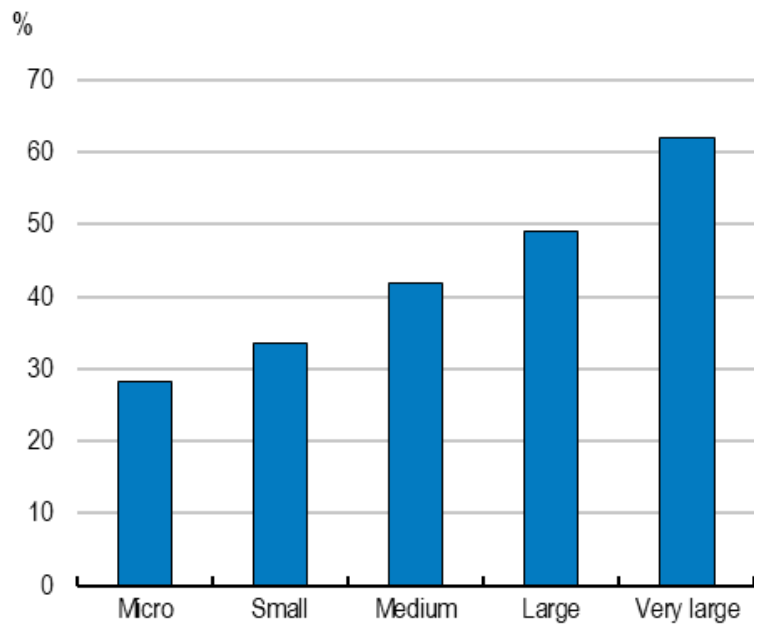

Note: Size categories are defined using the definition of up to 19 employees for micro firms, 20-49 for small, 50-245 for medium, 250-999 for large and at least 1000 employees for very large firms.

Source: Authors' calculation based on the 2016 SIPO China Patent Survey. 
12 | ECO/WKP(2019)53

Figure 5. The larger firms are more likely to collaborate in research in manufacturing subindustries

Share of firms collaborating in research by manufacturing sub-industry and firm size
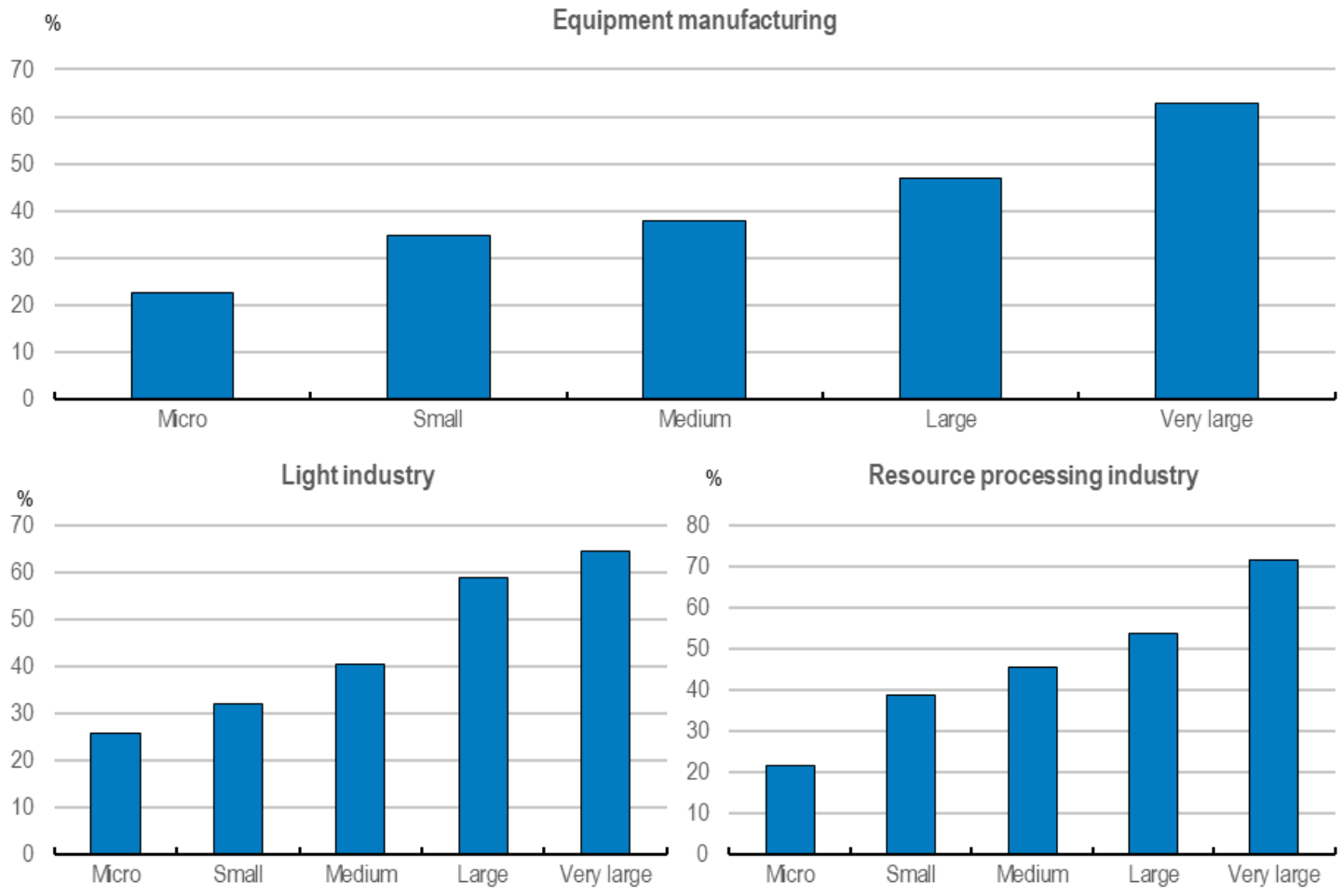

$\% \quad$ Resource processing industry
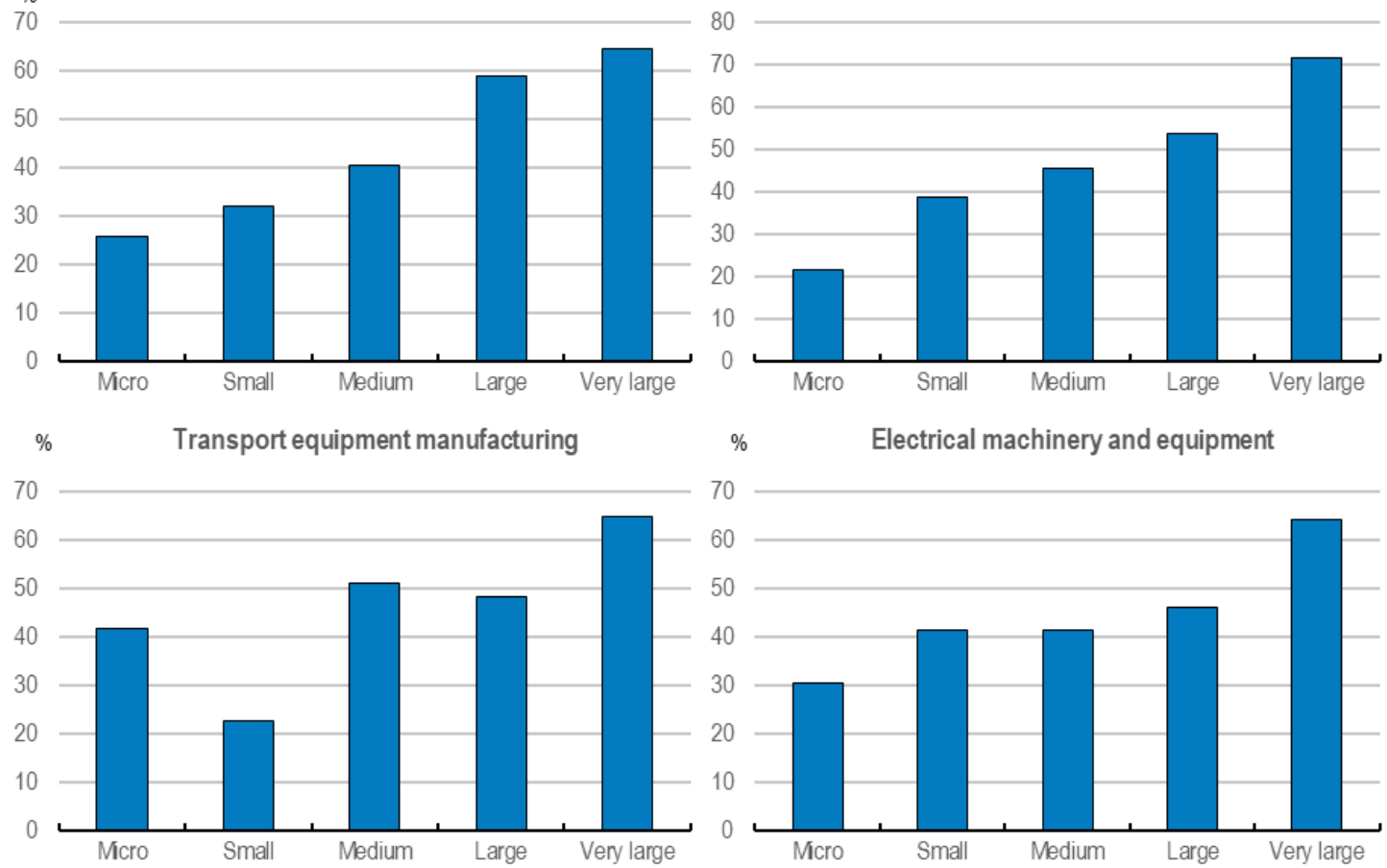

$\% \quad$ Electrical machinery and equipment

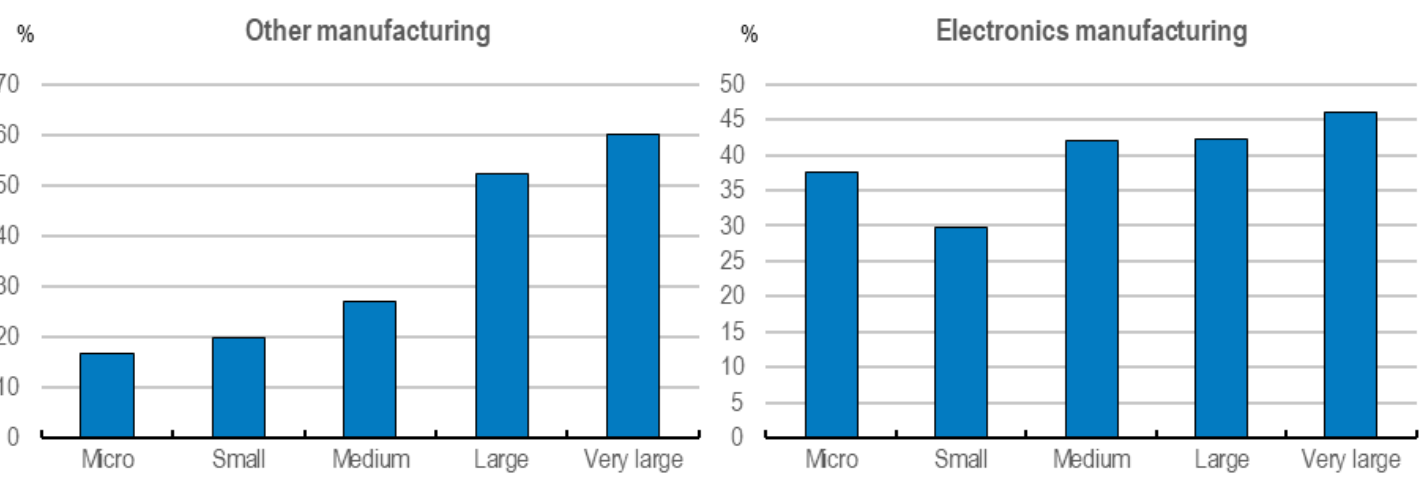


Selected service industries
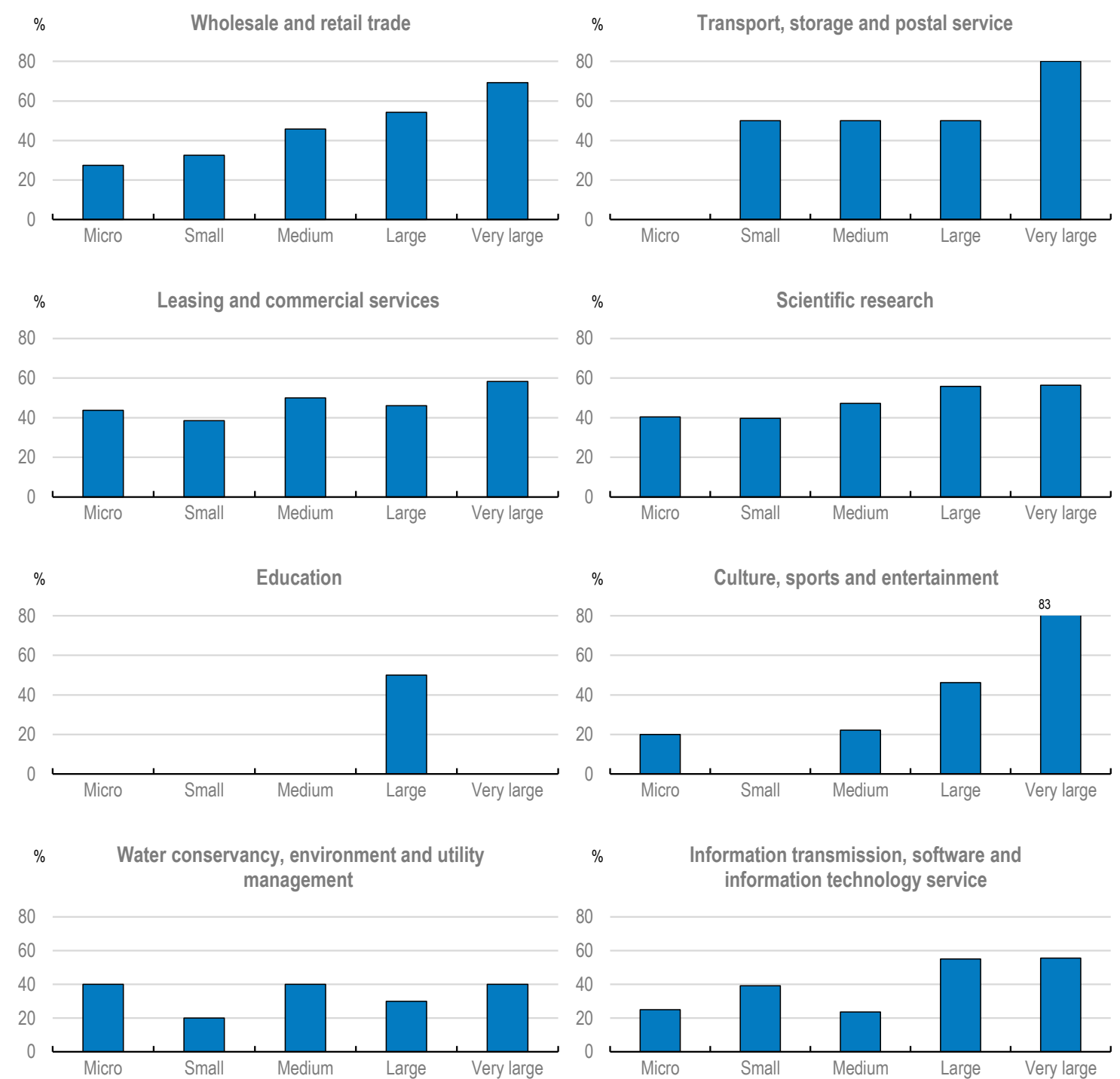

Note: Size categories are defined using the definition of up to 19 employees for micro firms, 20-49 for small, 50-245 for medium, 250-999 for large and at least 1000 employees for very large firms.

Source: Authors' calculation based on the 2016 SIPO China Patent Survey.

9. Similarly, in most provinces, larger firms collaborate more. In some cases, for instance, in the case of micro firms in Shandong and Chongqing, or small firms in Hunan and Guizhou, collaborative research is similarly common among smaller firms (Figure 6). There is also some variation across firms by ownership types by province, but in general a lower share of private firms than SOEs or foreign firms engage in collaborative research in most provinces. 
14 | ECO/WKP(2019)53

Figure 6. The largest firms are more likely to collaborate in R\&D in most provinces, though there are exceptions

Share of firms collaborating in R\&D by province and firm size

Panel A. Eastern provinces
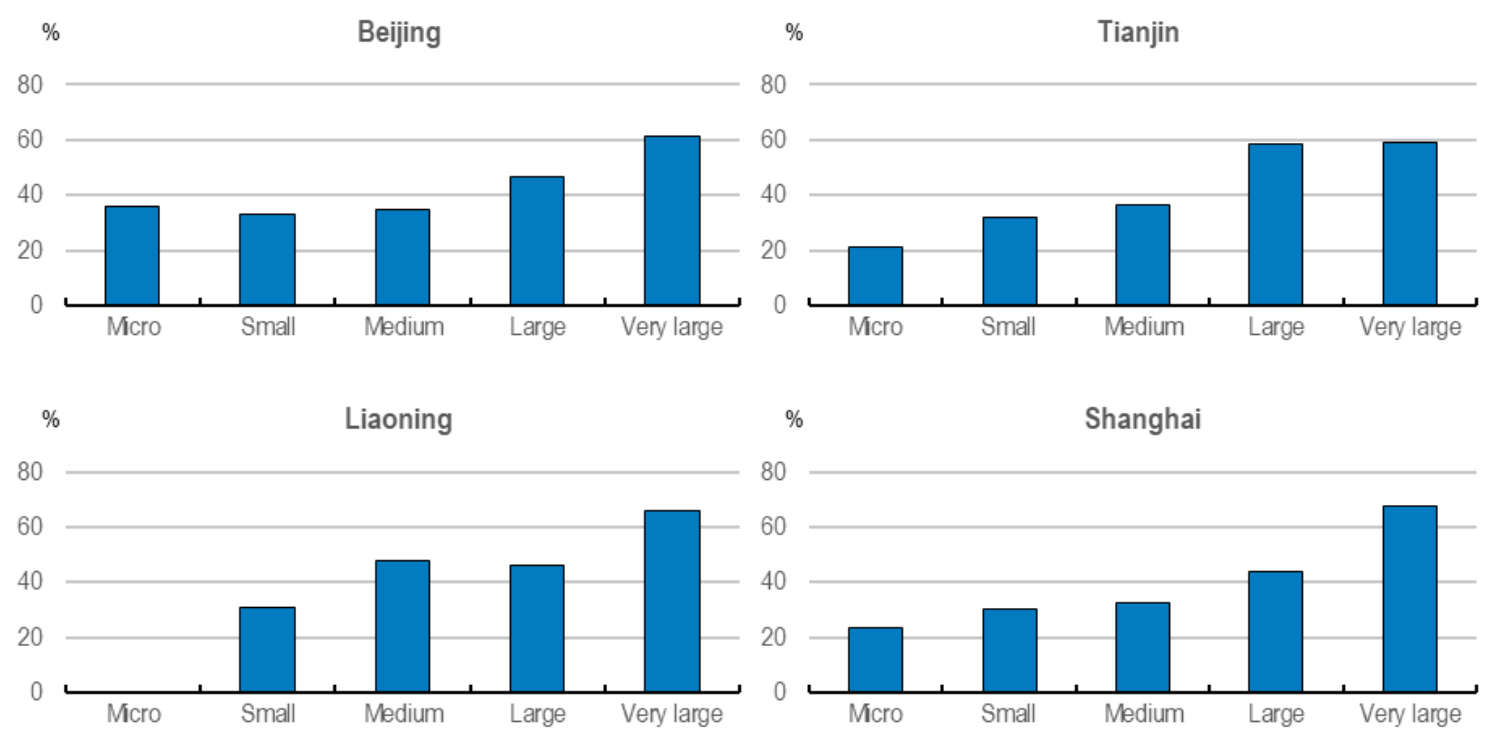

$\% \quad$ Shanghai
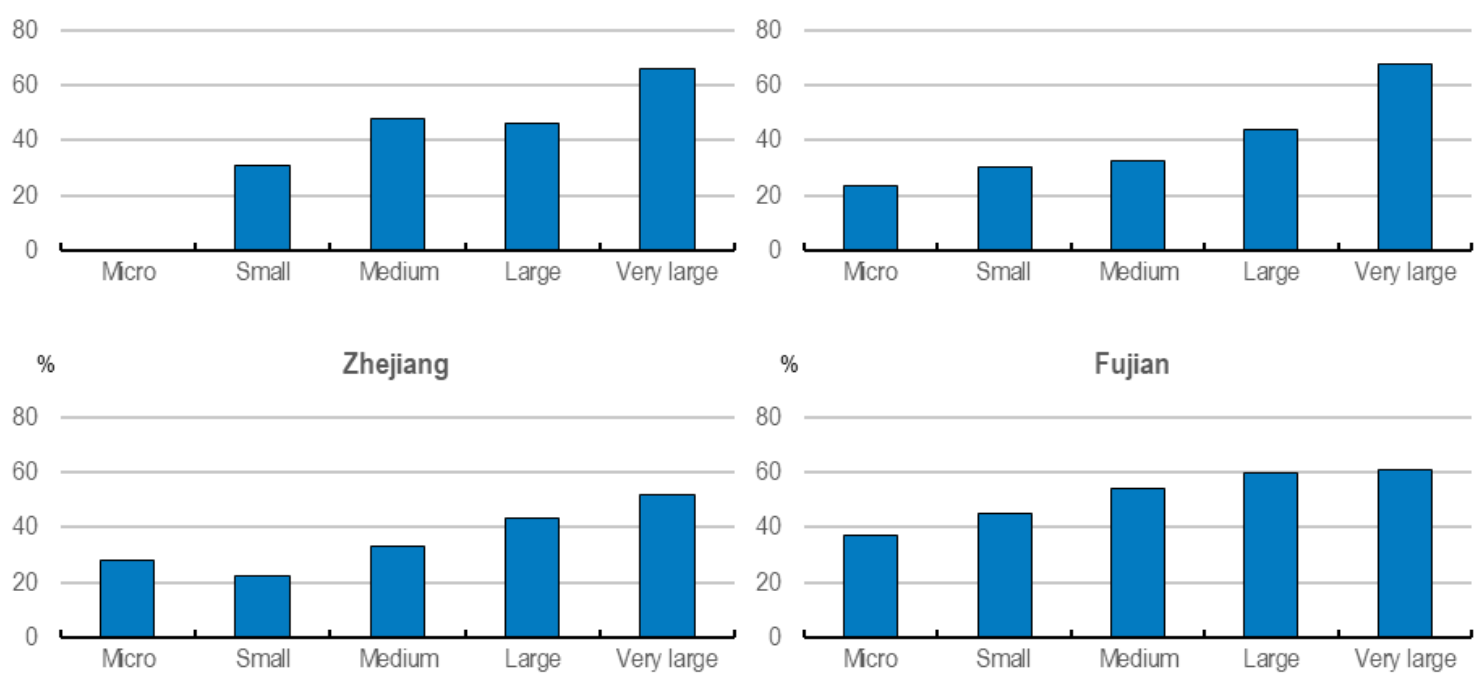

$\% \quad$ Fujian
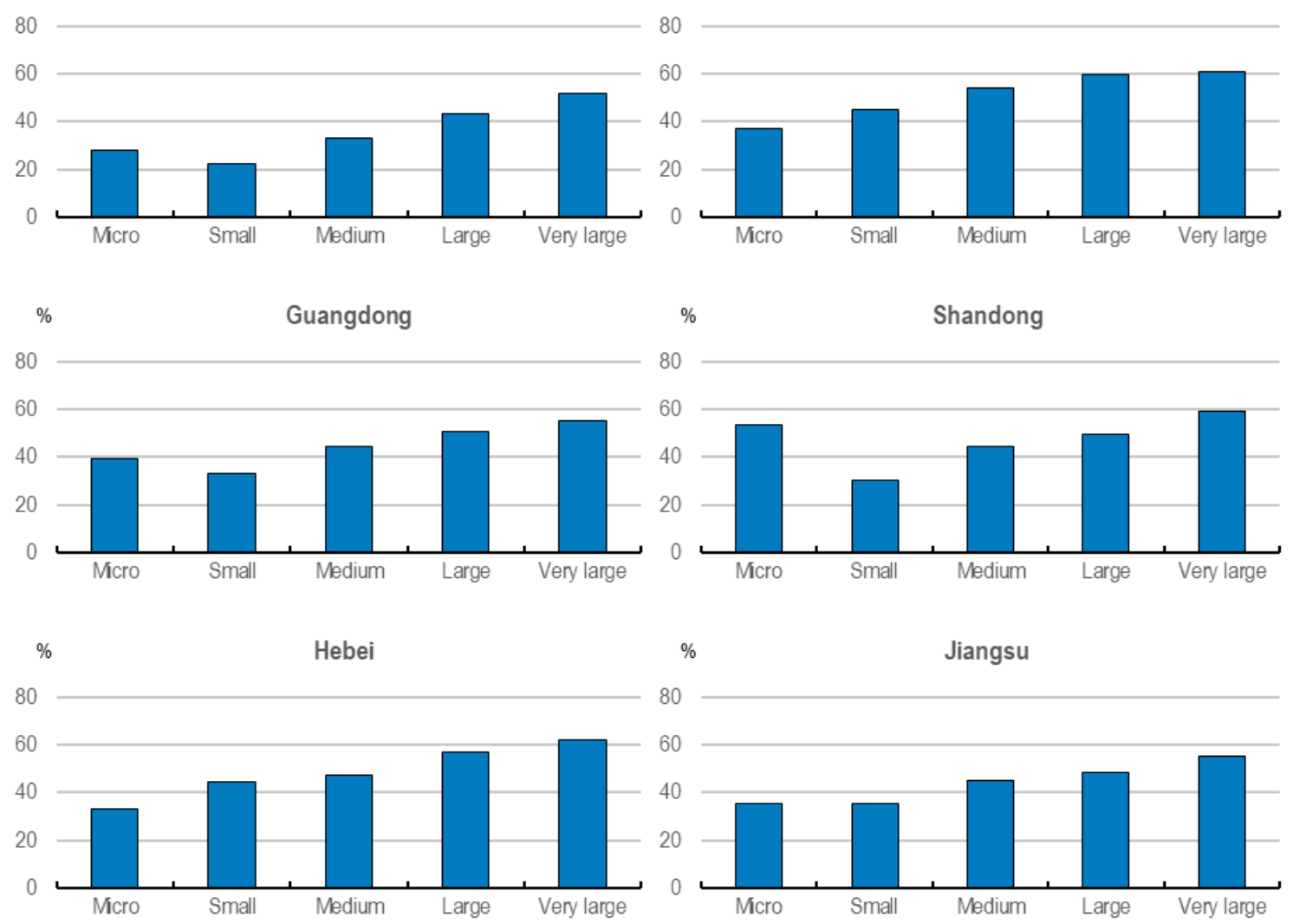
Panel B. Central provinces
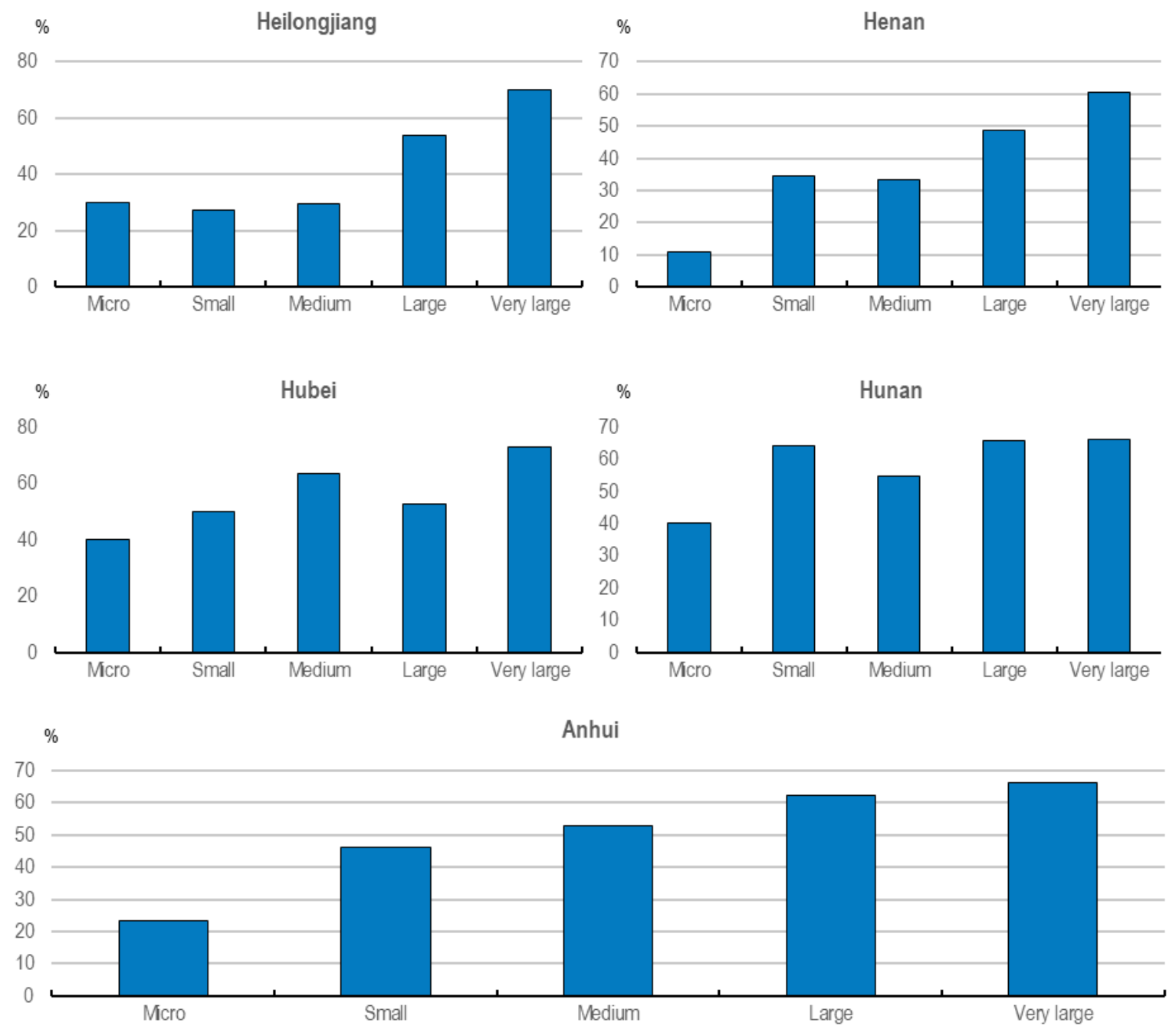
Panel C. Western provinces
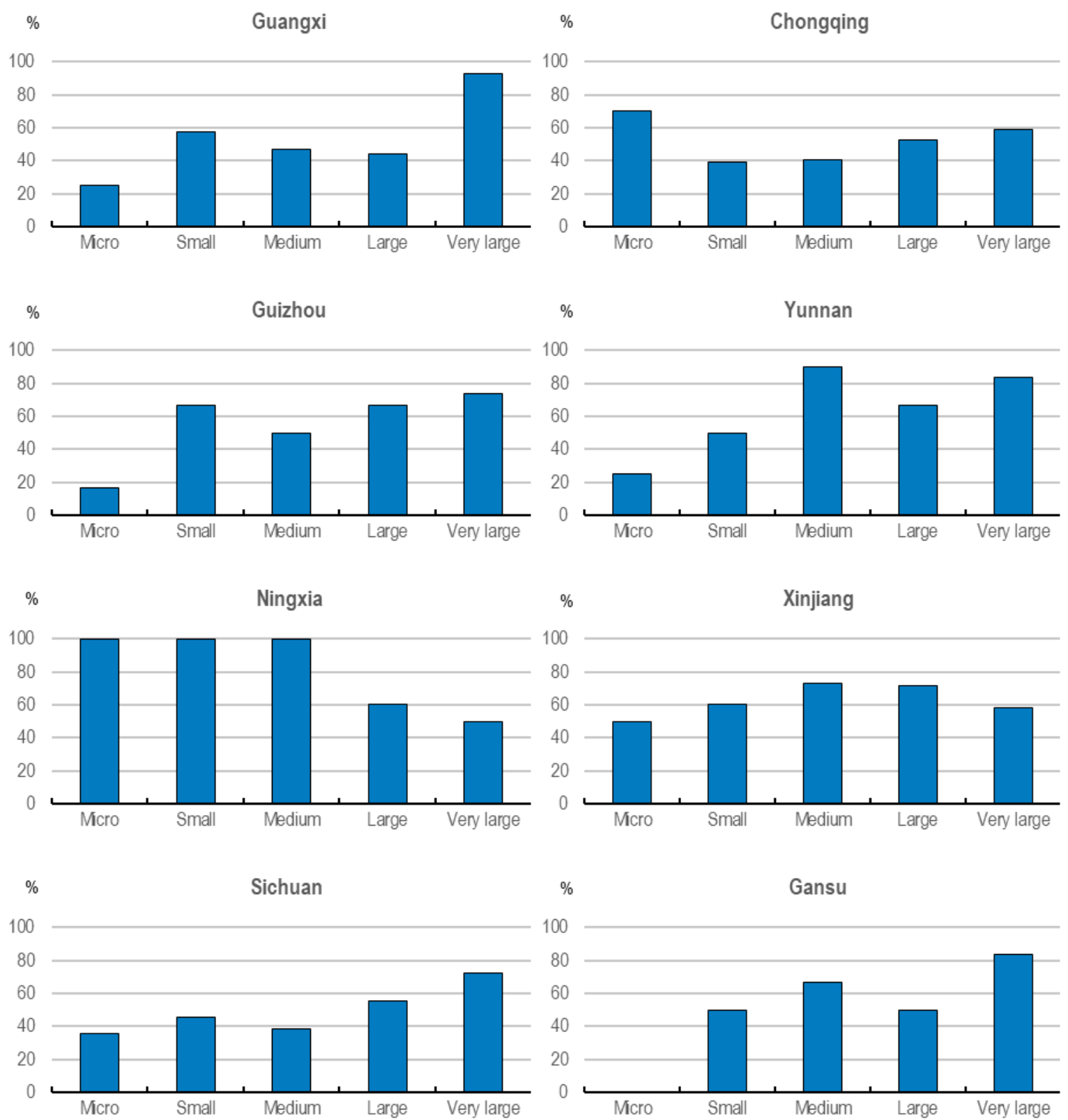

Note: According to the definition by China's National Bureau of Statistics, Eastern provinces include Beijing, Tianjin, Hebei, Liaoning, Shanghai, Jiangsu, Zhejiang, Fujian, Shandong, Guangdong and Hainan, Central provinces comprise Shanxi, Jilin, Heilongjiang, Anhui, Jiangxi, Henan, Hubei and Hunan and Western provinces cover Inner Mongolia, Guangxi, Chongqing, Sichuan, Guizhou, Yunnan, Tibet, Shaanxi, Gansu, Qinghai, Ningxia and Xinjiang Size categories are defined using the definition of up to 19 employees for micro firms, 20-49 for small, 50-245 for medium, 250-999 for large and at least 1000 employees for very large firms.

Source: Authors' calculation based on the 2016 SIPO China Patent Survey.

\section{Transport equipment and electronics makers hold most manufacturing patents}

10. Nearly $60 \%$ of patenting firms in the survey belong to manufacturing industries, a tiny $1 \%$ to primary industries and most of the remaining are services firms (for almost $8 \%$ of the firms it is not known which sector they belong to). Modern manufacturing industries hold more patents jointly than traditional industries, but on average, their patent holding does not differ significantly. An average manufacturing firm 
in the survey holds almost 90 effective patents, though the median number is around one third of it at 32 , given the very intense patenting activity in some very large firms. An average manufacturing patenter employs 1061 people (the median firm 209), among whom nearly $40 \%$ have a college degree (a third for the median firm) and 129 (the median is 30 ) or $19 \%$ of the staff (15\% for the median firm) are researchers.

11. Within manufacturing, transport equipment makers have the largest number of patents per firm, on average 150, again, the average figure masking very high concentration of patents in a few firms. Electronics manufacturers also fare better than the average manufacturer with 97 patents on average. Transport equipment makers jointly employ a similar number of people as electronics makers, but they number about half of that of electronics manufacturers, implying a larger average firm size. The firm with the largest number of patents (7950) is an electronics maker, though there is also a transport equipment manufacturer with over 7000 patents. There is no firm owning 5000-7000 patents and only four (among which one is a transport equipment maker) own between $4000-5000.13 \%$ of all patents recorded in the 2016 Patent Survey belong to electronics makers and $10 \%$ to transport equipment makers. While among transport equipment makers there are private, state-owned and foreign firms, among electronics makers there are very few SOEs. Electronics makers are concentrated in both the Yangtze and the Pearl River deltas (most in Jiangsu, Guangdong and Shanghai), while transport equipment makers in the Yangtze delta (Jiangsu, Zhejiang and Shanghai). Guangdong has a much larger scale in electronics than the other provinces, employing over $40 \%$ of electronics industry workers and $27 \%$ of industry researchers (Figure 7 ). If adding Jiangsu, the two provinces jointly employ two-thirds of electronics industry employees and half of research staff. Notwithstanding the sizes of their research forces, their median firm's researcher-intensity is below or just at the national average. The share of researchers is much higher in Heilongjiang, Guizhou, Hebei, Guangxi, Liaoning and Shanghai, though all except Shanghai have less than 10 electronics firms. In terms of employees, the transport equipment-making industry is less concentrated than electronics. Provinces along the Yangtze River (Hubei, Jiangsu and Shanghai) jointly employ about $40 \%$ of industry staff.

\section{Figure 7. Some Guangdong electronics firms are very researcher-intensive}

Kernel density of researchers in electronics

\section{A. China}

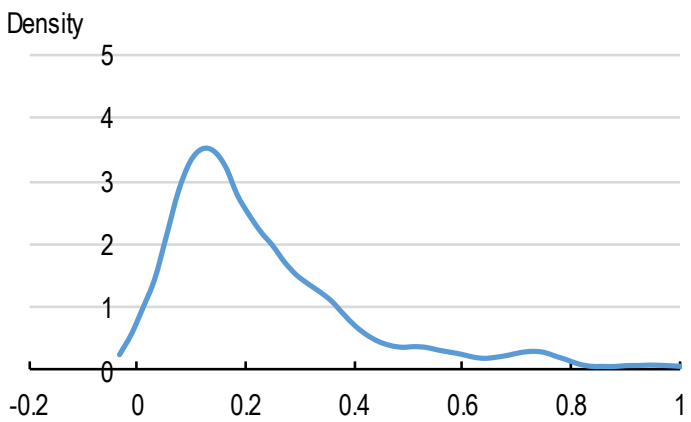

B. Guangdong

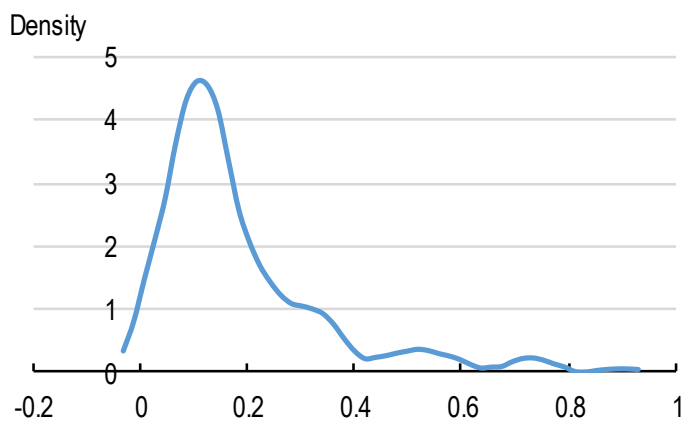

Source: Authors' calculation based on the 2016 SIPO China Patent Survey.

12. Among the seven manufacturing sub-groups, light industries perform the best in terms of patent per employee or patent per researcher. Resource processing, electronics and other manufacturing industries, in contrast, produce the fewest patents on those measures. Manufacturing firms, in general, spend a lower share of their revenue on R\&D than services firms. Electronics manufacturers are the most intense R\&D investors with $20 \%$ of them spending over $10 \%$ of their revenue on R\&D. Only $9 \%$ of transport equipment manufacturers spend similar relative amounts on R\&D, and at the other extreme, only $4 \%$ of 
light industry firms. There is some variation across industries in terms of median R\&D spending per effective patent or per researcher in different size groups. Electronics and electric machinery makers tend to be the largest spenders on both measures among both micro (below 20 employees) and very large firms (with at least 1000 employees). Transport equipment makers, in contrast, are ranking top only among large firms, but not among micro firms. Electronics manufacturers tend to be younger than transport equipment makers and there is an almost four-fold difference in per patent R\&D spending between the young and the mature firms, while for transport equipment makers the difference is only double. Moreover, there is not much difference in per patent spending among transport equipment-making firms below 15 years, it is only mature firms over 15 years that spend substantially more. This may reflect the importance of fixed costs of patenting and probably more homogeneity among patents in that industry. In contrast, the transport equipment-making industry is much less intensive in R\&D staff than electronics, with only Beijing firms having researchers make up over $20 \%$ of their workers. In electronics, firms in more than half of the provinces employ many researchers, over $20 \%$ of total staff.

13. The median manufacturing SOE spends more than double of that a median foreign firms on R\&D per patent, and roughly six times that of a median private firm. Most R\&D-intensive patenting among SOEs and foreign firms is in transport equipment and electronics manufacturing and resource processing industries. Private transport equipment and electronics makers' patenting is also highly R\&D-intensive, though instead of resource processing industries, electronic machinery makers come third. This may reflect larger required scale and thus more SOEs and foreign-invested firms in resource processing.

14. The median patent costs the highest in transport equipment manufacturing and resource processing industries, around five times as much as in light industries. Electronics makers spend the most on patent application and maintenance among manufacturers, both collectively and on average. While transport equipment makers also hold a large number of patents, on average they spend only about a third of that on patent application and maintenance. Higher patent fees may be related to greater importance of maintaining patents in the electronics industry.

15. The skewed patent structure towards transport equipment and electronics manufacturing partly reflects the importance of patents in those industries, partly government innovation support to those industries (OECD, 2017). Indeed, over a fifth of transport equipment makers report that over $90 \%$ of their patents benefited from government support, the highest share in manufacturing. Resource processing firms and electric machinery makers report only slightly lower figures. Another common feature of electronics and transport equipment makers is the high share of foreign-invested firms among them, $21 \%$ and $14 \%$, respectively, higher than in any other industry. Foreign participation is likely to increase pressure to "escape" competition by innovating. In most manufacturing sectors, larger firms tend to rely more on government support (Figure 8). In light industry the size does not seem to make a difference, and in some sectors such as transport equipment manufacturing, micro firms are also strongly supported. 
Figure 8. In most manufacturing sub-sectors the larger the firm the more it relies on government support

Share of firms indicating government support as a major source of funding by firm size and industry group
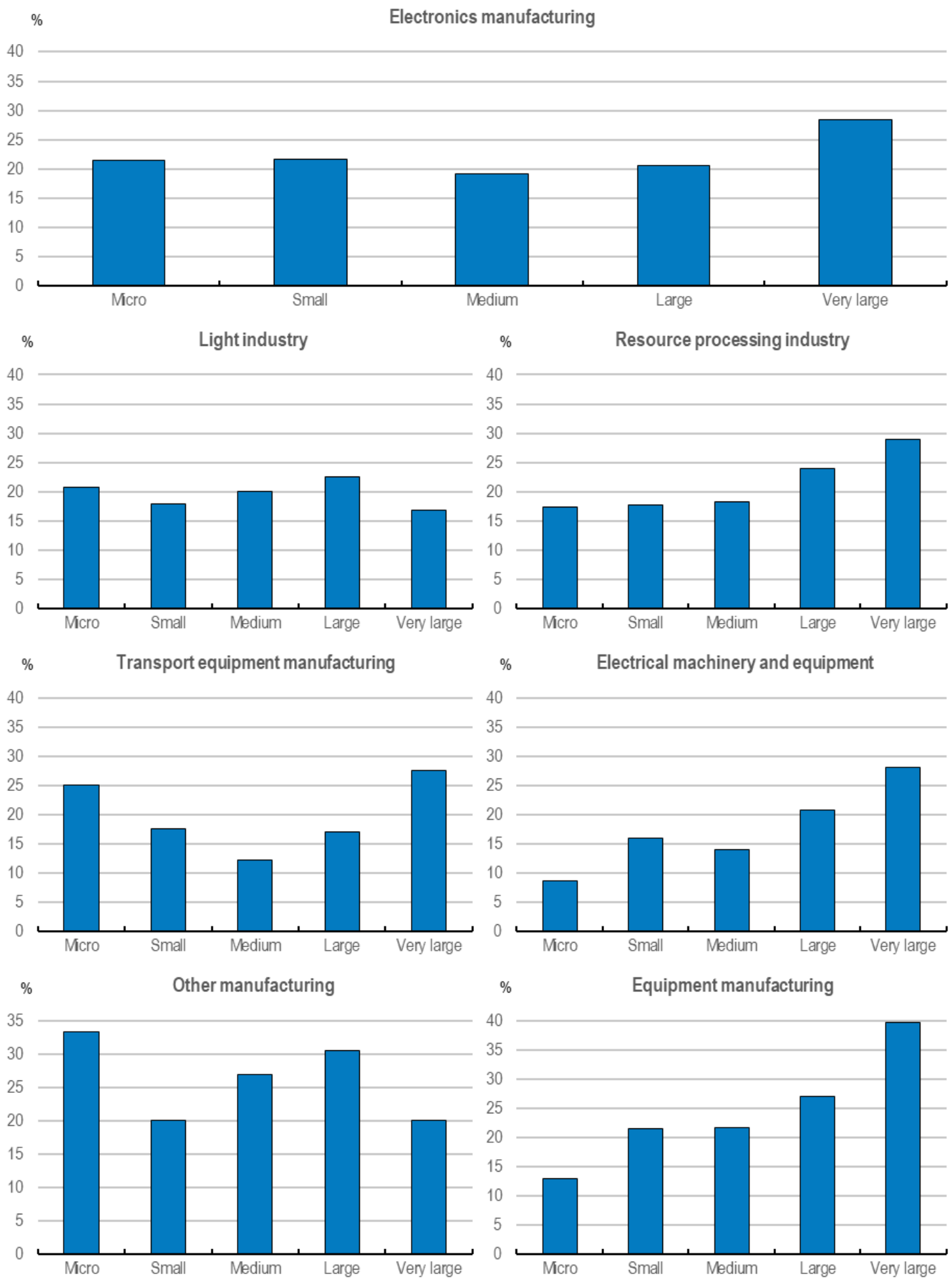

Note: Size categories are defined using the definition of up to 19 employees for micro firms, 20-49 for small, 50-245 for medium, 250-999 for large and at least 1000 employees for very large firms.

Source: Authors' calculation based on the 2016 SIPO China Patent Survey. 


\section{Research firms jointly are the largest patent holders in services}

16. Services firms hold over $30 \%$ of patents with research firms jointly holding over $12 \%$. They are followed by wholesale and retail and telecommunications firms with $9 \%$ and $4 \%$, respectively. Notwithstanding the high degree of concentration of services industry patents in these few sectors, these sectors do not produce a high number of patents per firm (77 in the case of research firms, 106 for wholesale and retail firms and 152 for telecommunications). In contrast, transport and storage firms hold 274 patents on average. Firms in modern service industries produce more patents on average, but not per employee or per researcher. Modern industries tend to be more skill intensive; they have a higher share of employees with tertiary education both in manufacturing and services (Figure 9).

\section{Figure 9. Modern industries have higher educated workforce than traditional ones}

Kernel density of employees with tertiary education
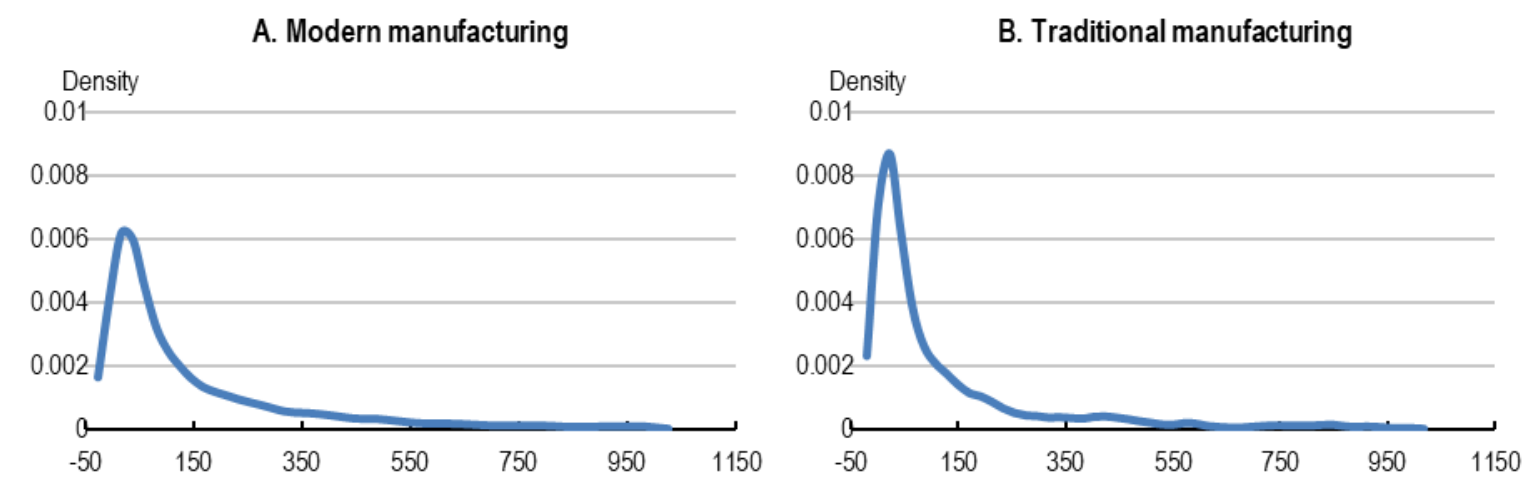

C. Modern services
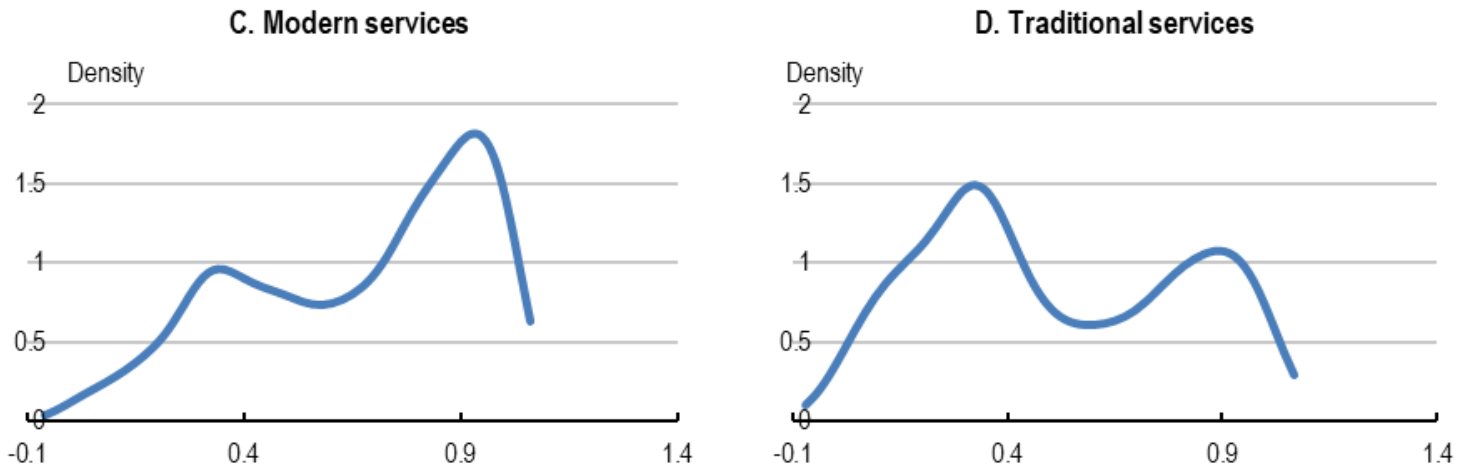

Note: Based on the official classification of industries into new/modern and traditional (National Bureau of Statistics, 2012).

Source: Authors' calculation based on the 2016 SIPO China Patent Survey.

17. Services firms spend more on R\&D than manufacturing firms and their R\&D spending per patent is also much higher. Within services, telecommunications firms spend most on R\&D: $36 \%$ of them spend more than $10 \%$ of their revenue on it, even higher than research firms (at $32 \%$ ). Leasing and commercial service providers also spend a relatively high share of their revenue on R\&D, while construction firms and utilities much less (only $7-8 \%$ of those firms spend more than $10 \%$ of their revenue on R\&D). Most R\&Dintensive patenting among foreign-invested enterprises is in construction, IT and research. Among SOEs and private firms, construction and IT firms also rank among the top ones, but transport and storage firms come next. Most patenting in services sectors, in particular traditional services is by SOEs. This is related to the still existing entry barriers to many such industries, such as utilities. However, even in modern 
services industries, SOEs are the major investors in innovation. The median SOE spends about $50 \%$ more on R\&D than the median foreign firms, and more than three times of the median private firm. The median patent cost in telecommunications, real estate and construction is between CNY 250,000-300,000, while in the financial sector it is CNY 7.5 million.

18. Higher costs preceding patenting in services come with more intense government support. A quarter of telecommunications firms report that over $90 \%$ of their patents were supported by the government. Other industries such as leasing and commercial services and water conservancy also recorded similar rates. At the other extreme, over half of utilities and mining and construction firms claim that less than $10 \%$ of their patents benefited from government support. As in the case of manufacturing, larger services firms also tend to be more dependent on government support (Figure 10).

Figure 10. Larger firms in many services industries are reliant on government support Share of firms indicating government support as a major source of funding by firm size and industry
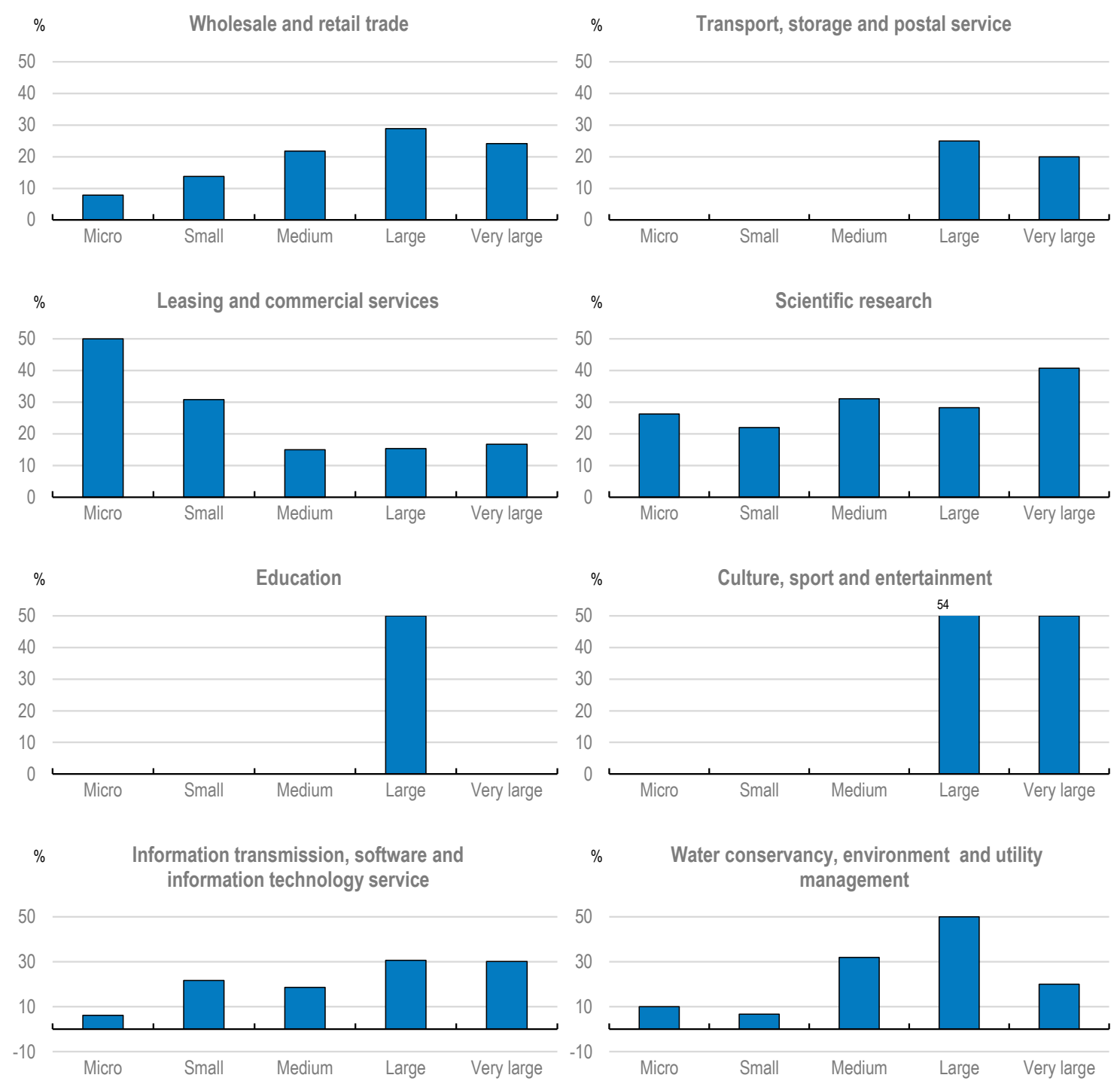

Note: Size categories are defined using the definition of up to 19 employees for micro firms, 20-49 for small, 50-245 for medium, 250-999 for large and at least 1000 employees for very large firms.

Source: Authors' calculation based on the 2016 SIPO China Patent Survey. 


\section{Most patenters are medium-to large, but giants produce most patents}

19. The sample in the survey mainly contains medium and large firms, with a wide variation of firm size patterns across provinces. Hebei, Hunan and Gansu have mainly giant firms with over 1000 employees and very few micro firms. Those provinces have large heavy industries and many SOEs. Heilongjiang, Guangxi and Jiangsu, at the other extreme, have many micro firms. Jiangsu, alongside Zhejiang and Tianjin has a low share of giant firms. In Anhui, Sichuan and Tianjin more than half of the firms are small-to medium size (from 20 to 249 employees).

20. Roughly half of micro firms are in traditional services with another third in modern manufacturing. The shares of those two industries are closer in the case of small firms (20-49 employees) at 37-38\%. From 50 employees upwards, the distribution of patenters across size categories is quite similar with 44$45 \%$ in modern manufacturing and $28-32 \%$ in traditional services. Lower shares of smaller firms among manufacturers may be related to high fixed costs of entry and minimum scale thresholds.

21. The 2016 SIPO China Patent Survey distinguishes seven firm registration forms: foreign-invested, $100 \%$ state-owned, $100 \%$ private, limited liability, incorporated, cooperative equity and others. As the ownership shares of limited liability and incorporated firms, which make up a large part of the sample, are unspecified in the survey, henceforth only foreign-invested, purely state-owned, purely privately owned and occasionally collectively-owned firms will be discussed. Only around $1 \%$ of micro firms are purely state owned, less than $5 \%$ foreign invested and a third purely privately owned. At the other extreme, $28 \%$ of the very large firms are SOEs and only $5 \%$ private ( $17 \%$ foreign invested).

22. Patents are concentrated in the very large firms (Figures 1-2). The number of effective patents a firm holds increases with its size. When looking at the number of patents per researcher, however, smaller firms appear to perform better (Figure 11): the median micro firm holds 2.3 patents; the median small firm 1.5 , while at the other end of the spectrum, a median firm with over 1000 employees holds 0.4 patents per researcher. The number of effective patents per researcher decreases with firm size in many provinces. Moreover, on this measure, micro firms outperform other size categories by a large margin in many provinces, in particular in the Eastern ones. 
Figure 11. Micro firms hold most effective patents per researcher in many provinces

Number of effective patents per researcher by firm size and province

Panel A. Eastern provinces
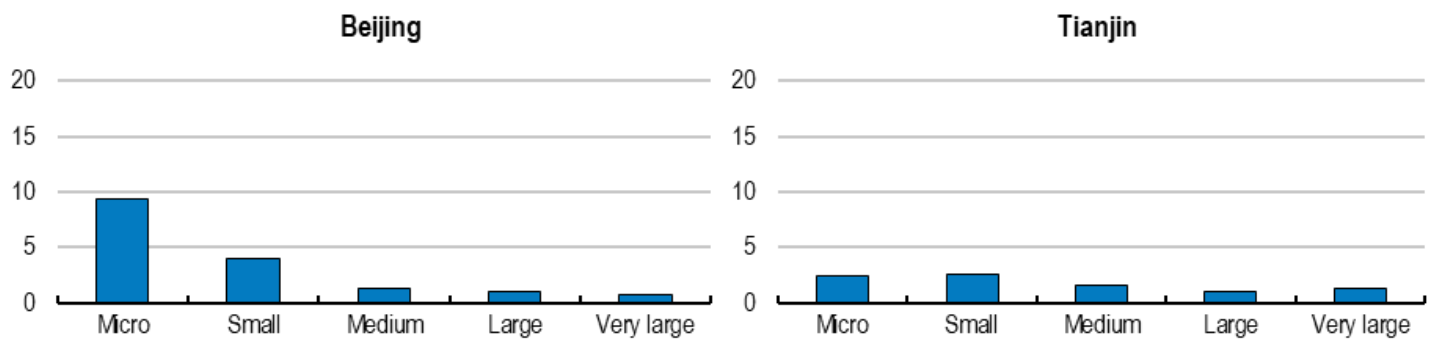

Liaoning

Shanghai
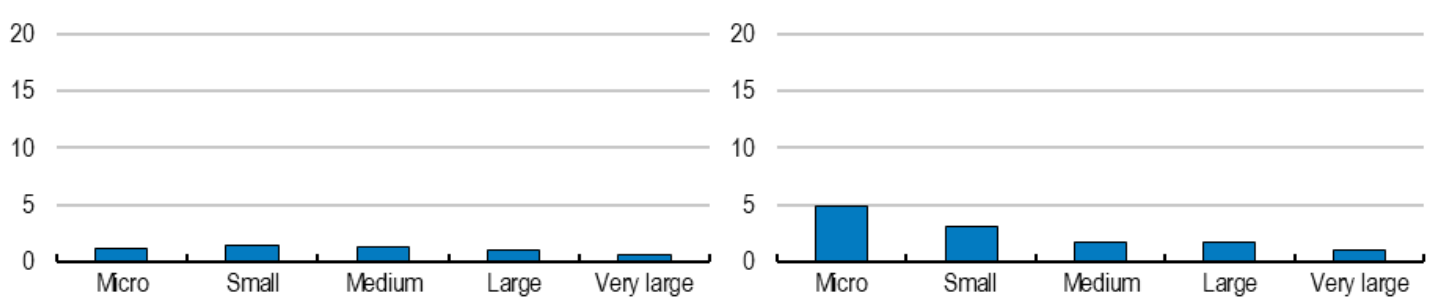

Zhejiang

Fujian
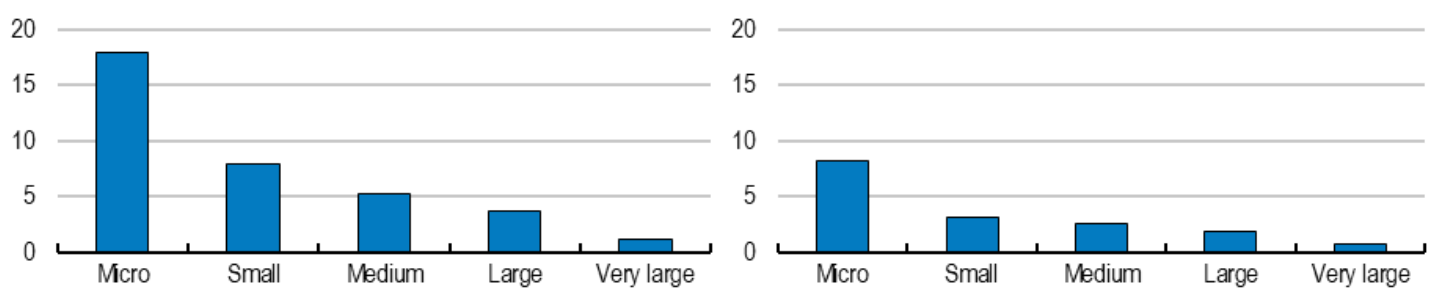

Guangdong

Shandong
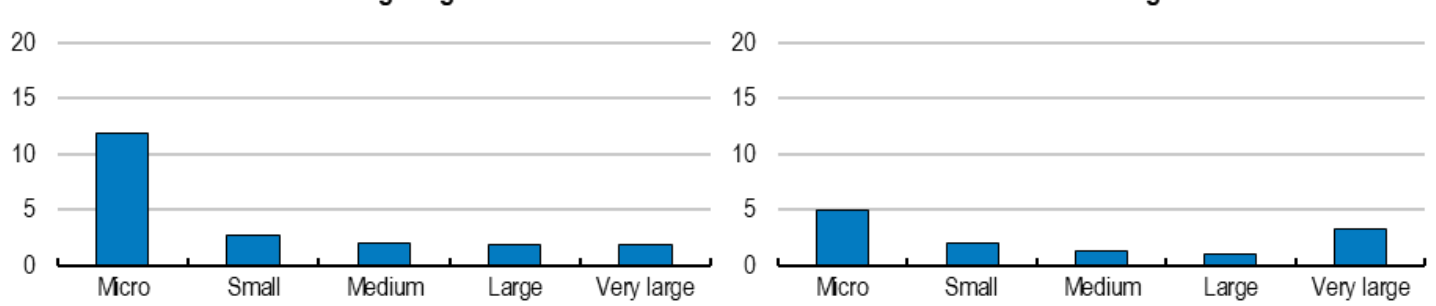

Hebei

Jiangsu
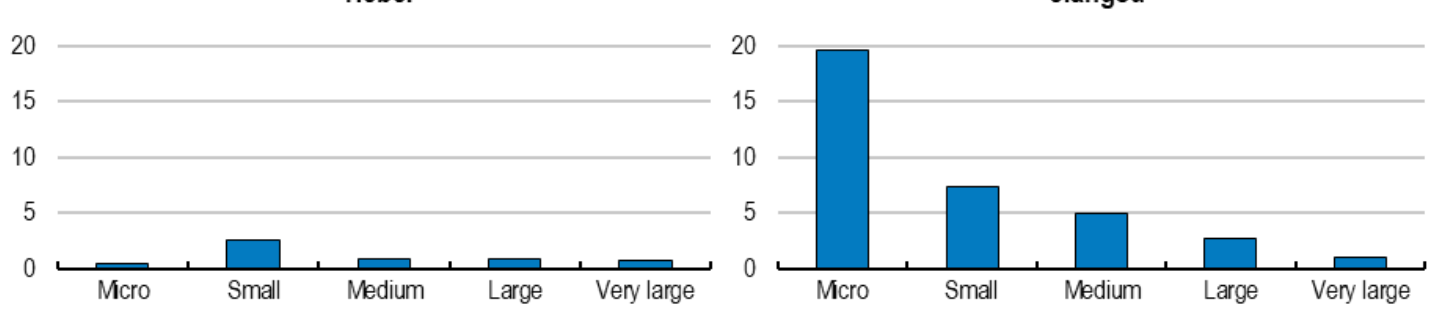
24 | ECO/WKP(2019)53

Panel B. Central provinces
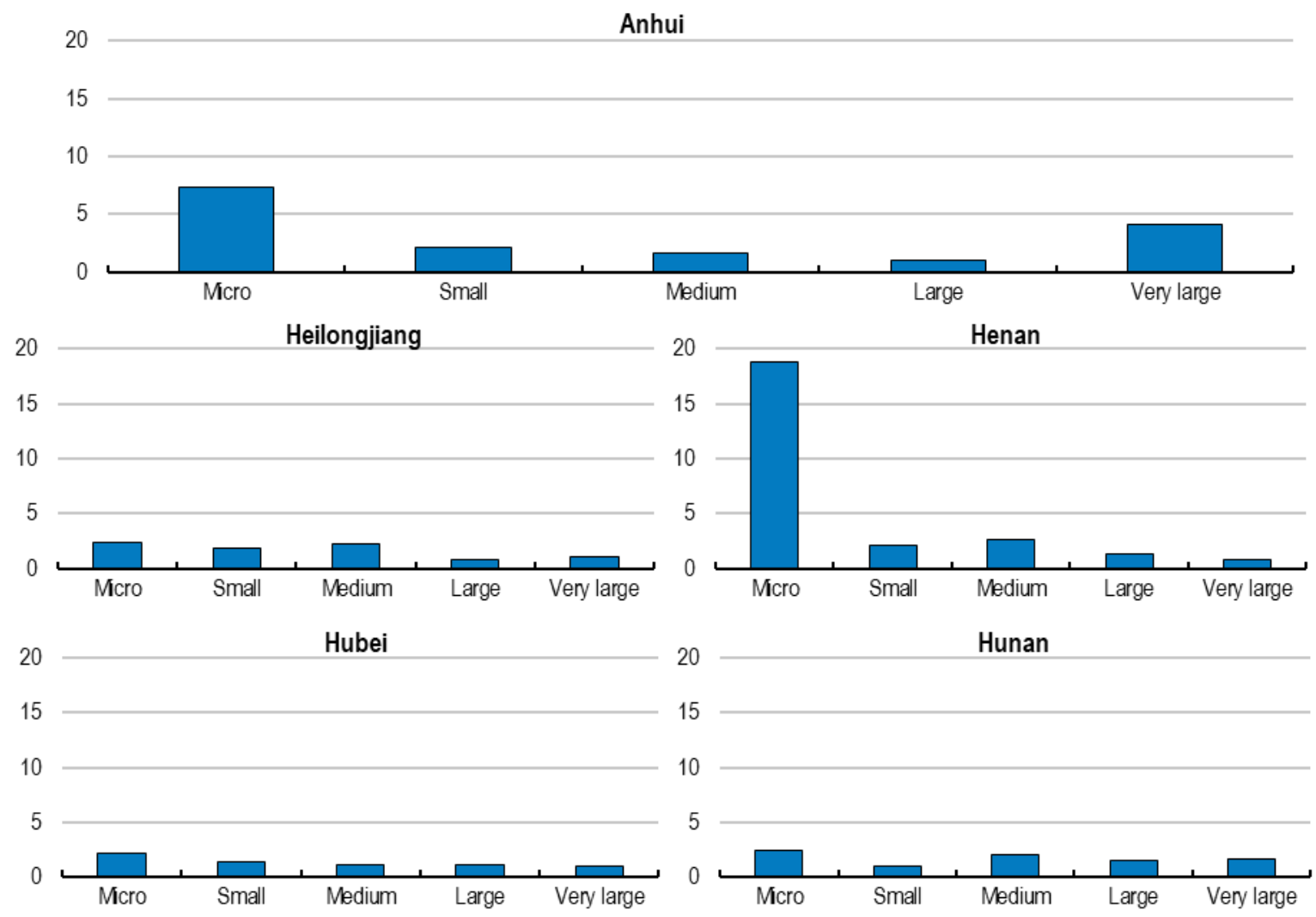
Panel C. Western provinces
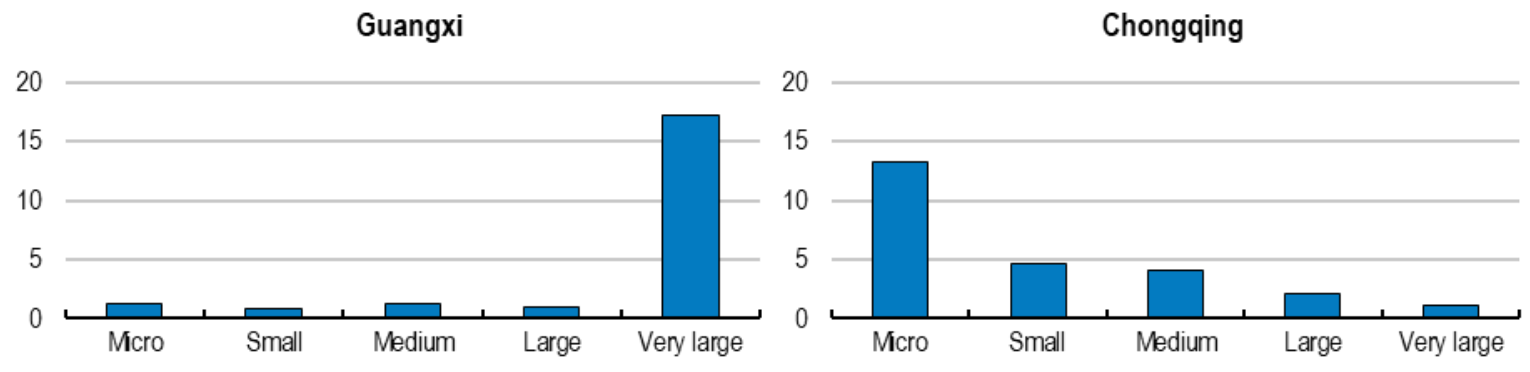

Guizhou

Yunnan
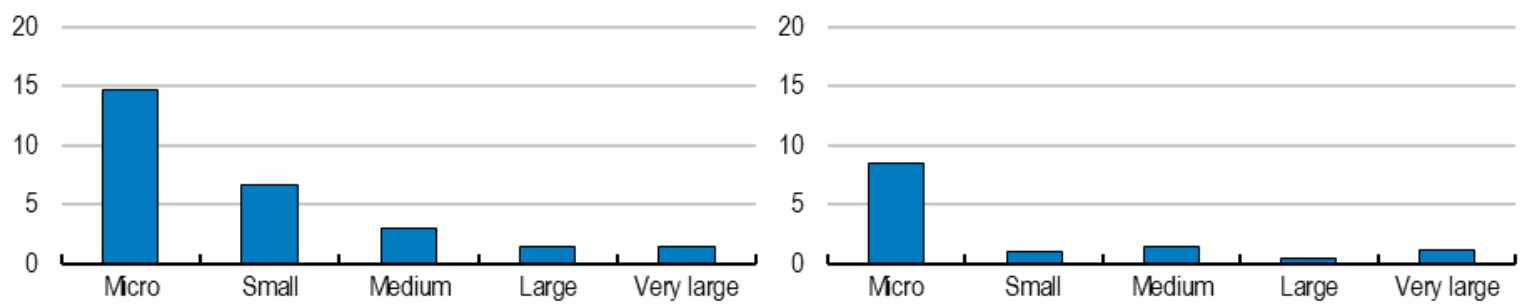

Ningxia

Xinjiang
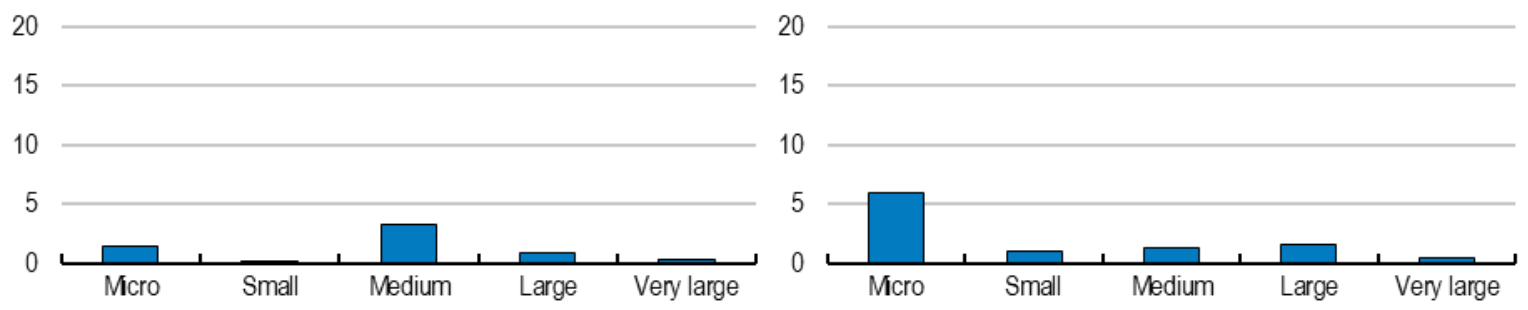

Gansu

Sichuan
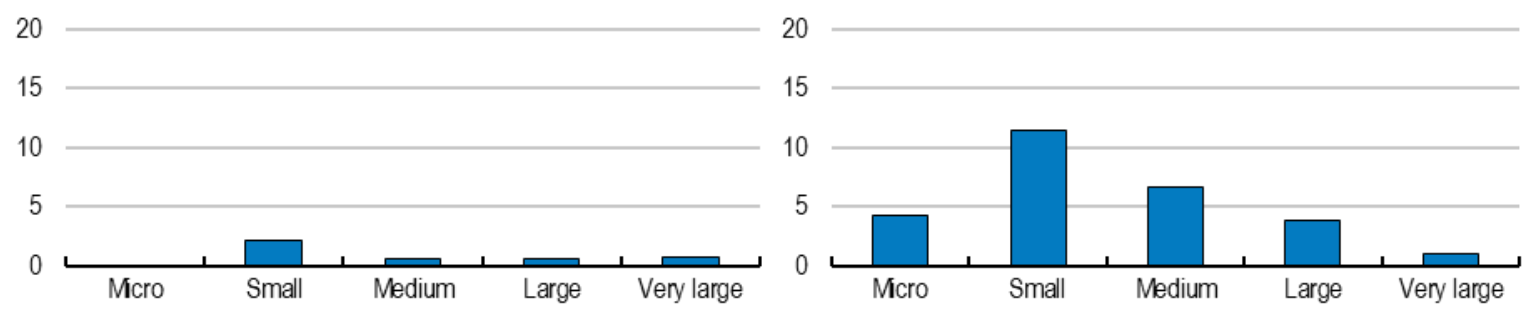

Note: According to the definition by China's National Bureau of Statistics, Eastern provinces include Beijing, Tianjin, Hebei, Liaoning, Shanghai, Jiangsu, Zhejiang, Fujian, Shandong, Guangdong and Hainan, Central provinces comprise Shanxi, Jilin, Heilongjiang, Anhui, Jiangxi, Henan, Hubei and Hunan and Western provinces cover Inner Mongolia, Guangxi, Chongqing, Sichuan, Guizhou, Yunnan, Tibet, Shaanxi, Gansu, Qinghai, Ningxia and Xinjiang Size categories are defined using the definition of up to 19 employees for micro firms, 20-49 for small, 50-245 for medium, 250-999 for large and at least 1000 employees for very large firms.

Source: Authors' calculation based on the 2016 SIPO China Patent Survey.

23. Medium-size firms have the lowest share of employees with tertiary education with the median firm at $36 \%$, while micro firms the highest at $60 \%$. The share of R\&D employees is also the highest for micro firms at $40 \%$, and it falls as firm size increases (Figure 12). This is explained by the fact that many micro patenting firms were set up by researchers. 
26 | ECO/WKP(2019)53

Figure 12. The share of researchers decreases with firm size

Density of research staff share by firm size

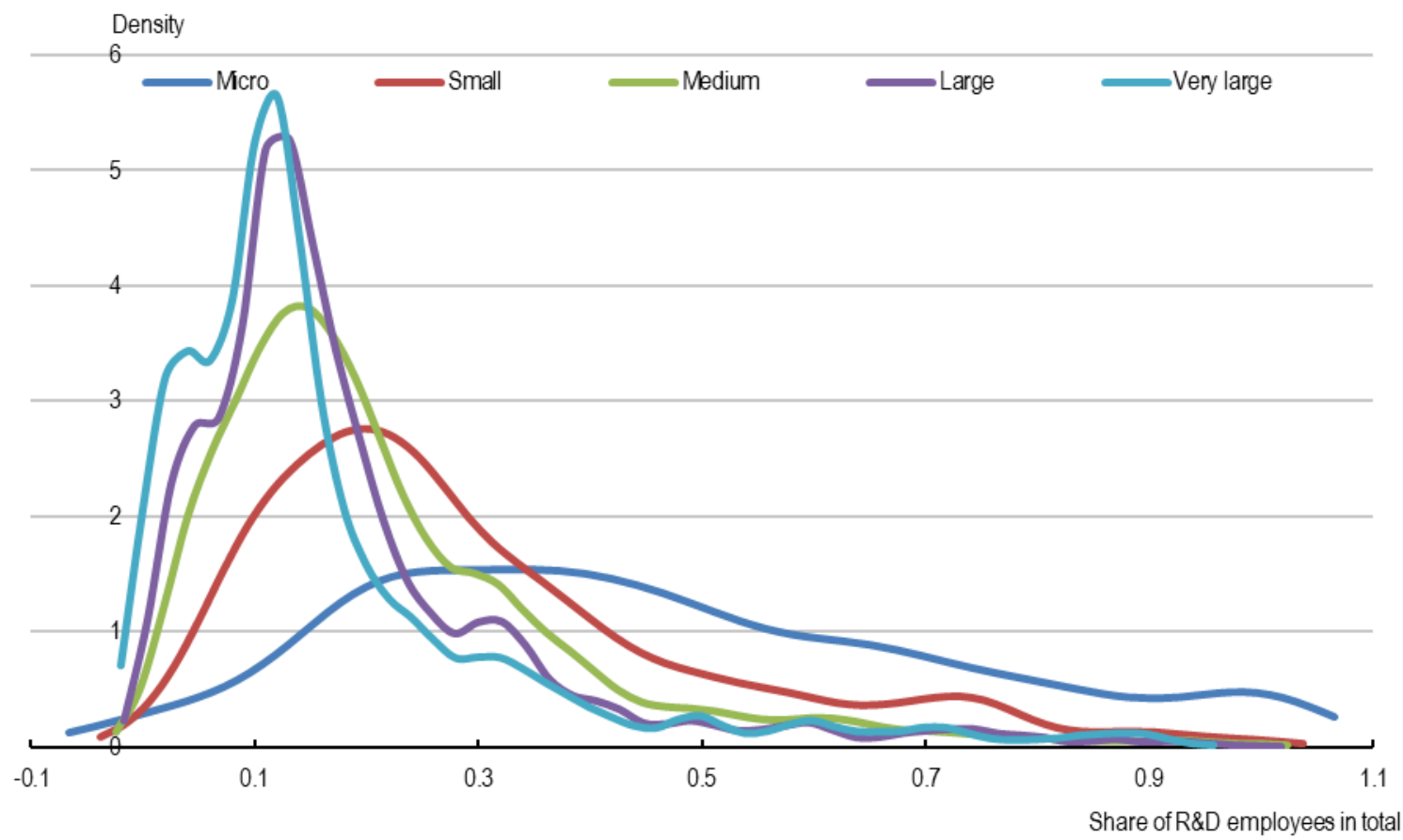

Note: Size categories are defined using the definition of up to 19 employees for micro firms, 20-49 for small, 50-245 for medium, 250-999 for large and at least 1000 employees for very large firms.

Source: Authors' calculation based on the 2016 SIPO China Patent Survey.

24. Micro and small firms spend over $5.6 \%$ of their sales revenue on R\&D, while this ratio for mediumsize firms is $5.2 \%$ and for large and giant firms is below $5 \%$ (Figure 13). These features may be related to the overrepresentation of technology-oriented start-ups in the sample, as other, ordinary micro firms are less likely to patent and therefore be included in the survey. As the sectoral distribution reveals, nearly a third of micro firms are research firms, $10 \%$ belong to equipment manufacturing and another $10 \%$ to electrical machinery manufacturing. 
Figure 13. Micro and small firms spend a somewhat greater share of their revenue on R\&D

R\&D spending to sales revenue

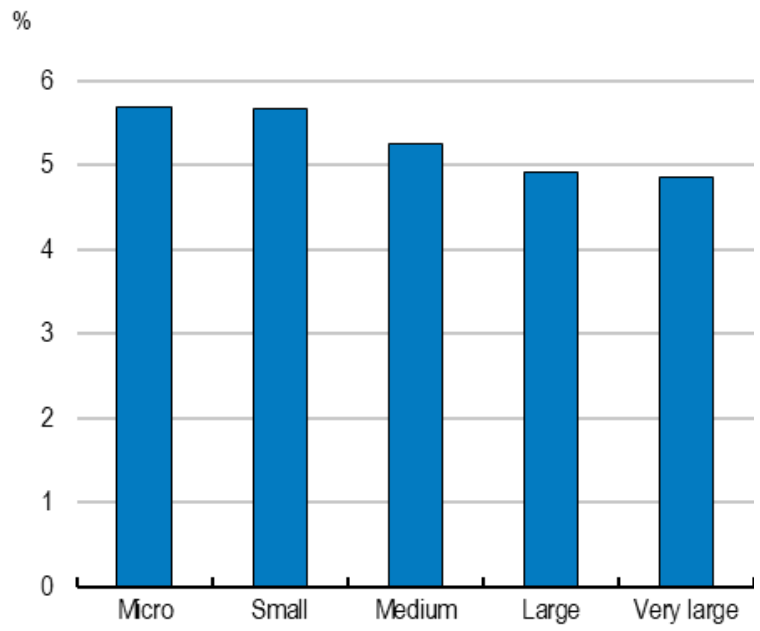

Note: Size categories are defined using the definition of up to 19 employees for micro firms, 20-49 for small, 50-245 for medium, 250-999 for large and at least 1000 employees for very large firms.

Source: Authors' calculation based on the 2016 SIPO China Patent Survey.

25. High patent productivity measured by patents per employee or per researcher in micro-firms and declining patent productivity in size have been observed in several studies based on datasets in various countries (Acs and Audretsch, 1991, Cohen and Klepper 1996a and 1996b). Although these measures are often used as efficiency measures, the results should not be interpreted as micro firms being more efficient than large firms. Firms with differing sizes may be engaged in different innovation processes: large firms may engage in costly innovation and they may better exploit innovations, especially process innovations (Cohen and Klepper 1996a, 1996b and Fritsch and Brezinski, 1999).

26. A high share (in some provinces $40-50 \%$ ) of larger firms (above 250 employees) rely on government support in most provinces. In contrast, in a few provinces like Jiangsu, Zhejiang, Fujian, Hebei it is micro firms that have the highest share of firms among all size categories that consider government finance as a major source of funding. Higher patent productivity (in terms of patents per employee or per researcher) in micro firms may justify government support in those provinces. While it is a subjective measure, the overall relatively low shares across firm size categories in Zhejiang, for instance, may suggest that patenting in that province is more dependent on firms' internal funds.

\section{Most patenters are mature firms with over 15 years of history}

27. Most patenters are mature firms over 15 years (Figure 14). The number of patents firms hold appears to increase with firm age: the median new firm (below two years) holds 13 , while the median mature firm (over 15 years) 54. Firm age is also increasing in firm size: smaller firms tend to be younger and the larger ones older (Figure 15). SOEs also tend to be older. Many manufacturing firms tend to have a history of over 15 years, regardless of the sub-industry. A somewhat larger share of electronics makers is younger and of resource processors is older than in other industries. In mining, an even higher share has a long history. In services, in contrast, many patenters, for instance, half of research firms are less than 10 years' old. Culture, sport and entertainment firms also tend to be younger. Sichuan, Yunnan and Fujian have a higher share of new firms than other provinces. At the other extreme, in Gansu more than half of patenters are mature firms. Guangxi and Hebei have similar shares of mature firms. 
28 | ECO/WKP(2019)53

Figure 14. Well-established firms are most represented in the survey

Number of firms by firm age

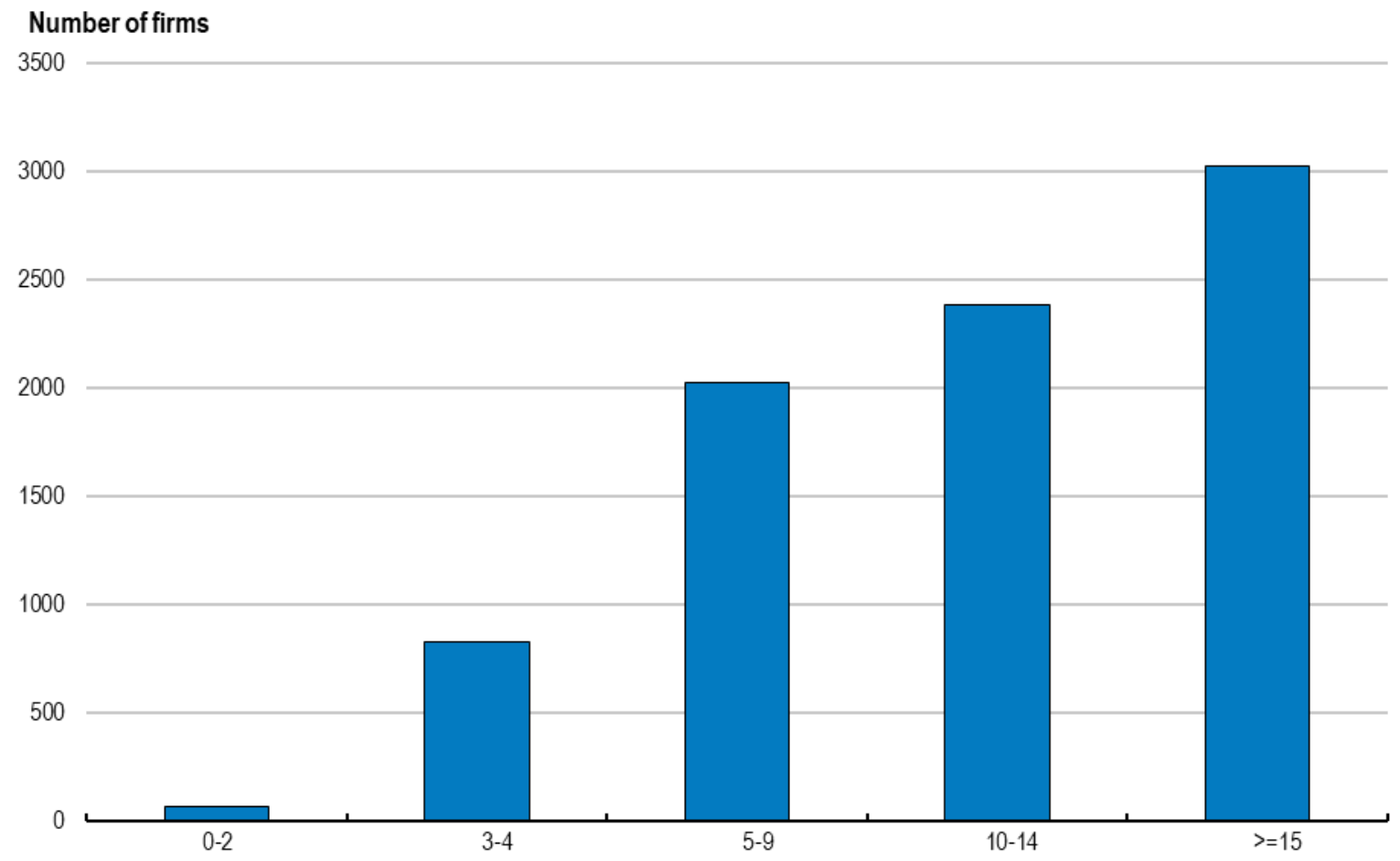

Note: Firm age is the number of years passed since the firm's establishment.

Source: Authors' calculation based on the 2016 SIPO China Patent Survey.

Figure 15. Firm age increases by firm size

Density of firm age by firm size

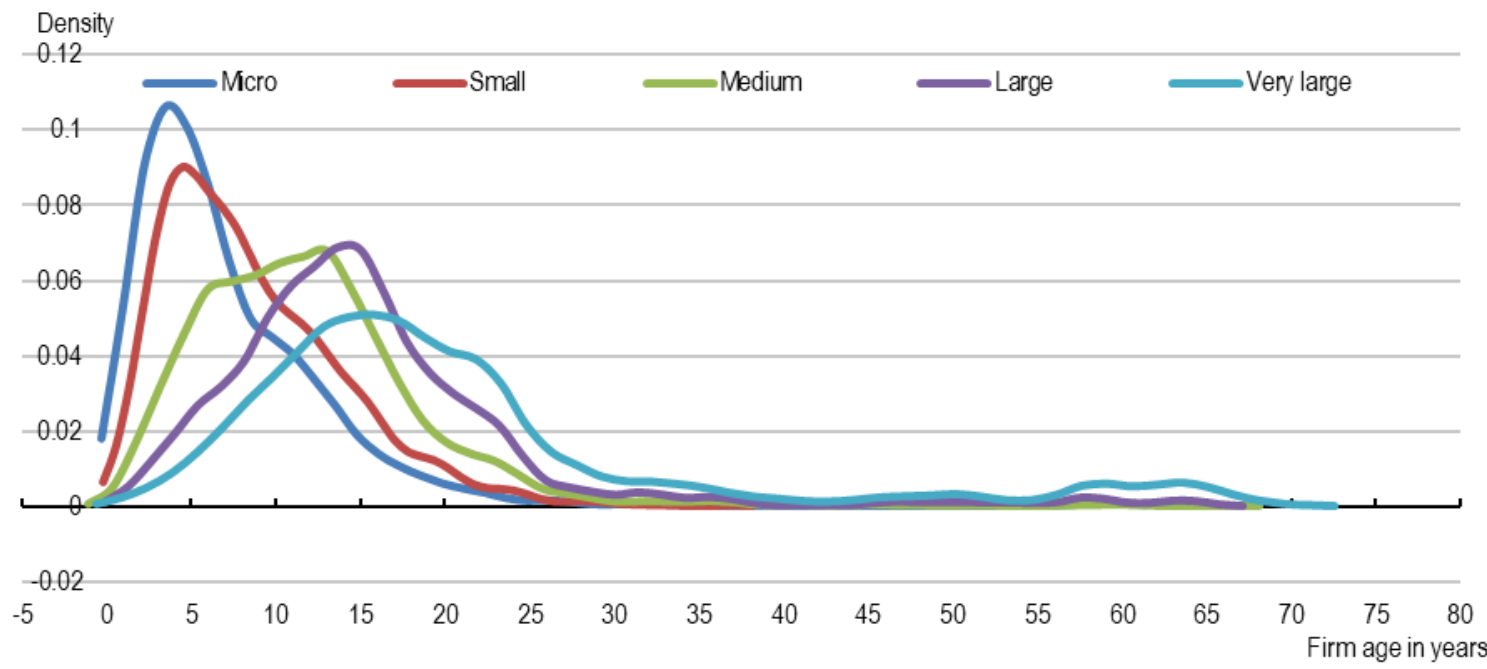

Note: Size categories are defined using the definition of up to 19 employees for micro firms, 20-49 for small, 50-245 for medium, 250-999 for large and at least 1000 employees for very large firms. Firm age is the number of years passed since the firm's establishment.

Source: Authors' calculation based on the 2016 SIPO China Patent Survey. 
28. In most provinces new firms (up to two years) hold the largest number of effective patents per employee or per researcher. This is particularly the case for the largest patenters including in Jiangsu, Guangdong, Zhejiang and Beijing. In Shanghai, on both measures the second youngest group of firms (34 years) rank top, followed by the new ones. Firms below five years spend over $10 \%$ of their sales revenue on R\&D, while this ratio is between three and five percent in the case of older firms. R\&D spending per patent tends to increase by firm age, in general. In several industries mature firms spend a couple of times of what the next oldest category spend. This is consistent with bigger firms and SOEs receiving more support found earlier as those tend to be older. Older firms are likely to have gained more experience in research and patenting and therefore be more ready to engage in R\&D-intensive patent development.

29. In the international literature there is evidence that new entrants invest more in R\&D than older firms. Coad et al. (2016), for instance, show that young firms in Spain face larger performance benefits from $R \& D$ at the upper quantiles of the growth rate distribution and larger decline at the lower quantiles, but such variation is not observed among older firms.

\section{Eastern provinces and municipalities are home to most patenting firms}

30. Most patenters are located in Jiangsu, followed by Guangdong and Zhejiang. These three provinces accommodate nearly half of patenting firms in the survey. Jiangsu has the largest number of patenters in many industries, including construction, wholesale and retail, light industry, electrical equipment and transport equipment manufacturing, but the three industries of equipment manufacturing, electronics and research make up nearly half of its patenters. A certain degree of specialisation by industry can be observed across provinces. Electronics patenting, which makes up the largest number of effective patents in the survey, is highly concentrated geographically. Guangdong and Jiangsu firms jointly hold $54 \%$ of all electronics patents. The next in the ranking, Zhejiang follows with a sizeable distance: its firms hold slightly over $5 \%$ of electronics patents. Foreign patenting firms in both Guangdong and Jiangsu employ more people than SOEs or private patenters. Zhejiang follows the same pattern. In other major patenting provinces, such as Beijing or Shanghai, SOEs employ much more people than the other two firm types (i.e. private and foreign-invested). Patenting in the transport equipment industry is not nearly as concentrated geographically as electronics patenting. Anhui ranks top, followed by Chongqing and Shanghai, the three jointly accounting for $40 \%$ of patents in the industry. Chery Automobile is a car maker located in Wuhu, Anhui, Changan is a Chongqing-based SOE and Shanghai also accommodates carmakers like Shanghai Automotive Industry Corporation - all these firms are behind the intense patenting activity in the provinces where they are located.

31. Although Jiangsu ranks top in many industries in terms of patenting, in some, such as telecommunications, it does not even make it to the top five. In that industry, Guangdong, Beijing, Zhejiang, Shandong and Shanghai firms are all ahead of it. Sichuan is specialised in leasing and commercial service patenting, it holds nearly a quarter of such patents. In research, not surprisingly, Beijing takes the lead, followed by Guangdong, Jiangsu, Shanghai, Hubei and Sichuan.

32. Jiangsu firms hold most patents, jointly almost $18 \%$ of all. Guangdong and Shanghai firms follow with $16 \%$ and $8.5 \%$, respectively. Zhejiang comes very close at $7.8 \%$. The median Beijing firm, however, holds more patents than firms in those provinces, at 60 , versus $33,36,32$ and 33 , respectively. This is attributable to Beijing being the centre for research in the country and to the large number of public research firms as well as headquarters of large firms. Next come Chongqing and Henan (with 47 and 40 patents, respectively, held by the median firm), neither of which performs particularly well in terms of the total number of patents their firms hold. While in Chongqing also the average number of patents is high (only below that of Beijing and Hunan), which may reflect high propensity to patent in the municipality, Henan has a relatively low average but high median number of patents per firm, which suggests a more even distribution of patents across firms than in other provinces. 
33. Some of the provinces with a large number of effective patents have the highest share of R\&D staff -- with Beijing and Shanghai on the top, followed by Jiangsu -- (the median firm has $30 \%, 23 \%$ and $18 \%$, respectively). At the other extreme are Gansu (10\%), Zhejiang somewhat below $13 \%$ and Xinjiang somewhat over $13 \%$. While it is not surprising that the most successful patenters have a high share of researchers, Zhejiang appears to be an outlier: successful in patenting notwithstanding the low share of researchers. There are few researchers in all types of enterprises in Zhejiang, though their share is higher in SOEs than in foreign or private firms. The larger the firm, the lower the share of researchers is among employees, as in most other provinces. An even more striking feature of Zhejiang patenters is their lowest share of employees with higher education among all provinces. Zhejiang is different from other provinces in a sense that most of its patenters are in light manufacturing, nearly a fifth. This sector is mainly dominated by private firms and it is not particularly innovation intensive.

34. Beijing's and Shanghai's inputs are the highest not only in terms of human capital, but also R\&D outlays, Hebei closely following them on this measure. The median patenter in Beijing spends double of that in Hebei or Shanghai and quadruple of that in Jiangsu, Fujian or Zhejiang, which shows an excessive concentration of material inputs into innovation in the capital. The median firm in Beijing spends also way above per employee than the median firm in any other province and in per researcher terms only Yunnan and Shanghai spend similar magnitudes. Beijing patents are the most R\&D intensive alongside Yunnan's and Hubei's, with the median spending above CNY 300000 per effective patent. In addition, the median firm spends 2-3 times more on patent application and maintenance than in other provinces. Furthermore, $30 \%$ of Beijing patenters spend more than $10 \%$ of their revenue on R\&D, the highest share among all provinces (followed by Heilongjiang at $22 \%$ and Guizhou at $21 \%$ ). The high R\&D intensity and researcherintensity in Beijing may be related to the overwhelming share of research firms among Beijing patenters $(57 \%)$. No other province has such a strong orientation towards research. In Liaoning, which ranks second, only $25 \%$ of patenters are in the research sub-sector and in Shanghai $22 \%$.

35. The extent of government support varies across provinces. In Chongqing, over a third of firms report that more than $90 \%$ of their patents are supported by the government. In Anhui $29 \%$, Shanghai, Hebei, Zhejiang, Gansu and Heilongjiang between $20-25 \%$ do so. While the amount of support is not known, this would mean supporting virtually all patents of only a handful or a couple of dozens of firms in Gansu, Heilongjiang, Chongqing and Hebei; in Shanghai, Anhui and Zhejiang the government supports basically all patents of a couple of hundreds of firms. At the other extreme, this share would be $6 \%$ in Liaoning and in Ningxia none of the firms reported such a high share of government-supported patents. In six provinces (Liaoning, Shandong, Heilongjiang, Guangdong, Henan and Gansu) at least half of the firms only received government support for less than $10 \%$ of their patents, with Liaoning ranking top at twothirds.

36. In some cases, the public support landscape for patents is polarised with a high share of firms strongly supported for nearly all of their patents and a high share receiving support for only a few of their patents (Figure 16). There are three provinces (Heilongjiang, Zhejiang and Xinjiang) where the shares of both extremes are above average (i.e. the shares of firms that received government support for over $90 \%$ and below $10 \%$ of their patents). A high share of SOEs in Heilongjiang and Xinjiang may explain the large shares of patents supported, while a high share of micro firms explains the high shares of little-supported firms in Heilongjiang and Xinjiang. Zhejiang patenters are mainly private, potentially explaining high shares of low public support. Shanghai also comes close to this group of provinces with a high share of micro and foreign firms. Alongside Zhejiang, it may have more resources to subsidise innovation, explaining the high shares of strongly-supported firms in both. 
Figure 16. Government support by firm size varies across provinces

Share of firms indicating government support as a major source of funding by firm size and province

\section{A. Eastern provinces}
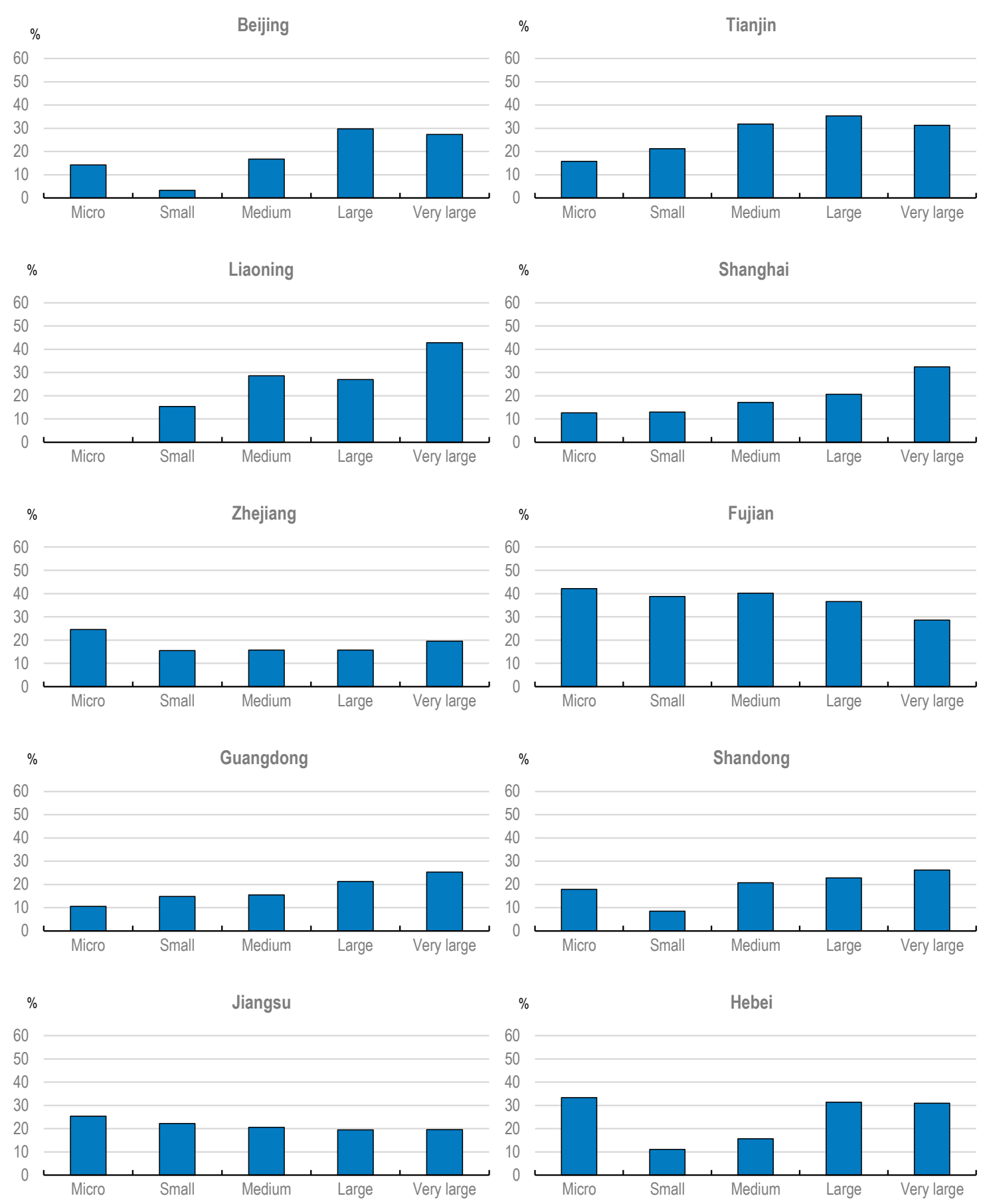
32 | ECO/WKP(2019)53

B. Central provinces
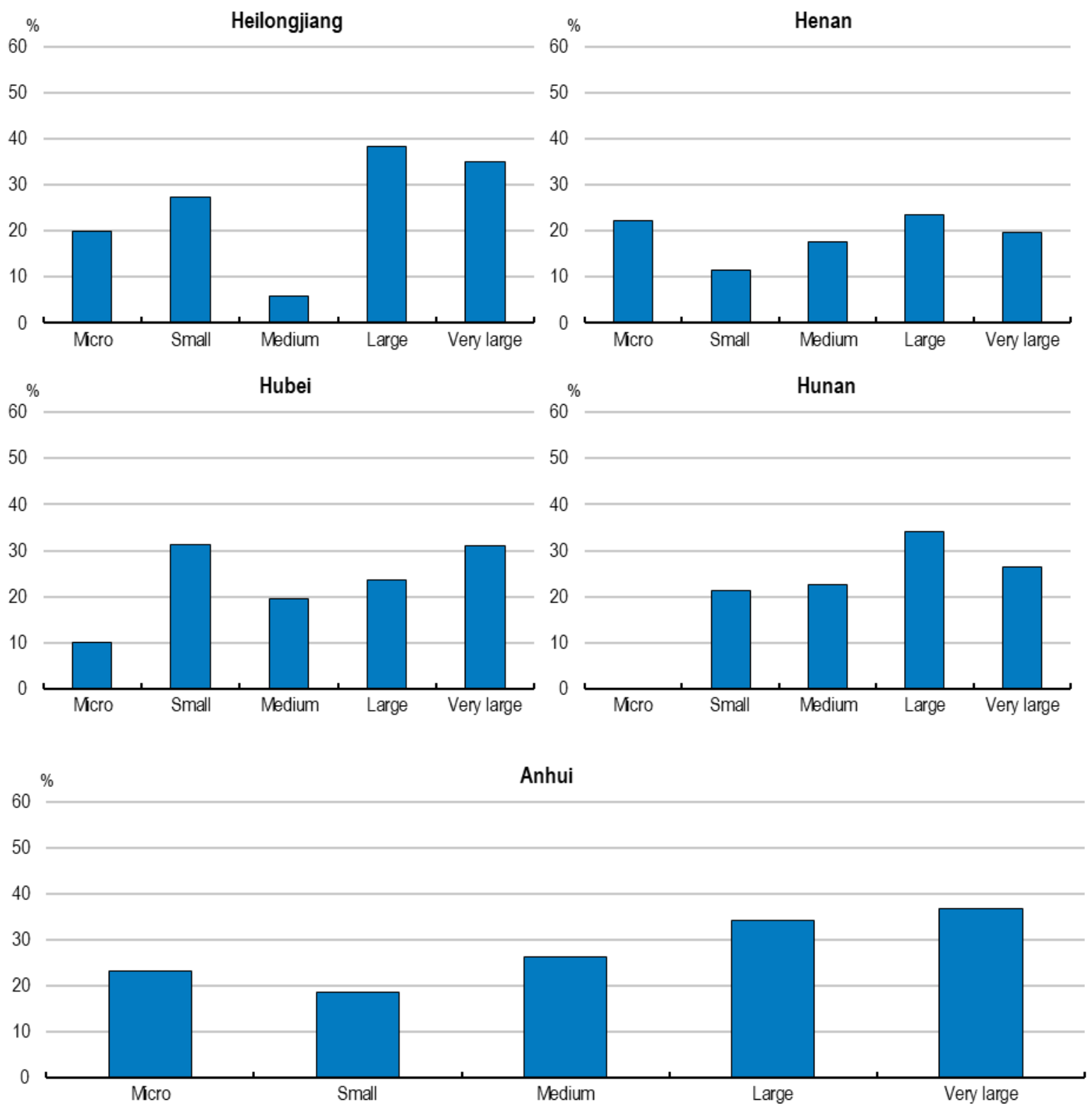
C. Western provinces
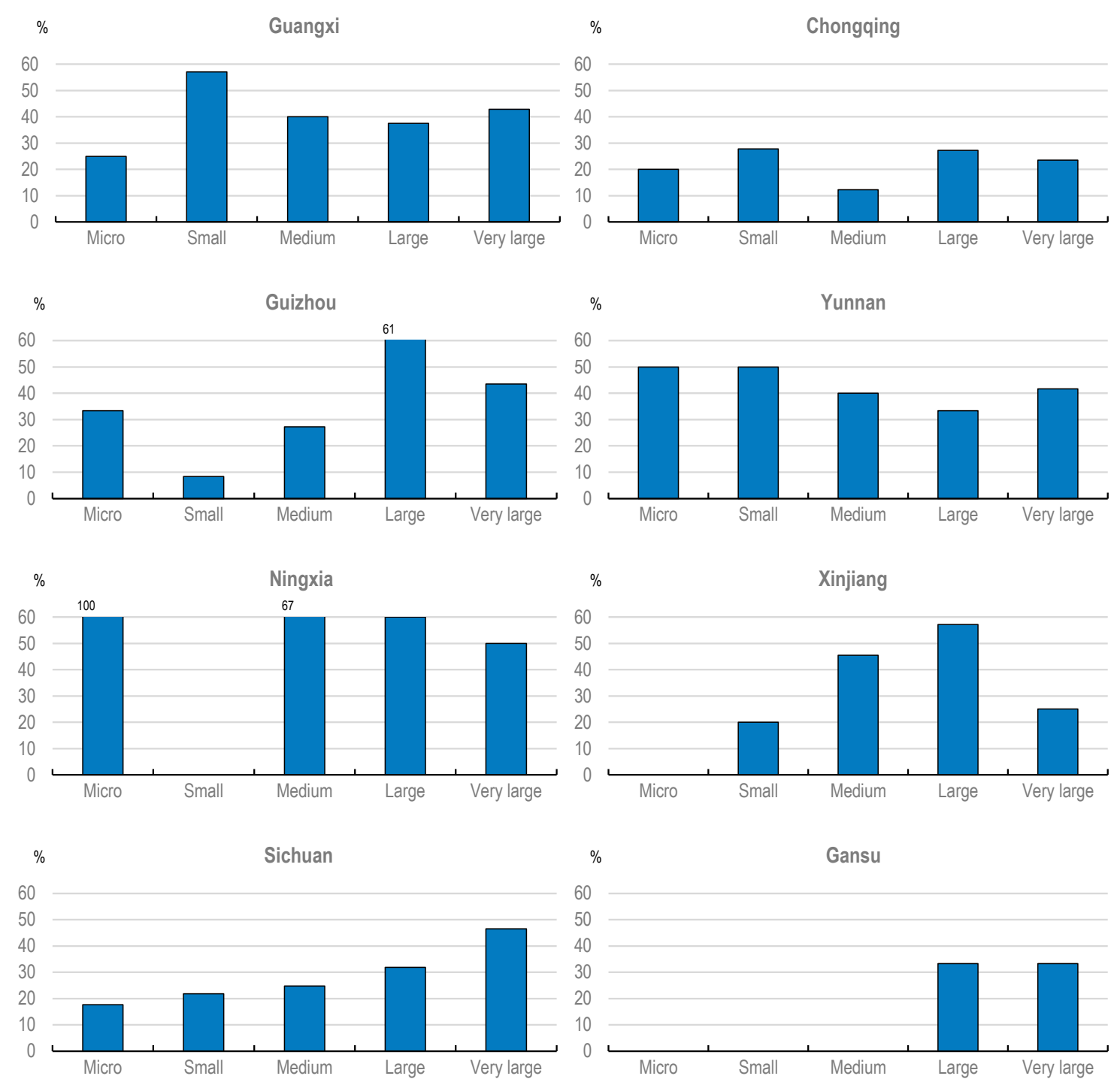

Note: According to the definition by China's National Bureau of Statistics, Eastern provinces include Beijing, Tianjin, Hebei, Liaoning, Shanghai, Jiangsu, Zhejiang, Fujian, Shandong, Guangdong and Hainan, Central provinces comprise Shanxi, Jilin, Heilongjiang, Anhui, Jiangxi, Henan, Hubei and Hunan and Western provinces cover Inner Mongolia, Guangxi, Chongqing, Sichuan, Guizhou, Yunnan, Tibet, Shaanxi, Gansu, Qinghai, Ningxia and Xinjiang Size categories are defined using the definition of up to 19 employees for micro firms, 20-49 for small, 50-245 for medium, 250-999 for large and at least 1000 employees for very large firms.

Source: Authors' calculation based on the 2016 SIPO China Patent Survey.

\section{The patent landscape is dominated by SOEs}

37. The number of firms exclusively held by the State in the sample is fewer than a thousand, but they jointly hold around 150,000 patents, more than foreign-invested firms at around 100,000 and purely privately-owned firms at around 75,000 (Figure 17). Patenting by foreign firms in China was growing at 20$60 \%$ depending on the origin of the patenter in the late 1990 s-early 2000 s, a much faster rate than patenting by firms from the same countries in the United States. Hu (2014) investigated the major drivers of such patenting surge by foreigners and found that it was the competitive threat hypothesis that could better explain this behaviour, i.e. the increase of competing imports prompted foreign firms to boost their 
patenting in China. In contrast, $\mathrm{Hu}$ (2014) found no evidence of the market covering hypothesis, i.e. foreign firms' sales to China did not appear to boost their propensity to patent in China.

\section{Figure 17. Private firms are well represented but the number of effective patents is higher in SOEs}

Number of firms and number of effective patents by firm type
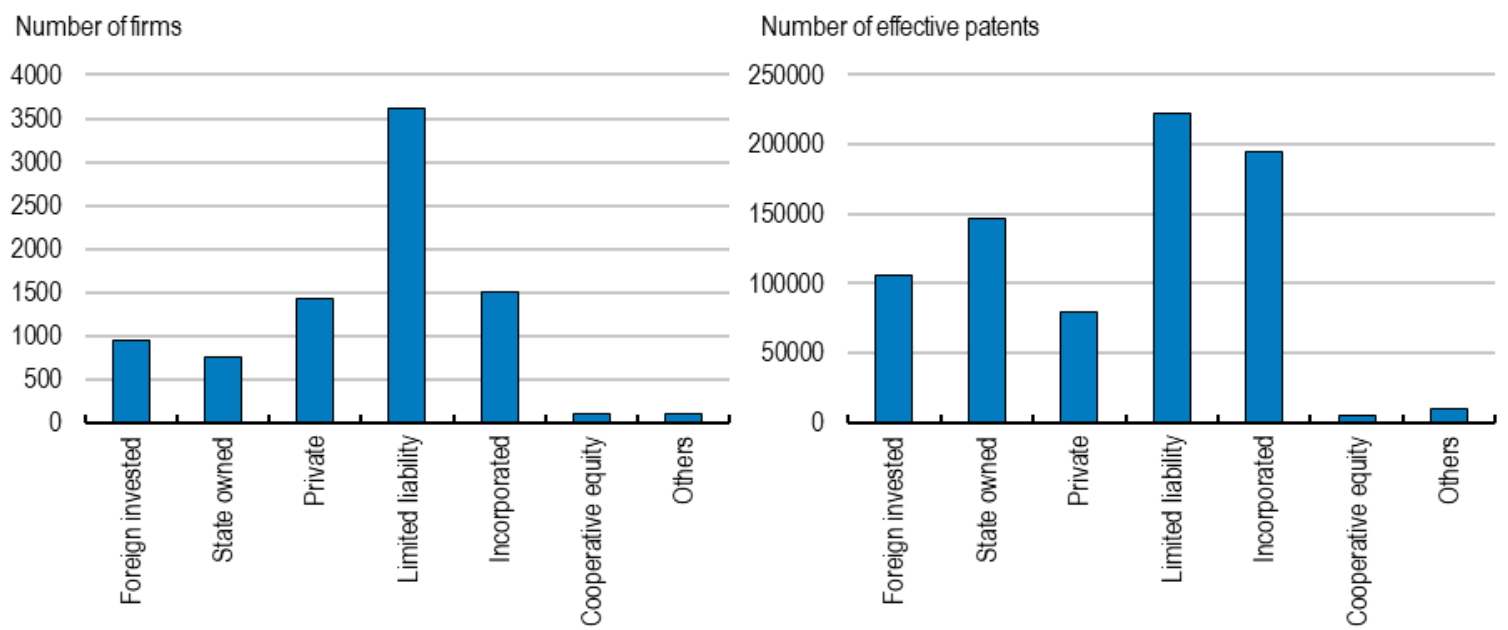

Note: Based on ownership categories defined by China's National Bureau of Statistics.

Source: Authors' calculation based on the 2016 SIPO China Patent Survey.

38. The dominance of SOEs among patenters is more obvious in Western China, for instance nearly a third of Guizhou's patenters are SOEs and above a quarter of Xinjiang's and Yunnan's. Similar shares are observed in the industrial rustbelt (Heilongjiang and Liaoning) and the heavy-industry-oriented province Hebei, East of Beijing. Shanghai, Fujian and Guangdong have the highest share of foreign patenting firms. Around a fifth of patenters are purely privately-owned firms in Tianjin, Jiangsu, Guangxi and Zhejiang.

39. The large number of patents held by SOEs to some extent reflects the sheer size of such firms. In terms of patents per researcher, the situation is quite different: collectively owned and private firms outperform other firm types (Figure 18). The national-level picture masks some differences at the province level. In some provinces such as Hebei, Hunan, Tianjin and Liaoning, foreign firms hold more patents relative to the number of their researchers than the other two firm types, while in Yunnan and Gansu, it is SOEs that hold the most. Private and foreign firms tend to have a lower share of researchers and employees with tertiary education than SOEs (Figure 19). SOEs have the highest share of employees with college degree among the three firm categories in most provinces, except Beijing and Gansu, where it is foreign firms and Sichuan and Xinjiang, where it is private firms. This is reflected in the pecking order of fresh graduates, who tend to prefer the public sector. 
Figure 18. Cooperatives and private firms hold most patents per researcher

Density of effective patents per R\&D employee, 2015

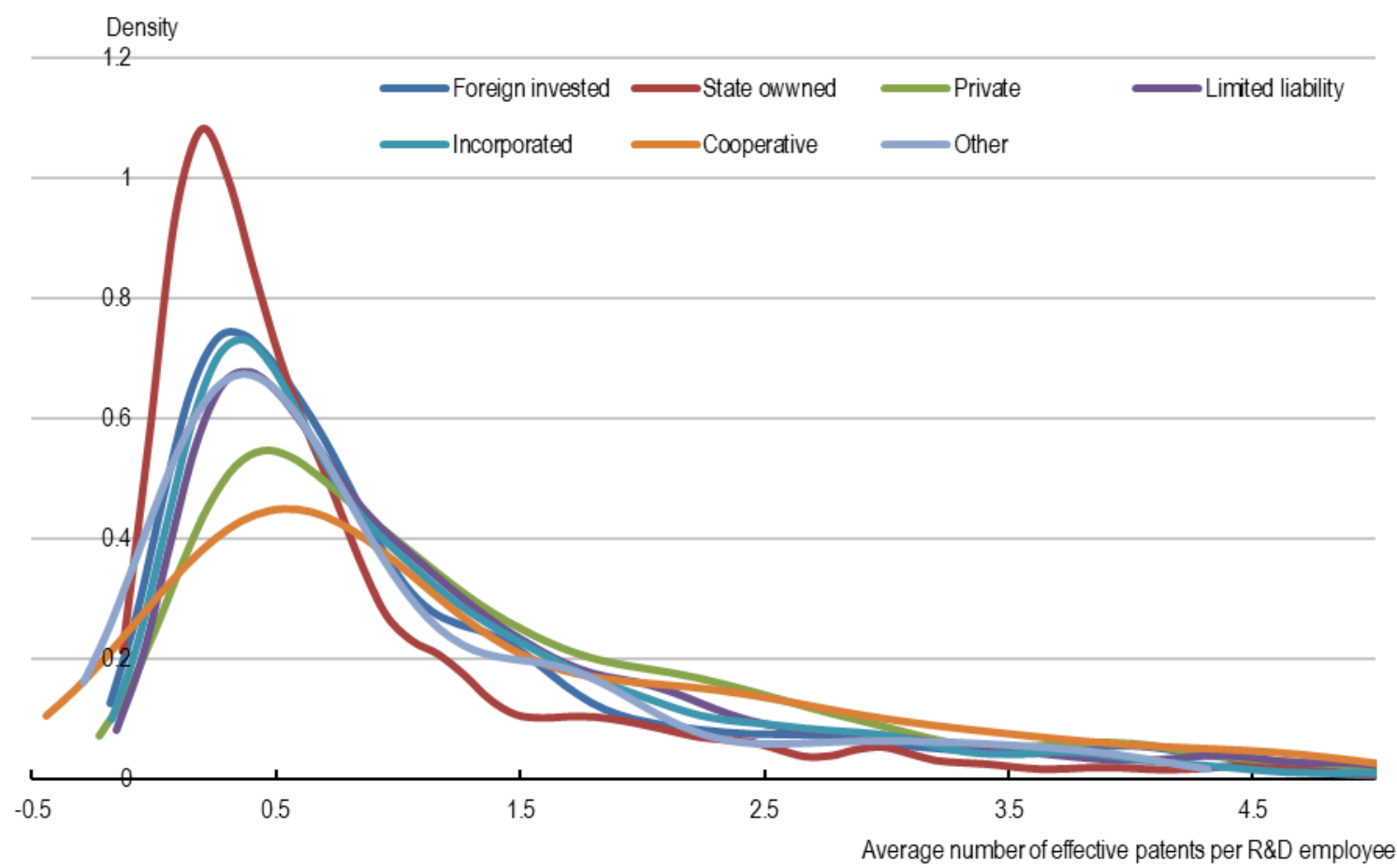

Note: Based on ownership categories defined by China's National Bureau of Statistics.

Source: Authors' calculation based on the 2016 SIPO China Patent Survey.

Figure 19. Foreign and private firms have a low share of researchers and employees with tertiary education

Density of share of researchers and of employees with tertiary education in total employees, 2015

\section{A. Share of R\&D employees}

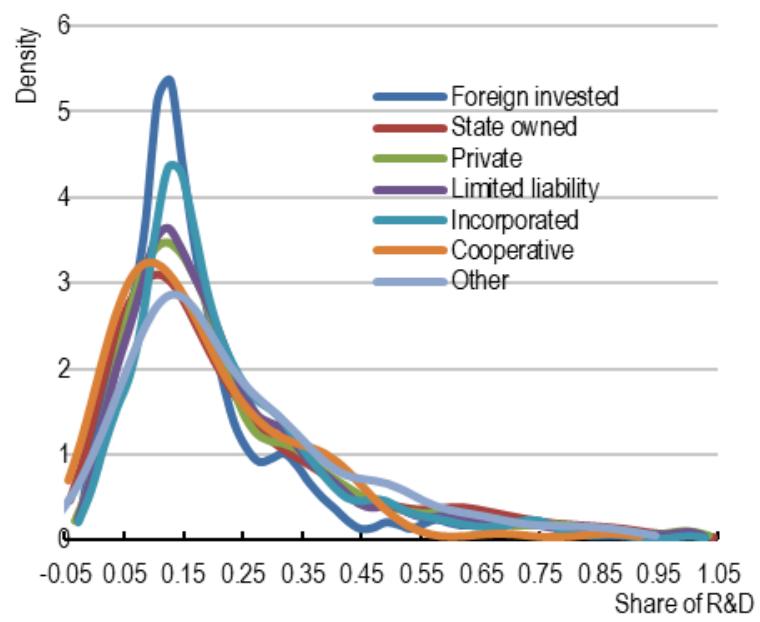

B. Share of employees with higher education

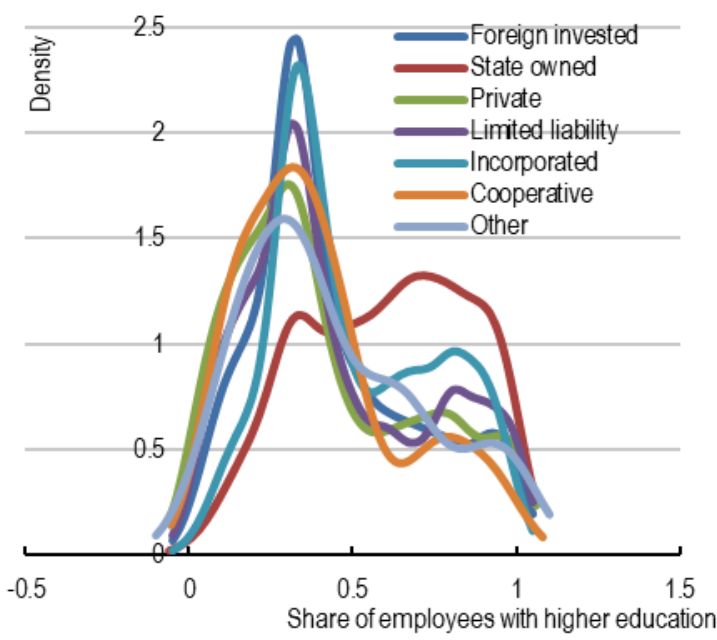

Note: A Based on ownership categories defined by China's National Bureau of Statistics.

Source: Authors' calculation based on the 2016 SIPO China Patent Survey. 
40. SOEs' material input into the patenting process is also larger than that of foreign or private firms. They spend more on R\&D than the other two firm types both in absolute terms and per effective patent (Figure 20). In terms of R\&D to sales, however, private firms and collectives spend more, which may be related to their relatively smaller sizes in terms of sales.

\section{Figure 20. SOEs spend more than private or foreign firms on R\&D both in absolute terms and per effective patent}

Density of R\&D spending in CNY million and per effective patent, 2015

\section{A. R\&D spending (in CNY million)}

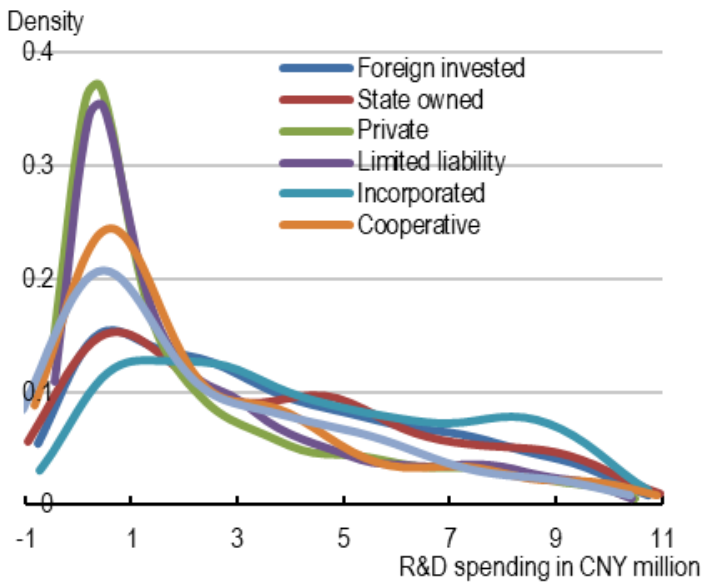

B. R\&D spending per patent

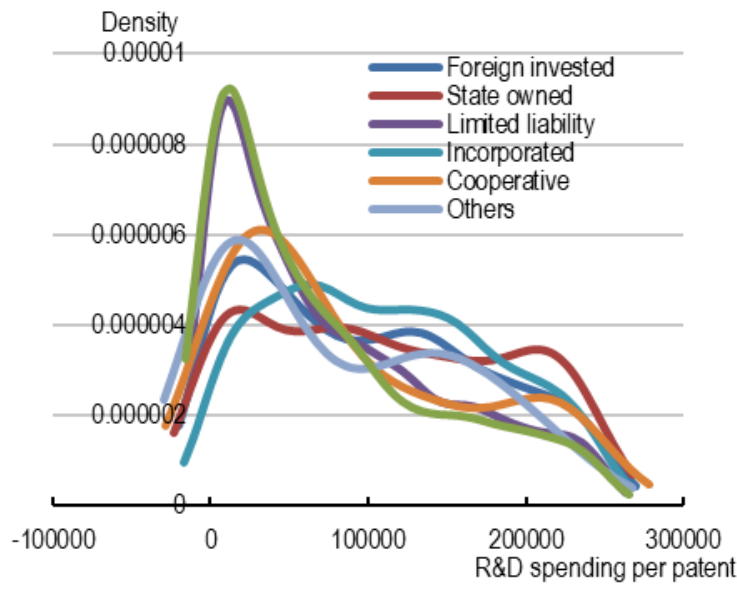

Note: Based on ownership categories defined by China's National Bureau of Statistics. Source: Authors' calculation based on the 2016 SIPO China Patent Survey.

41. SOEs appear to be the major beneficiaries of government support. A much larger share of SOEs say that government support is a main source of their funding than private or foreign firms. Though, again the national picture masks certain differences at the province level. In Tianjin, Fujian and Yunnan, the share considering government funding as a major source is higher for foreign firms. The share of firms that received government support for less than $10 \%$ of their patents is the highest in the case of private firms, even higher than for foreign firms. At the other extreme, the share of private firms receiving support for over $90 \%$ of their patents is smaller than that of SOEs or foreign-invested firms.

\section{Who are the real inventors?}

42. Invention patents protect true inventions (they are similar to utility patents in the United States), for instance a new technical solution relating to a product, a process or an improvement thereof. They are granted for 20 years. Utility model patents, in contrast, protect new technical solutions, relating to a product's shape, structure or a combination thereof. They are often incremental improvement over an existing technology or product. Utility model patents are valid for 10 years. A patentable design must possess a prominent difference from prior art designs and combinations thereof. In contrast to invention and utility model patents, a patentable design does not need to involve novel technology, but is usually an artistic creation which features a decorative or aesthetic exterior appearance of an object.

43. In many countries only invention patents can be patented, neither utility model nor exterior design patents. Liang and Xue (2011) note that the Chinese patent system is closer to the Japanese than the US in a sense that its primary purpose is to facilitate diffusion. This "petit patent" system is said to encourage 
gradual innovation and the diffusion of knowledge, which is an important way of catching up for latecomers in the global innovation arena.

44. Invention patents are a higher quality of innovation, therefore the share and the surrounding factors of invention patenting can be informative of the quality of patenting. The 2016 SIPO China Patent Survey covers 764,389 effective patents held by 8426 firms. From the total number of patents, $19 \%$ are invention patents, the remaining being mainly utility model (54\%) and to a lesser extent exterior design (26\%) patents. Among the three patent types, invention patents have the highest concentration, followed by exterior design patents. Firms in modern industries, both manufacturing and services, tent to hold a higher share of invention patents compared to traditional industries. In modern manufacturing industries, the largest firms tend to have the highest share of invention patents in their total patents, but this difference is not so obvious in traditional manufacturing (Figure 21). Firms in modern industries, whether in manufacturing or services, tend to hold more invention patents in both absolute terms as well as relative to other patents. This may be related to higher technology intensity and/or recent emergence of some of those industries and therefore greater prominence of fundamentally new products and processes.

Figure 21. Very large firms in modern manufacturing industries tend to have a greater share of invention patents

Share of invention patents by firm size
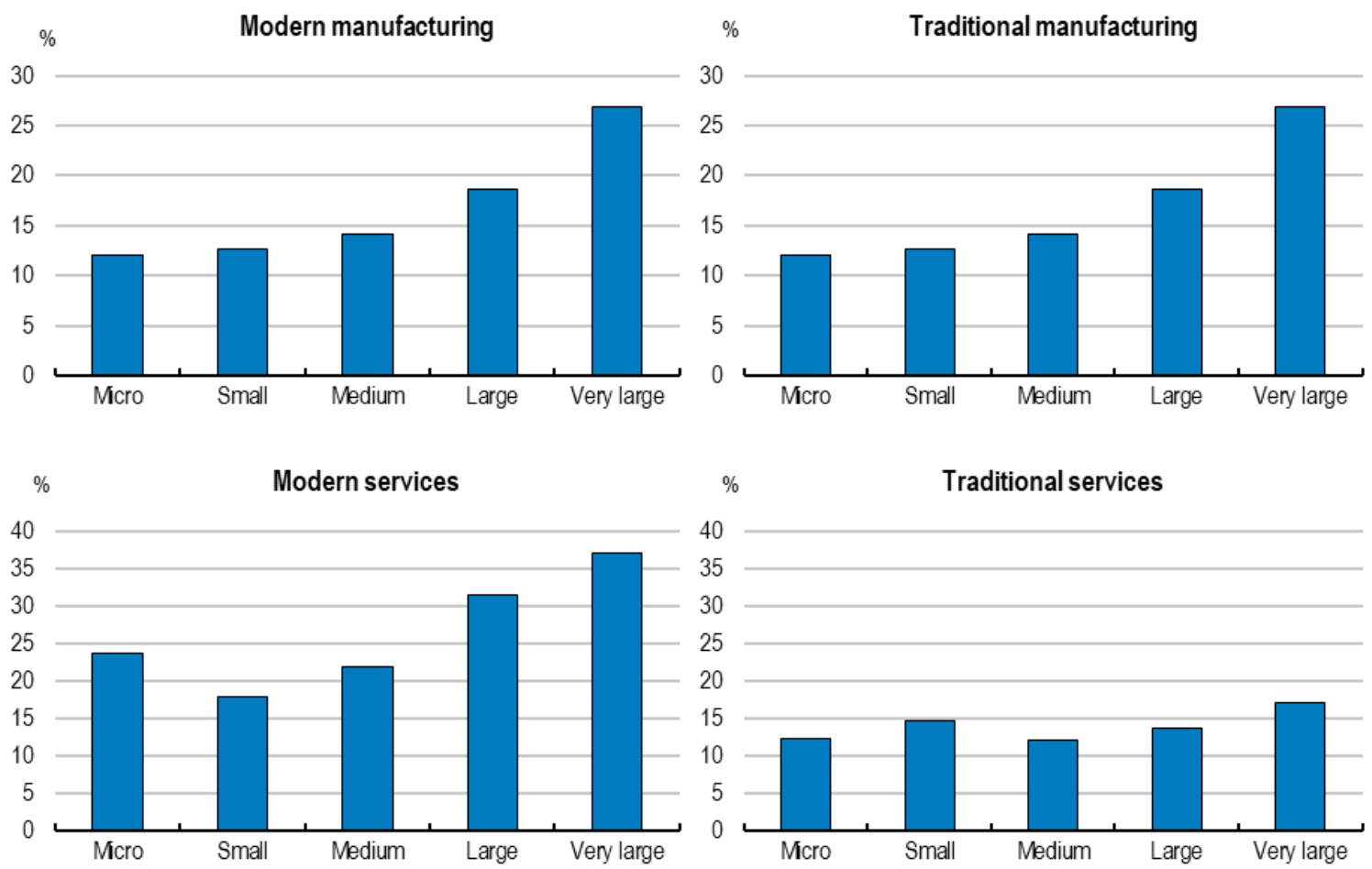

Note: Size categories are defined using the definition of up to 19 employees for micro firms, 20-49 for small, 50-245 for medium, 250-999 for large and at least 1000 employees for very large firms.

Source: Authors' calculation based on the 2016 SIPO China Patent Survey. 


\section{Electronics makers lead in invention patents}

45. Electronics makers jointly hold $19 \%$ of all invention patents, more than any other sub-sector, reflecting the dynamism and innovation-orientedness of this industry. Resource processing firms come next with $12 \%$, followed by transport equipment makers and general equipment manufacturers with $6-7 \%$ each. Electronics makers also rank top in terms of invention patents per firm, with 28 invention patents on average, followed by transport equipment makers and resource processing industries, both close to 19 . Equipment and electrical machinery makers, in contrast, have around five invention patents and firms in light industries below five. Invention patenting, similarly to patenting activity in general, is highly concentrated in a small number of firms. The median electronics maker holds the largest number of invention patents (three), followed by transport equipment and general equipment manufacturers and resource processing firms, each holding two. The median light industry firm, in contrast, holds no invention patents.

46. Resource processors have the highest share of invention patents in their total patent holdings at $24 \%$ on average, followed by electronics makers at $17 \%$ and equipment manufacturers at $11 \%$ (Figure 22 ). High industry averages mask high levels of concentration of patents in some firms. The median invention patent ratio is similar for resource processors and electronics makers at around $9 \%$ each, the highest among all manufacturers. 
Figure 22. Resource-processing industries hold the largest share of invention patents among manufacturing industries

Share of invention patents in total by manufacturing sub-industry, 2015
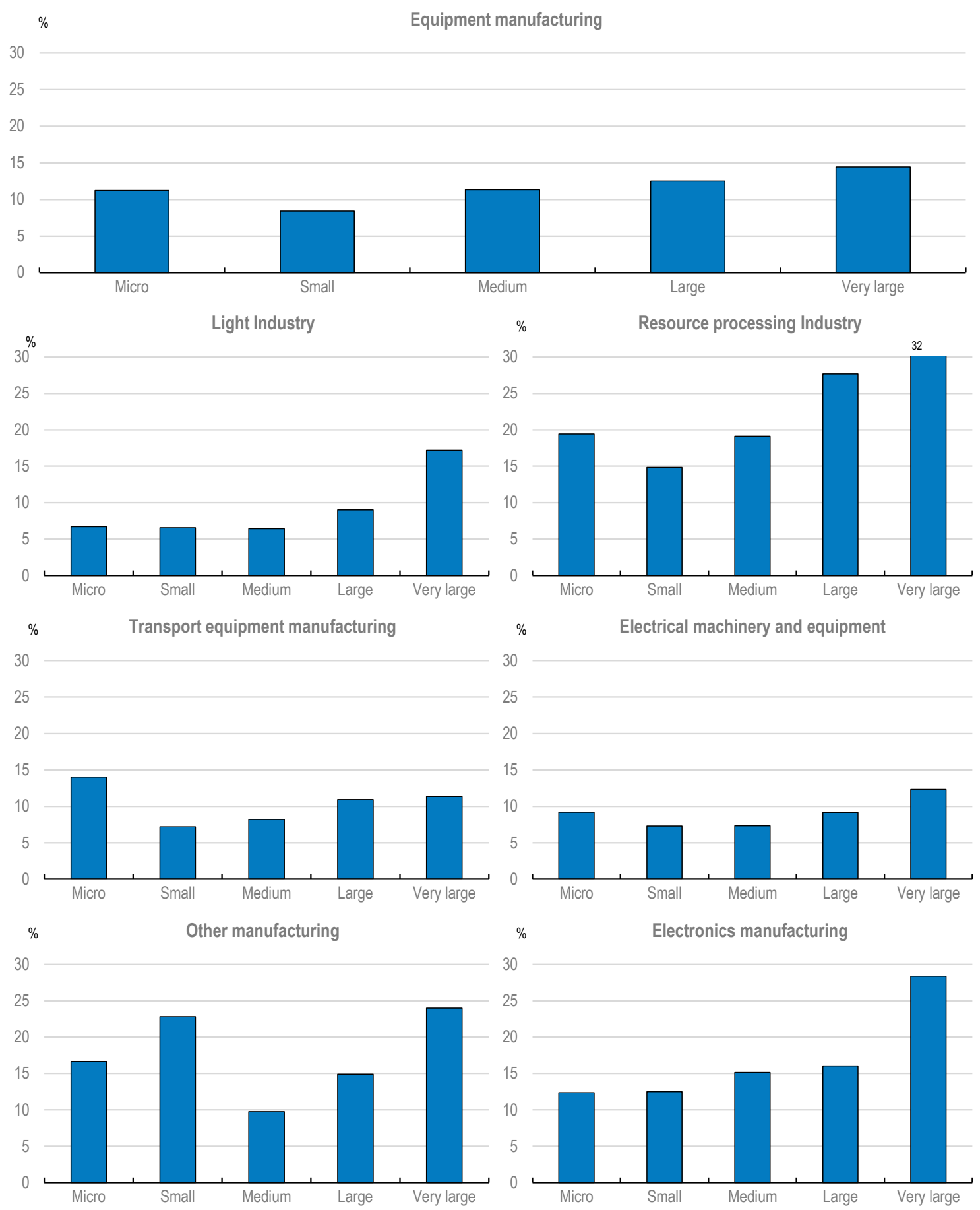

Note: Size categories are defined using the definition of up to 19 employees for micro firms, 20-49 for small, 50-245 for medium, 250-999 for large and at least 1000 employees for very large firms.

Source: Authors' calculation based on the 2016 SIPO China Patent Survey. 
47. Modern manufacturing industries, especially their larger firms, are more likely to hold design patents (Figure 23). The average medium-sized light industry firm holds most design patents, followed by large firms in the same industry and giant firms in wholesale/retail sales and transport equipment manufacturing. Electronics makers are not performing that well in design patenting.

\section{Figure 23. Larger firms and modern industries are more likely to hold design patents}

Number of design patents per firm by firm size and modern/traditional manufacturing, 2015

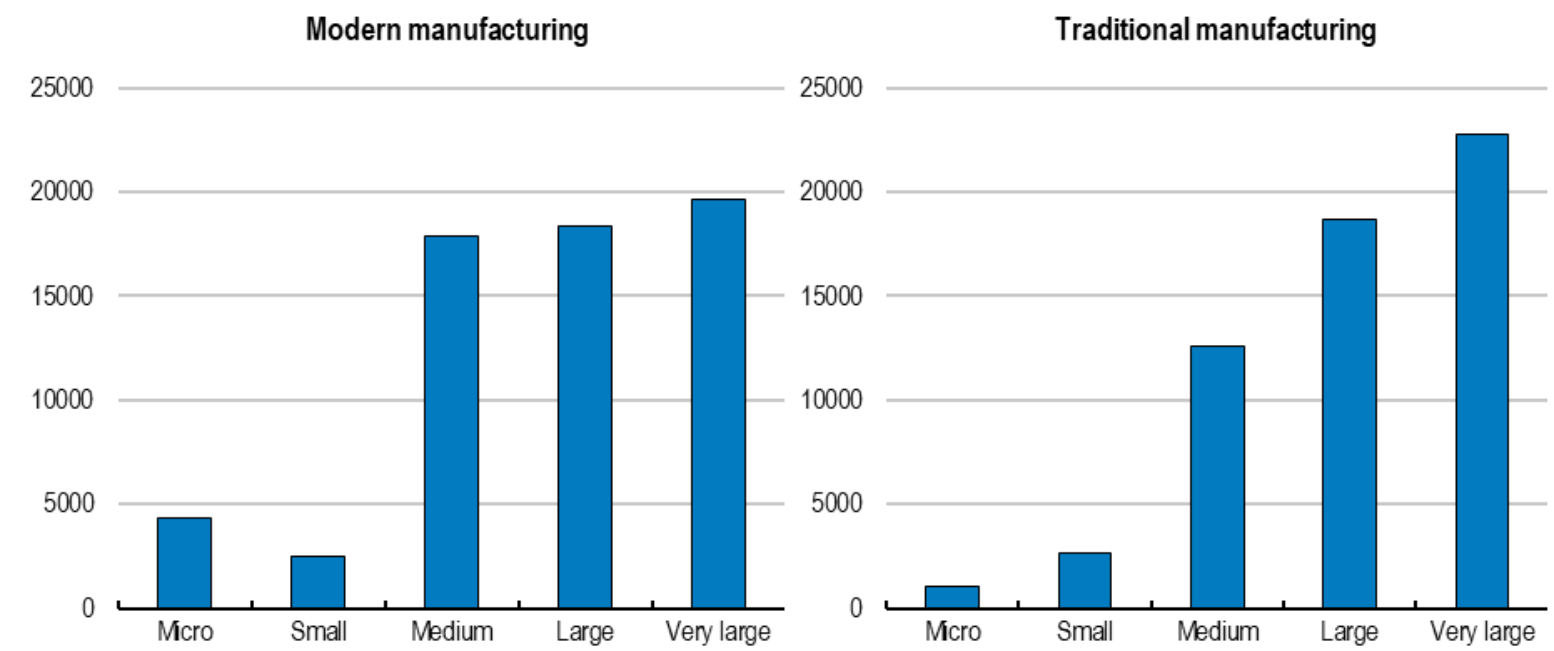

Note: Based on the official classification of industries into new/modern and traditional (National Bureau of Statistics, 2012). Size categories are defined using the definition of up to 19 employees for micro firms, 20-49 for small, 50-245 for medium, 250-999 for large and at least 1000 employees for very large firms.

Source: Authors' calculation based on the 2016 SIPO China Patent Survey.

\section{Research firms and telecommunications and trading firms hold most invention patents in services}

48. From the 16 service industries at the 2-digit level of the Chinese industry classification, invention patent holders broadly follow the pattern of overall patent holders: research firms rank first, holding $18 \%$ of all invention patents, followed by telecommunications and wholesale and retail firms with $10 \%$ and $5 \%$, respectively. The ranking looks somewhat different if looking at the number of invention patents per firm: transport and storage firms rank top with 180 invention patents on average and with a single firm holding over 1500 invention patents, more than half of all in the industry. Transport and storage firms are followed by telecommunications and research firms with 68 and 22, respectively.

49. While $27 \%$ of research firm patents are invention patents, this share is $45 \%$ for telecommunications firms and $12 \%$ for wholesale/retail. As in the case of overall patents, transport and storage firms hold also the largest number of invention patents, on average 180. The median telecom firm holds the largest number of invention patents at 11 , followed by research firms and construction firms with three each.

\section{Mainly larger firms hold invention patents}

50. Invention patenting appears to be a business mainly for larger firms. The median firm in the micro and small categories does not hold any invention patents (though there is a micro firm that holds 279 and a small firm 170) and even in the medium category, the median firm holds only one invention patent. The 
largest firms produce most invention patents: firms with over 1000 employees jointly hold $59 \%$ of all invention patents (and $48 \%$ of all patents). The pattern varies widely across provinces, however, with micro firms in Hunan, Guangxi, Liaoning and Shandong jointly holding most of invention patents among all firm sizes, reaching above $30 \%$ in the latter three (Figure 24 ).

Figure 24. The largest firms hold the highest share of invention patents in many provinces The share of invention patents in total by firm size and province, 2015

\section{A. Eastern provinces}
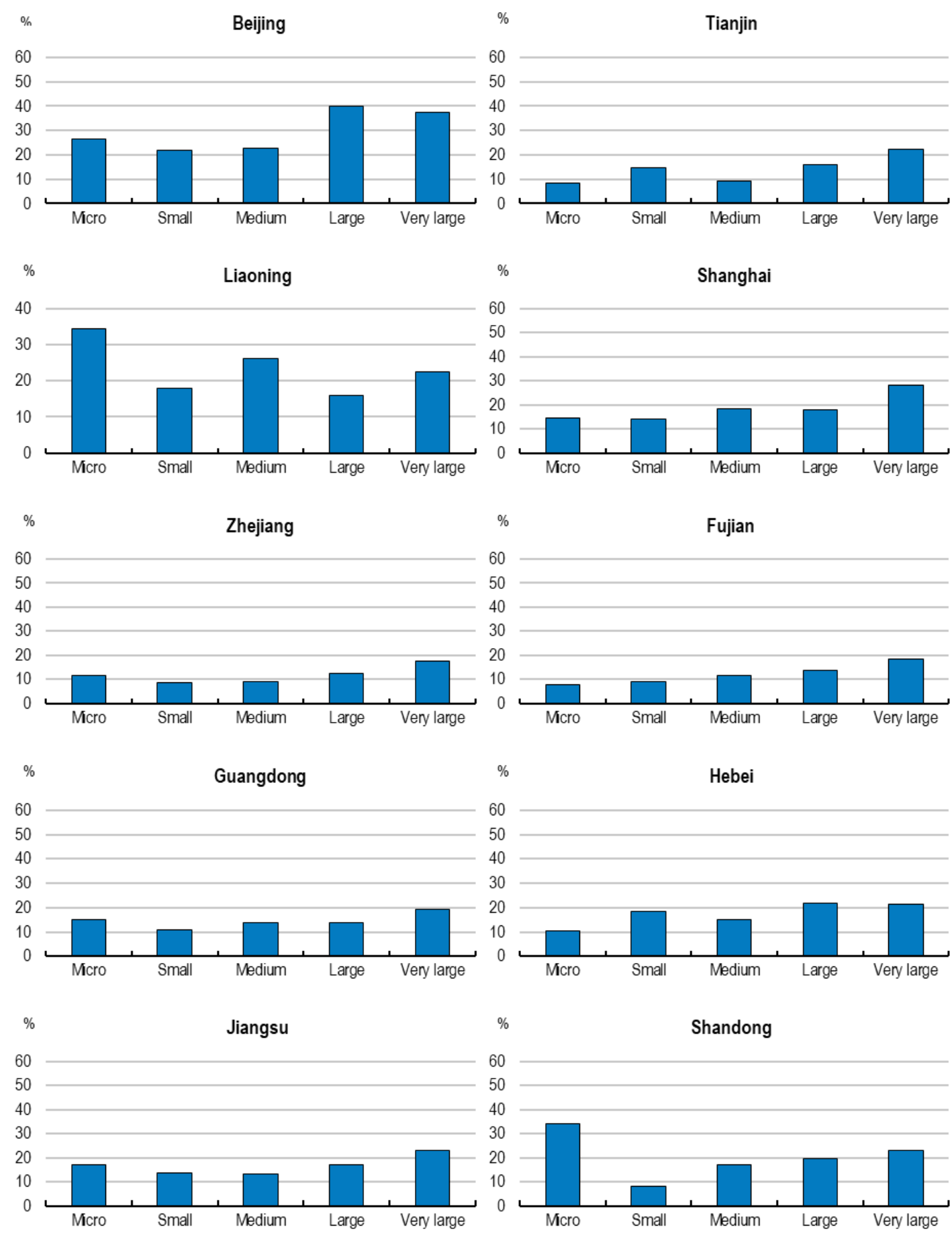
42 | ECO/WKP(2019)53

B. Central provinces
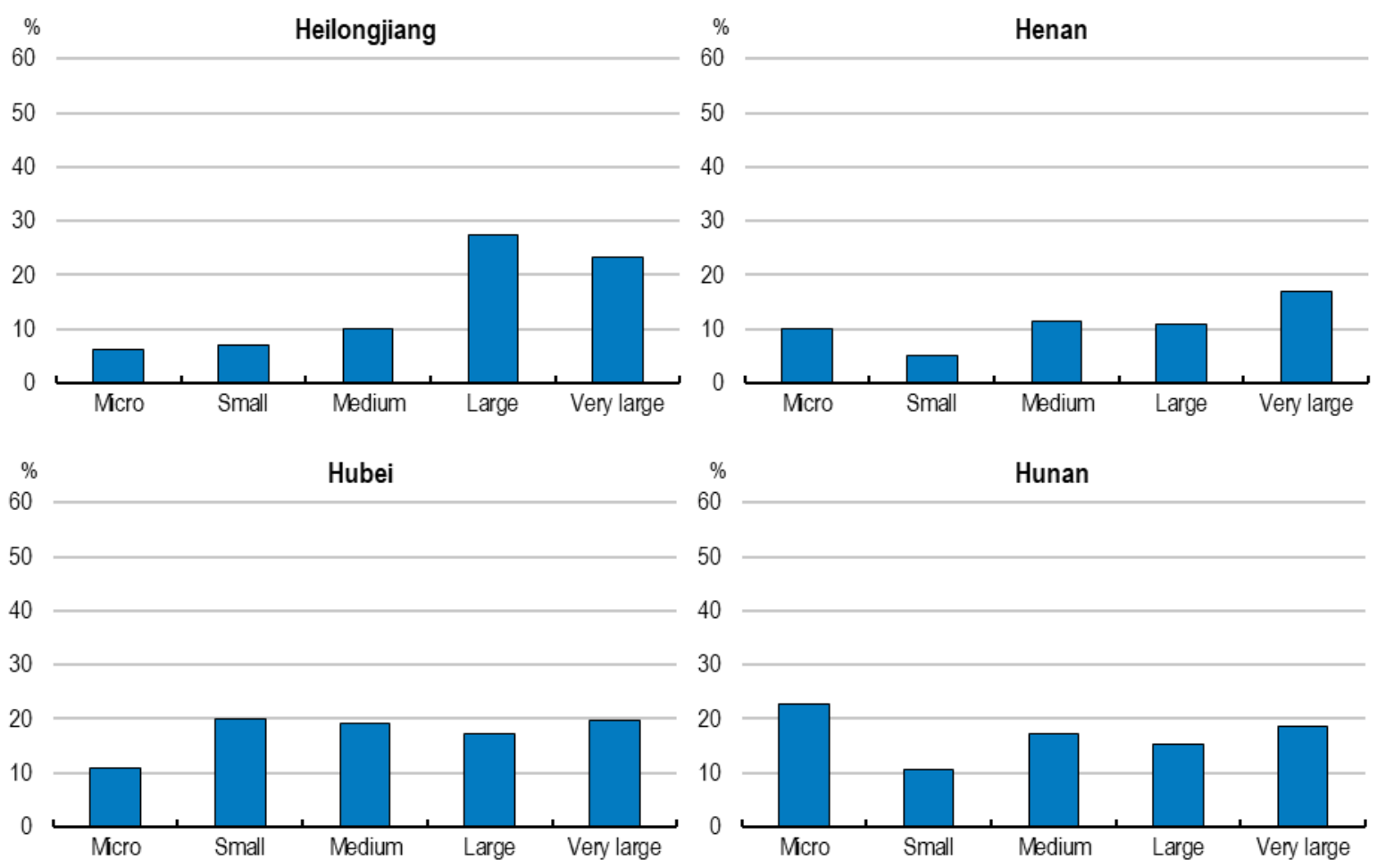

$\%$

Anhui

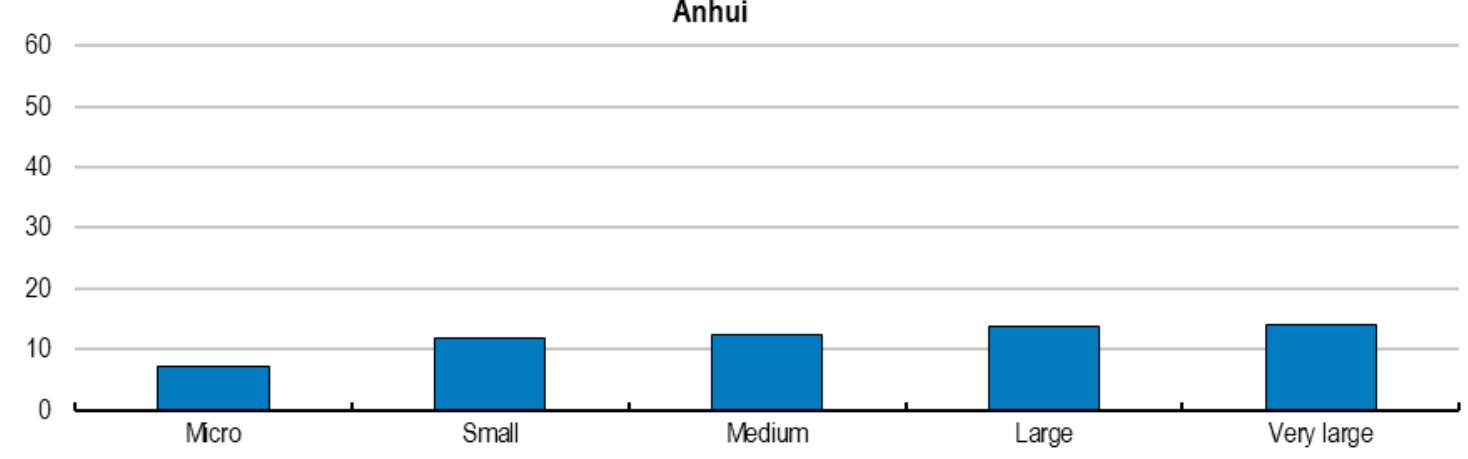


C. Western provinces
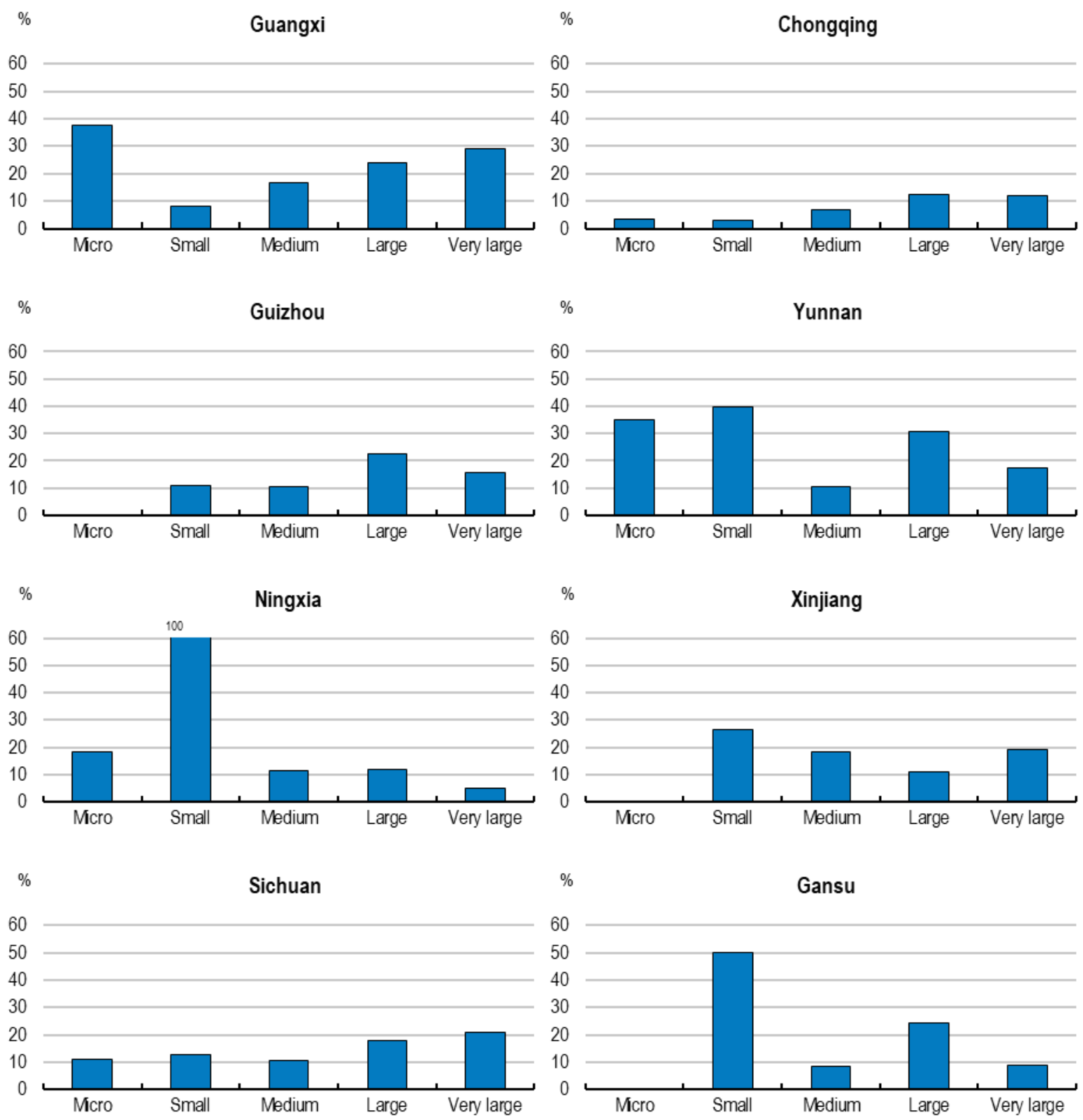

Note: According to the definition by China's National Bureau of Statistics, Eastern provinces include Beijing, Tianjin, Hebei, Liaoning, Shanghai, Jiangsu, Zhejiang, Fujian, Shandong, Guangdong and Hainan, Central provinces comprise Shanxi, Jilin, Heilongjiang, Anhui, Jiangxi, Henan, Hubei and Hunan and Western provinces cover Inner Mongolia, Guangxi, Chongqing, Sichuan, Guizhou, Yunnan, Tibet, Shaanxi, Gansu, Qinghai, Ningxia and Xinjiang Size categories are defined using the definition of up to 19 employees for micro firms, 20-49 for small, 50-245 for medium, 250-999 for large and at least 1000 employees for very large firms.

Source: Authors' calculation based on the 2016 SIPO China Patent Survey.

51. For exterior design patents, the picture of patent holding by firm size appears somewhat similar to that for invention patents. The median firm from the micro to the medium category does not hold any design patent. A major difference is that some smaller firms appear to perform particularly well in design patenting. There is a micro firm holding 624 such patents and micro firms jointly hold over $5 \%$ of design patents (while less than $2 \%$ of invention patents). Micro and small firms are not important design patenters in most industries, except the light industry, research, wholesale and retail sales, construction and agriculture. 
Looking at the province level, larger firms tend to hold more design patents, but in Jiangsu and Sichuan, medium-size firms hold the most. The oldest firm group of over 15 years appears the most successful in patenting, though in Sichuan, for instance, it is the 5-10 year old group and also newly established firms appear to perform well.

52. While utility model patenting is the major form of patenting in China, with more than half of patents registered in this category, micro firms perform only slightly better in utility model patents than in invention patents, jointly owning $2 \%$ of all such patents. The distribution of utility patents across micro firms is less skewed towards a few firms than that of design patents, the median micro firm holds five such patents and the firm with the largest holding only 261 , similar to the largest holder of invention patents in this size category.

53. Invention patents are highly concentrated in a small number of firms in Gansu, Ningxia, Yunnan, Guizhou, Zhejiang and Xinjiang, all with the Hirschmann-Herfindahl Index (HHI) above 1000. The "small number" here can be as high as 494 in Zhejiang as there are a large number of patenting firms there. In most of these provinces there are few patenters, which hold a large share of patents. In Zhejiang invention patenting is much less common than utility model patenting (with 782 utility patent holders), though there are many patenting firms there. Similarly, in Jiangsu and Guangdong, home provinces to a large number of patenting firms, utility model patenting is more common, with 1101 Jiangsu firms holding invention and 1574 utility model patents. Comparable figures are 789 and 1146, respectively, for Guangdong firms.

\section{SOEs are the largest invention patenters}

54. SOEs are the largest holders of invention patents among ownership categories, with the median SOE holding 15 and the group jointly a quarter of all. Their invention patent share in all patents is also the highest. The median foreign-invested firm holds three invention patents and the median private firm none. Purely privately-owned firms jointly hold only somewhat over $6 \%$ of all invention patents and the share of invention patents among their patents is lower than in the case of foreign-invested firms or SOEs. SOEs have a higher share of invention patents in the total than foreign and private firms in most provinces. In Beijing, Hubei, Liaoning, Shandong, Guangxi, Sichuan, Guizhou and Yunnan foreign firms rank top among the three ownership types.

55. In the case of exterior design patents, there is large variation across provinces in ownership types of the top-ranking firm. In some major innovators such as Beijing, Shanghai and Guangdong, foreign firms perform better than SOEs or private firms in terms of the number of design patents held, in Jiangsu and Zhejiang, the private sector leads, while in Hebei, Hubei, Hunan and Liaoning SOEs.

\section{Gauging patent relevance: utilisation rates and expected revenues}

56. The rate of utilisation of patents is an important indicator of patents' relevance. While in general patenting activity is not necessarily aiming at future application, patenting by enterprises is more considered as being application oriented in comparison, for instance with universities or research institutes. To what extent patents are utilised may allow inferring of potential productivity effects stemming from patenting. In the age of digitalisation, governments play an increasingly important role in laying down the frameworks for the utilisation and commercialisation of scientific research (OECD, 2015).

\section{Guangdong is the best utiliser of patents among the largest patenting provinces}

57. The rates of patent utilisation vary widely across provinces. A fifth or more of patenters have an utilisation rate below $10 \%$ in Xinjiang and Tianjin. Low utilisation is less common in Liaoning, Chongqing and Guangdong, between 2-5\%. All those provinces also have a high share of firms with utilisation rates of above $80 \%$. Less common low utilisation and more common high utilisation is the common feature of 
Beijing, Shanghai, Hebei, Shandong, Hunan, Guizhou, Fujian, Heilongjiang and Sichuan alongside those three provinces. In Liaoning, Heilongjiang, Shandong and Guangdong, the low number of firms with low utilisation may be related to most firms' lack of government support, therefore the need to be more utilisation oriented in patenting. In contrast, in Beijing, Shanghai, Hebei and Chongqing, government support may be more focused on utilisation. Invention patents appear to be even less utilised than patents overall, with a quarter or more firms in Xinjiang, Tianjin, Anhui and Jiangsu utilising less than $10 \%$ of their invention patents. Utilisation of design patents is even lower, with at least $40 \%$ of firms in Ningxia, Tianjin, Xinjiang, Hubei and almost as many in Jiangsu utilising less than $10 \%$ of their design patents. The situation is better for utility patents, with a much smaller share of firms not utilising most of their utility patents.

58. Thus, the major patenting provinces in terms of the number of patenting firms they accommodate or the number of patents those firms hold are not necessarily the best performers in utilisation. Jiangsu, for instance, which is the best performer by the number of patenting firms as well as patents, does not perform better than the average province on both measures of low share of firms with low utilisation and high share of high utilisation. In particular its invention patents are underutilised. Guangdong is the only province among the major patenting provinces on those measures that is clearly a good utiliser of its innovation outputs. Beijing is also a good utiliser, and is top performer on a different measure (number of patents the median firm holds). Shanghai and Zhejiang barely hit the bar on some of those measures of utilisation.

59. Patents can be utilised by applying them in production by the patenting firms or by licensing or transferring the patent right to another firm. Firms in Yunnan, Guizhou or Hunan apply over $90 \%$ of their patents in production. At the other extreme, almost a quarter of Xinjiang and Tianjin firms make use of less than $10 \%$ of their patents in production. More design patents than invention or utility patents are not used in production by the patenter. Licensing is not a very common way of commercialising patents, more than three-quarter of firms in China report that they licensed less than $5 \%$ of their patents to third parties. Very few firms have high licensing rates. In Liaoning, Heilongjiang, Sichuan and Zhejiang, the highest licensers, about $4 \%$ of the firms license over $90 \%$ of their patents. For invention patents, this ratio is only slightly higher at $5-6 \%$ in Yunnan and Guizhou, but there the sample is very small. Similar ratios are seen for design patent licensing in those two provinces alongside Sichuan. Transferring of patent rights is even less common than licensing. $86 \%$ of firms in China say they transfer less than $5 \%$ of their patent rights. Sichuan appears to have the most "professional" patenters and/or a well-functioning patent market: $4-6 \%$ of invention and design patenters transfer over $90 \%$ of their patents to other firms.

\section{Transport equipment makers, telecommunications service providers and wholesalers/retailers have the highest utilisation rates}

60. Services industries have a higher variation across patent utilisation rates, while in manufacturing, $31-48 \%$ of firms utilise more than $90 \%$ of their patents. Transport equipment makers lead in utilisation, be it invention, design or utility patents. Among services industries, telecommunications do well in utilisation of invention patents, while wholesalers and retailers in that of utility and design patents. Leasing and business services providers and telecommunications firms do well in licensing invention patents and mining and utilities firms utility patents. Among manufacturing firms, those belonging to light industries lead in design patent licensing. Invention patents are highly concentrated in a few firms in many services industries such as transport and storage, water conservancy and culture. In contrast, the concentration ratio is generally low in manufacturing.

\section{Large and medium-size as well as older firms perform better in patent utilisation}

61. Large and medium-size firms have the highest share of firms with utilisation rate of over $90 \%$, while micro firms the lowest, followed by small firms. At the other extreme, these two latter size groups have the highest share with very low, less than $10 \%$ utilisation. As for the utilisation of invention patents, 
large firms appear to have even higher rates, while smaller firms, especially micro firms even lower. This may be related to capacity constraints among smaller firms to put into production new technologies, which are usually embedded in invention patens. Not surprisingly, they more often license their patent rights than larger firms.

62. Young firms below five years do not perform particularly well in utilising patents, especially new firms (below two), and especially utilising design patents. Putting into production their patents is although their major choice, but less common than for older firms. Low utilisation may be explained by most of them being micro firms. Young firms, however, tend to transfer their patents more often than micro firms instead of licensing as the latter do. Thus, their size alone, does not explain their behaviour. Probably the lack of experience in navigating through the legal aspects of licensing and little prospects for putting into production themselves makes them transfer their patent rights.

63. Foreign-invested firms appear to be doing much better in patent utilisation than SOEs or private firms, with nearly $40 \%$ of them utilising over $90 \%$ of their patents, and the share of very low utilisation is also the lowest among these firms. Foreign firms do more or less equally well in putting into production of all three types of patents. This may be because their research and patenting is more application-oriented or they may register patents that are already registered and utilised in other countries. Private firms do not perform well, especially in utilising invention patents. True enough, they only have a small share of invention patents among the patents they hold. Private firms are most likely to license their patents regardless of the type of the patent. They are less likely to have the scale and probably the extent of diversification to put all patents into production by themselves than SOEs or foreign-invested firms.

\section{Utilities, transport firms, micro, young and private firms and those in some Western provinces expect the highest income from patenting}

64. Another measure of patent relevance is how much income is expected from a patent. High expected income may indicate future commercialisation plans. A return of CNY 50,000-100,000 per patent appears to be the norm for the greatest share of firms in nearly all manufacturing industries and in nearly half of services. In water conservancy, expected revenue is ten times more and in utilities and transport and storage twenty-to-hundred times more. Those are all capital-intensive industries with many giant firms. Transport and storage is also highly R\&D intensive, ranking third on this measure (i.e. R\&D as a percentage of sales) for domestic firms. While most patenters in water conservancy benefit from government support, for utilities firms, it is not the case. Roughly a sixth of research, telecom and wholesale/retail sales firms expect less than CNY 50,000 revenue from a patent. These three sectors are the largest patenters in services, jointly holding a quarter of all patents. The scale of patenting activity at the firm level, however, is relatively small in those sectors. That is, each firm does not produce too many patents. They are small in scale, but highly R\&D intensive. The low expected returns may mostly be related to their smaller scales and therefore likely to patents of lower commercial value.

65. Most firms in almost all size categories expect CNY 50,000-100,000 income from a patent. The only exception is micro firms, where a slightly higher portion expects 20-100 times of it. Moreover, a fifth of micro firms hope on a return of over CNY 5 million per patent. This share is higher than in any other size group. Furthermore, the larger the firm is, the less revenue it expects to earn from each patent. This may be related to their larger production scale and possibly economies of scale in patenting.

66. As smaller firms tend to be also younger, not surprisingly, it is new firms (below two years) that expect an income of 20-100 times of what most firms in other age categories would expect. And the highest share of firms that count with revenue of over CNY 5 million per patent is among new firms. Surprisingly, however, the median firm hoping to earn over CNY 5 million per patent invests less than $1 \%$ of that amount in R\&D. This amount is lower than in the case of firms that expect lower income from patenting. Firms with high expectations towards income from patenting on average hold seven invention patents, 28 utility model patents and 32 design patents, lower numbers than among firms with more modest expectations, except 
for the number of design patents. This may provide part of the answer why firms investing little in R\&D and hiring fewer researchers expect higher incomes: from design patents, income may be higher.

67. In most provinces, for the largest share of firms expected income is CNY 50 000-100 000 per patent, in Heilongjiang and Gansu CNY 500 000-1 million and in Yunnan and Ningxia CNY 1-5 million. Regardless firms ownership, most firms hope to have CNY 50 000-100 000 return on each patent. Both the number and the share of firms expecting over 5 million per patent is the highest among private firms. This may look surprising at first sight as SOEs are greater R\&D dispensers than private firms and so are foreign enterprises. Indeed, the median private firm spends about a third of that of a foreign company and a fifth of that of an SOE per patent. But there are some private firms that invest heavily in patents. And private firms are strong in design patenting, where expected returns on a patent tend to be higher.

\section{How different are "super" patenters?}

68. The China Patent Survey covers all patenters with at least 100 patents, thereby providing a rich source for identifying their profiles and how they differ from "ordinary" patenters. There are 2276 such patenters, or about $0.8 \%$ of all patenters and over a quarter of survey respondents. They jointly hold 603,880 or $79 \%$ of patents covered in the survey (Figure 25). Among the effective patents they hold, $21 \%$ are invention patents, $52 \%$ utility model and $27 \%$ design patents. The distribution across the three patent types is somewhat different from other, "ordinary" patenters: super patenters have a slightly higher share of invention and design patents and a slightly lower share of utility model patents. Nevertheless, in most industries, the share of utility patents held by super patenters is higher than those of other patent types (Figure 26).

\section{Figure 25. Super patenters are also super inventors}

Number of effective patents held by patenters with 100 and more patents and others by patent type

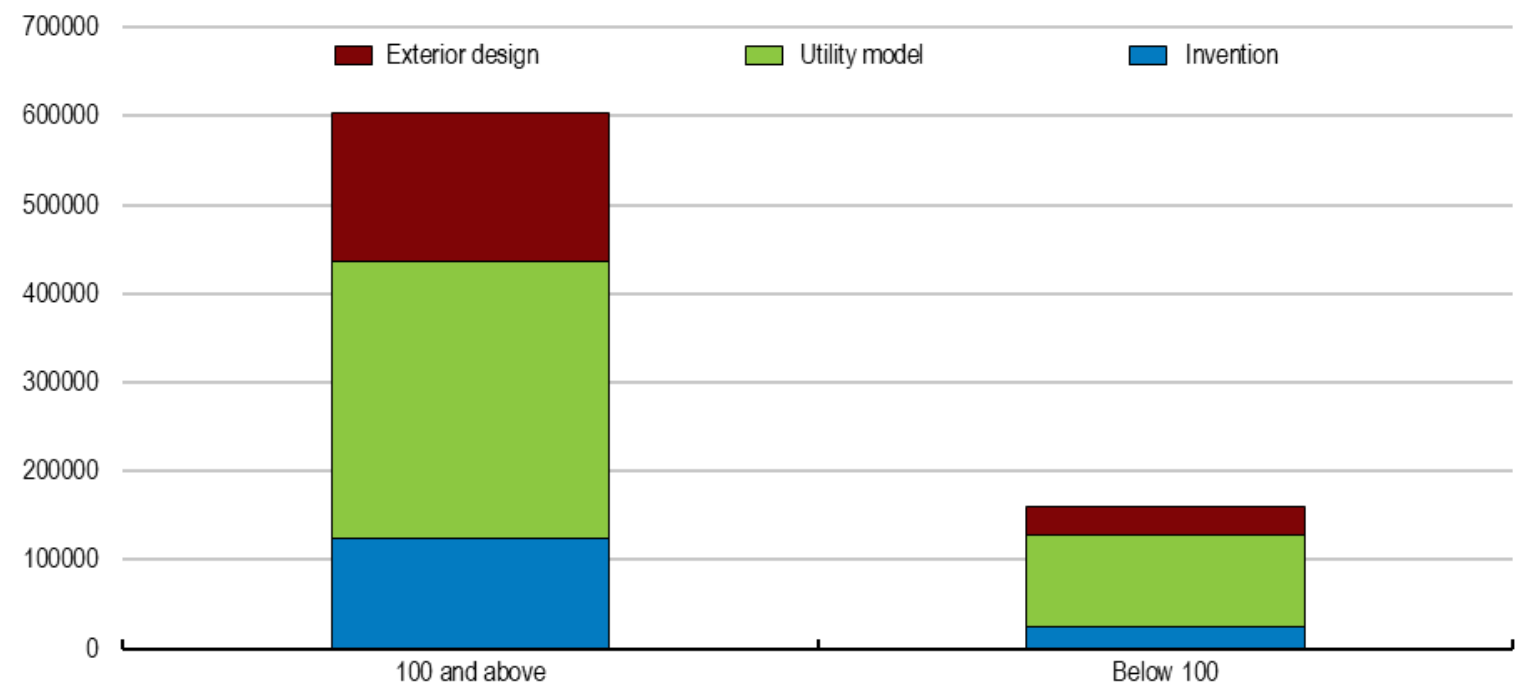

Note: The 2016 SIPO China Patent Survey covers all firms with 100 and more patents and includes a sample of the remaining patenters representative by the number of patents.

Source: Authors' calculation based on the 2016 SIPO China Patent Survey. 


\section{Figure 26. Utility patenting is most common}

Share of utility and invention patents and total number of patents held by super patenters

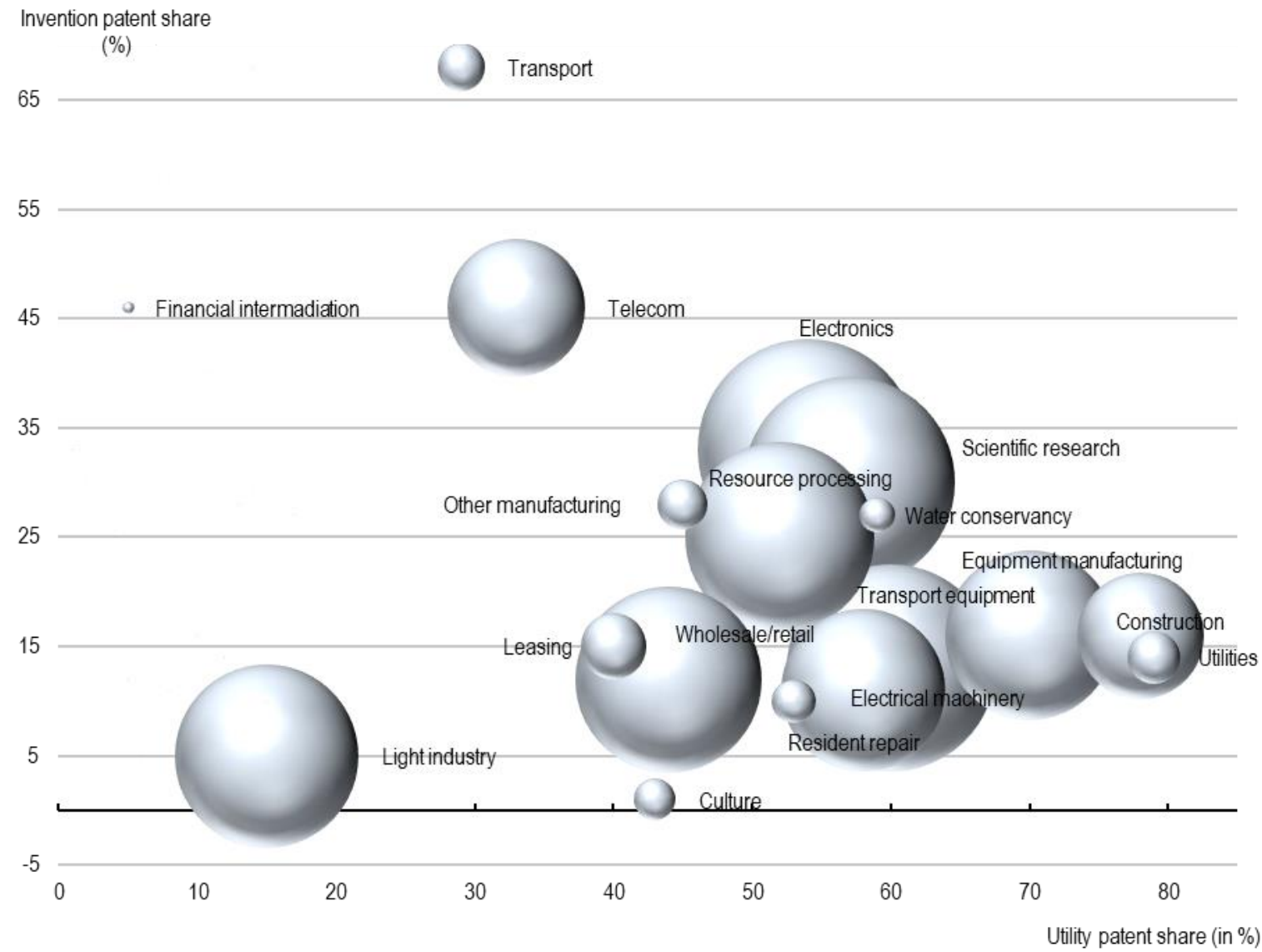

Note: The size of the bubble is proportionate to the number of effective patents held.

Source: Authors' calculation based on the 2016 SIPO China Patent Survey.

69. The median super patenter employs 830 people (the average 3741 vs. 124 and 443 , respectively for ordinary patenters), of which $15 \%$ are researchers (22\% for the average vs. $17 \%$ and $23 \%$, respectively for firms with fewer than 100 patents) and $42 \%$ of their workforce (49\% for the average vs. $38 \%$ and $46 \%$ for ordinary patenters) have a college degree. These features alone appear not less "ordinary" than the equivalents for the ordinary patenters, though super patenters are bigger in terms of the number of employees, employ a higher share of college graduates and a somewhat lower share of researchers. What makes them different is that their median firm holds 160 patents (261 for the average vs. 18 and 26, respectively, for other patenters), of which $10 \%$ (18\% for the average vs. $4 \%$ and $15 \%$, respectively, for other firms) are invention patents. The median super patenter spends CNY 27 million on R\&D or CNY 152,742 per patent and CNY 5 million on patent applications and maintenance, while the median ordinary patenter spends less than CNY 3 million on R\&D or CNY 166,000 per patent and CNY 1 million on patent application and maintenance. The lower R\&D spending per patent in the case of super patenters may reflect economies of scale in patenting activities. Super patenters also produce nearly twice as many patents per employee and per researcher than ordinary patenters, also supporting that hypothesis. Modern industries, both in manufacturing and services, spend more on R\&D per effective patent than traditional industries. 
70. Most super patenters are in manufacturing, with electronics, transport equipment makers and resource processors ranking top (Figure 27 ). These three sectors jointly produce $58 \%$ of patents by manufacturing super patenters. Among ordinary patenters, the ranking would differ somewhat: the first and third places would be the same, but instead of transport equipment makers, general equipment manufacturers rank second. These three industries jointly produce $60 \%$ of patents by ordinary patenters in manufacturing. Moreover, among the seven manufacturing sub-sectors discussed in this study, ordinary patenters in nearly all industries except other manufacturing, produce more patents than transport equipment makers notwithstanding that transport equipment makers rank second overall in the number of effective patents held. These findings may imply that a minimum scale as well as scale economies may be more important for patenting in transport equipment manufacturing than in other industries. That is why it is mostly super patenters that hold most patents in that industry as they tend to be larger in size and the hold many patents, where economies of scale may be reaped. In terms of patents per firm, again electronics makers rank first, followed by light industry and resource processor firms. Among ordinary patenters, this pattern would again be different: equipment manufacturers rank first, followed by resource processors and electronics makers.

\section{Figure 27. Electronics and transport equipment makers lead among super patenters}

Number of patents by manufacturing industry held by patenters with at least 100 patents

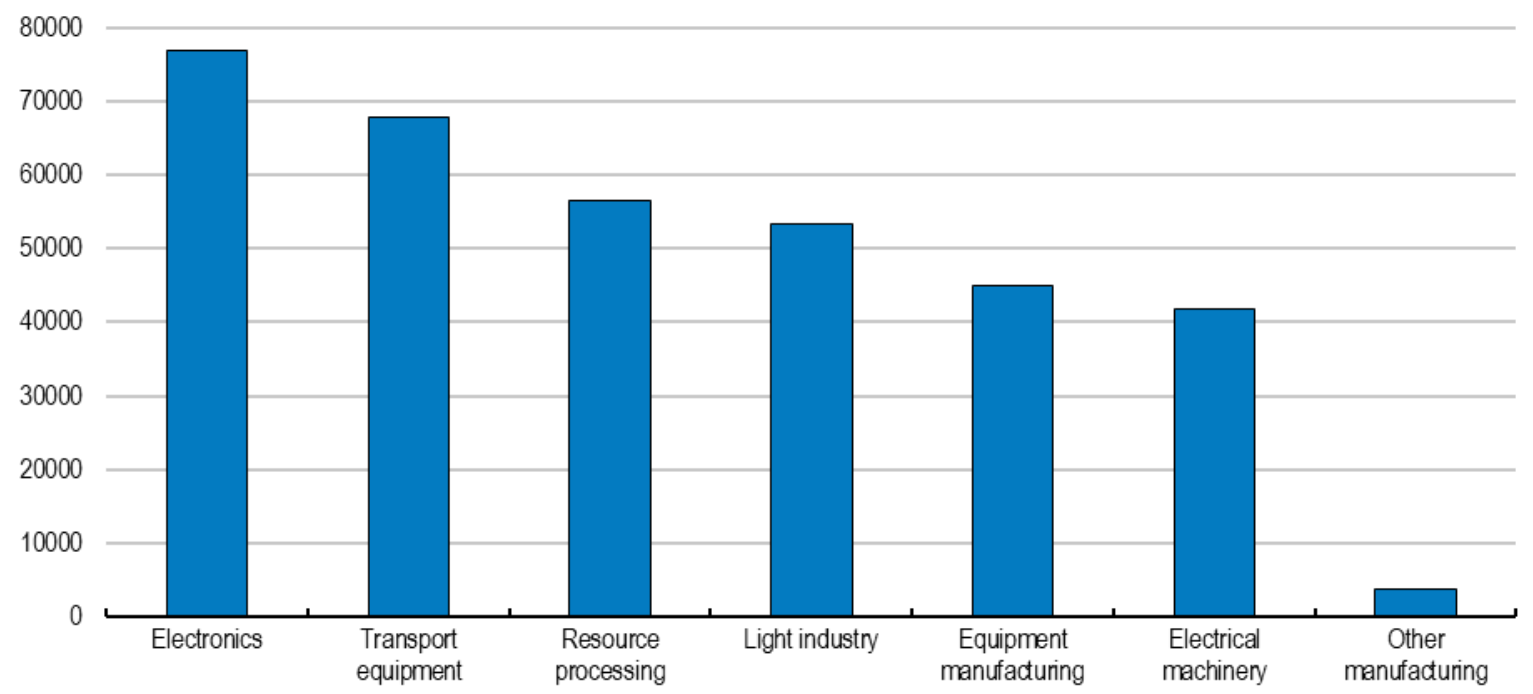

Source: Authors' calculation based on the 2016 SIPO China Patent Survey.

71. Most services super patenters are in research, wholesale and retail trade and telecommunications (Figure 28 ), these three industries jointly produce $77 \%$ of all patents by services super patenters. The third place would be taken by construction among ordinary patenters and the share of those three industry patents would be $82 \%$ among services ordinary patenters. Thus, the concentration of patents by super patenters (and also ordinary patenters) appears higher in services than in manufacturing. Also within each services industry, super patenters account for most patents, their share is much higher than in manufacturing industries. 
Figure 28. Research and wholesale and retail sales lead among super patenting services firms

Number of patents by services industry held by patenters with at least 100 patents

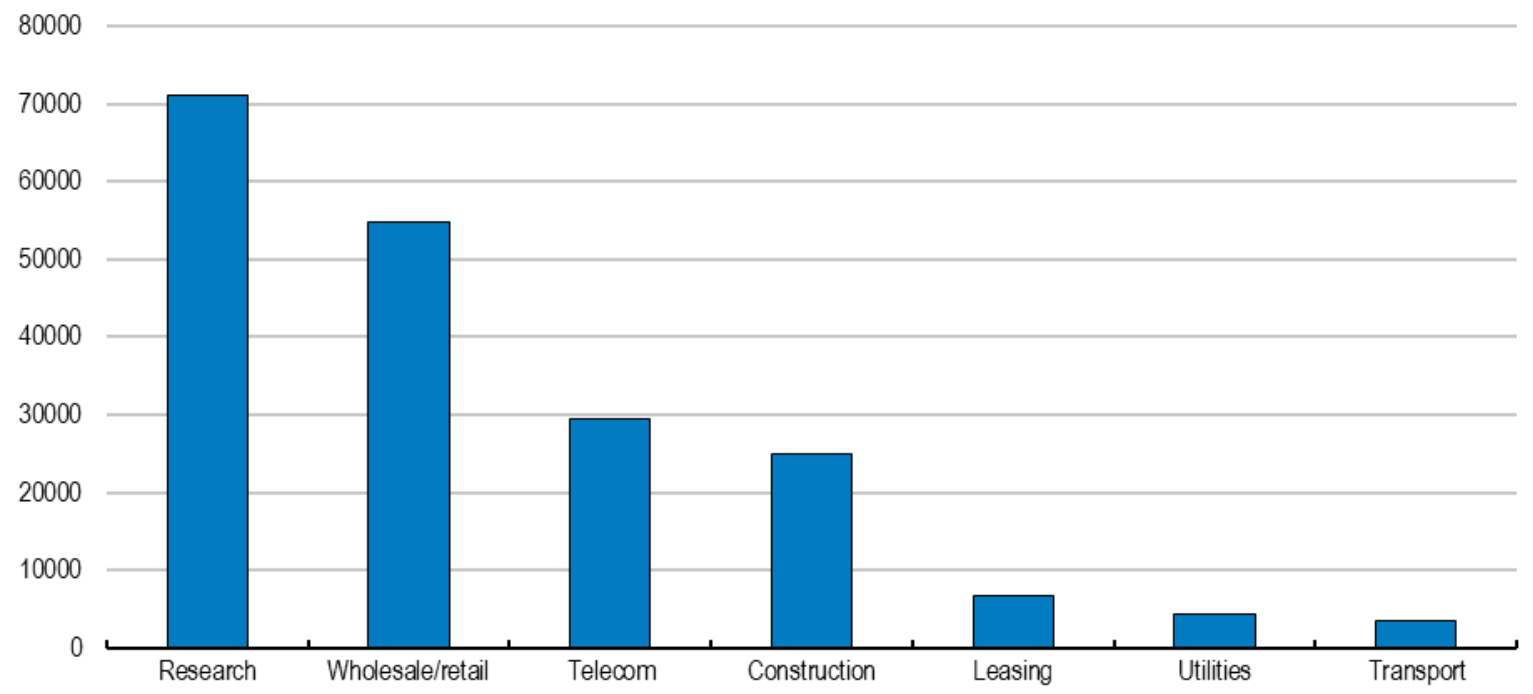

Source: Authors' calculation based on the 2016 SIPO China Patent Survey.

72. The transport and storage industry has the highest share of invention patents at $68 \%$, followed by telecom at $46 \%$, electronics makers at $33 \%$ and research firms at $30 \%$. While there are only a handful firms among super patenters in transport and storage, these figures reveal that the latter three industries are the drivers of real inventions in China, especially taking into account that their shares in total patents also tend to be high. Super patenters in other large patent producer industries like transport equipment manufacturing, resource processing, wholesale and retail sales and construction tend to focus on utility patents with shares of $60 \%, 52 \%, 44 \%$ and $78 \%$, respectively. The highest shares of design patents are exhibited in light industries (81\%) and wholesale and retail sales (44\%). Interestingly, higher shares of invention patents are not necessarily associated with higher R\&D spending per patents. Although transport and storage, telecom and research firms spend a lot on R\&D per patent, but so do firms in highly utilitypatent-intensive industries like construction or transport equipment manufacturing.

73. Most super patenters are of giant size in most industries. An exception is the light industry, where micro firms make up over a third of them. In equipment, electrical machinery, transport equipment and electronics manufacturing industries, micro firms make up 5-10\% of super patenters. In contrast, their share as well as that of small firms is much smaller in resource processing, potentially indicating larger necessary scales to patent in those industries. In services also super patenters tend to be giant firms mainly. In leasing and commercial services, research and culture-related services micro firms make up 10$20 \%$ of super patenters. In contrast, there are virtually no micro and small firms among super patenters in transport and storage and water conservancy. This again might be indicative of a necessary minimum scale for patenting to reach in those industries.

74. Super patenters tend to be mature firms over 15 years. In particular in big patenting provinces like Guangdong, Jiangsu, Beijing and Shanghai, over a third of super patenters belong to this age category. In Guangdong less than a tenth of super patenters are new firms (i.e. below two years) and in Jiangsu, Beijing and Shanghai less than a fifth. Zhejiang, which is also a large patenting province, is somehow an outlier: among Zhejiang super patenters, the highest share is that of firms between 10-15 years and the share of new firms is higher than that of firms between 2-9 years. This reflects enterprise dynamism in that province. In Hunan and Guizhou also there is a high share of new firms among super patenters. In Sichuan and 
Chongqing, the distribution of super patenting firms across age categories appears relatively even. Largescale innovation at all stages of the firm's life may reflect supportive environments.

75. Most super patenters are located in Jiangsu and Guangdong (together accounting for nearly a third of super-patenter patents), followed by Shanghai, Zhejiang, Beijing and Shandong (Figure 29). Beijing firms have the highest share of invention patents, at one-third. The median Beijing super patenter spends more than 5 times on R\&D per patent than the median firm in Jiangsu. Some provinces, that otherwise do not hold a high share of super patenters' patents, appear to be more specialised in invention patenting than Jiangsu or Guangdong. These provinces include Hubei, Liaoning, Yunnan and Guizhou, all with around $20 \%$ invention patent shares. Among them the median firm in Yunnan, Hubei and Liaoning spends even more on R\&D per patent than their Beijing peer.

\section{Figure 29. Most patents are produced by Jiangsu and Guangdong super patenters}

Number of patent by province and patent type

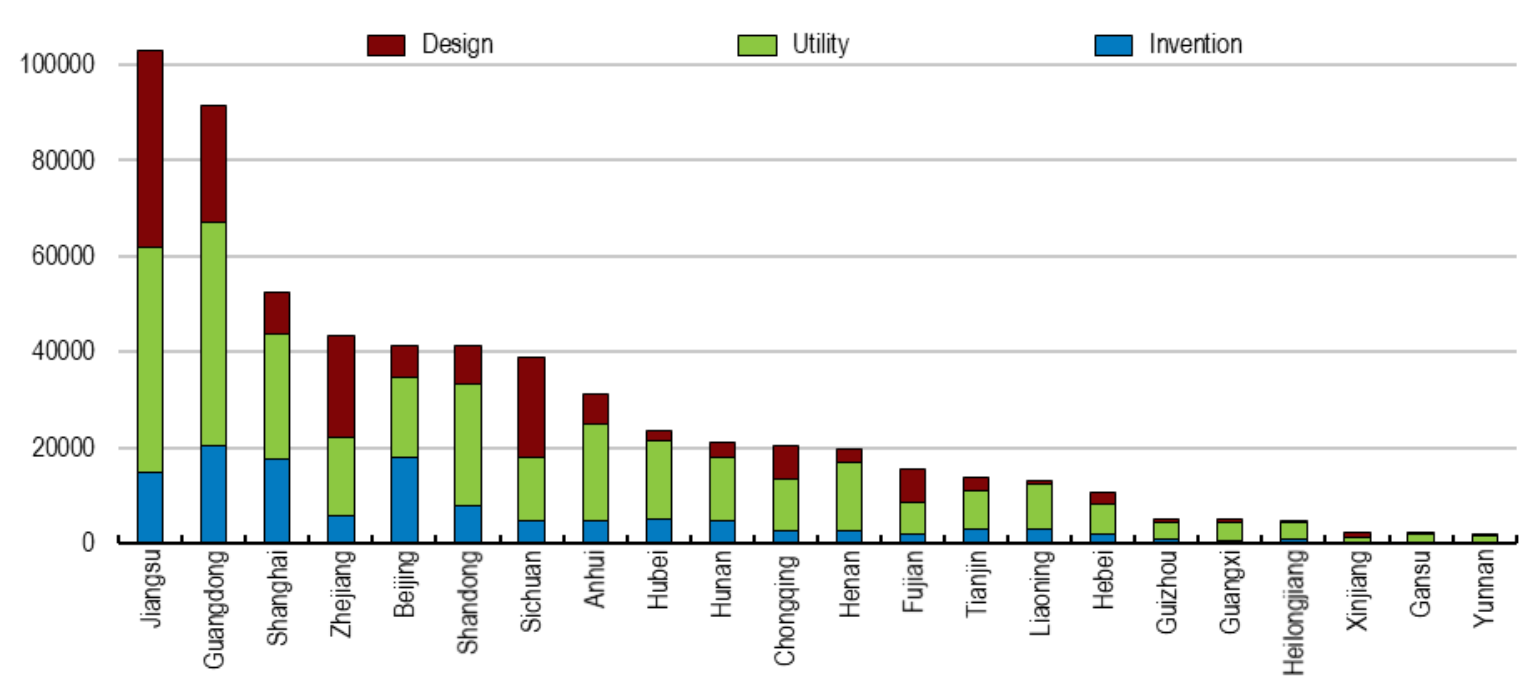

Source: Authors' calculation based on the 2016 SIPO China Patent Survey.

76. The SOE share in super patenters' patents is $22 \%$, much higher than that of foreign-invested firms at $14 \%$ and more than double of private firms' share at $9 \%$. Among these three types of firms, SOEs also produce the largest number of invention patents. Also, SOEs spend more than double on R\&D per patent than foreign firms and more than ten times of private firms. Interestingly, however, for SOEs utility patents are the major output, accounting for two-thirds of all patents they hold (Figure 30). Foreign super-patenters have a more balanced share of invention and utility patents at $28 \%-46 \%$, while private firms rank top in design patenting. This pattern is quite different from the earlier decades in China's innovation history, where there was a clearer specialisation of foreign firms in invention and of domestic firms in utility model patenting (Liang and Xue, 2011). This development may partly reflect the rapid catching up by domestic innovators and partly the adaptation of foreign firms to the Chinese domestic market, which has increasingly become their focus after decades of considering China mainly as a production platform. This trend has also been accompanied by an ever increasing share of services FDI into China. 
Figure 30. SOEs lead in invention and utility patenting and private firms in design

Number of patents held by state-owned, foreign-invested and private super patenters

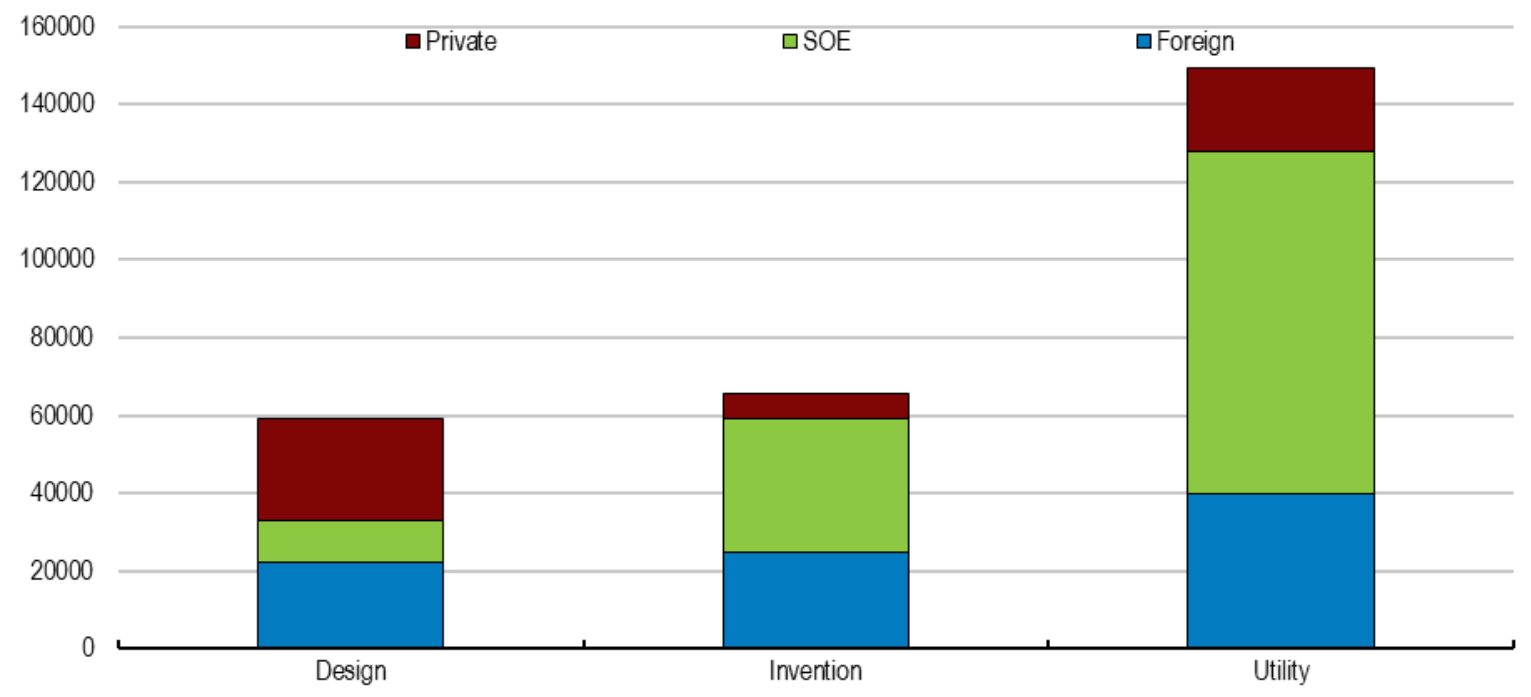

Note: State-owned firms refer to firms fully owned by the State, private firms to fully privately-owned firms and foreign-invested to firms with foreign capital.

Source: Authors' calculation based on the 2016 SIPO China Patent Survey.

77. In sum, the median super-patenter is seven times larger than ordinary patenters, spends nine times more on $R \& D$, but in per patent terms slightly less than smaller peers. This may indicate the existence of economies of scales in patenting. Their patenting activity is less researcher intensive, but more knowledge intensive than that of ordinary patenters. They are more likely to be manufacturers than service providers, mainly in electronics, transport equipment manufacturing or resource processing. Services super patenters tend to specialise more in invention patents than manufacturers. Super patenters are of giant size and mature, with at least 15 years in most industries. Jiangsu and Guangdong rank top. SOEs lead in invention and utility patenting, while private firms in design.

\section{What drives patenting activity?}

78. Empirical analysis provides insights into what factors are associated with more innovation outputs. Innovation outputs are measured by the number of effective patents per employee and the impact of various inputs such as R\&D spending, human capital and other firm-specific characteristics are examined (Box 2). R\&D investment creates new products and production processes (Griliches 1990, Jaffe, Trajtenberg and Henderson 1993, Usai 2011, Wang 2010). Firm size is included, as firms' scale can have an effect on innovative output as increasing returns to scale yield externalities (Feldman and Audretsch 1999). Higher inputs in the form of R\&D spending and higher share of researchers appear to be associated with more patenting. Smaller and older firms tend to patent more. Furthermore, government support is an important driver of patenting. More costly patenting processes relative to R\&D spending, in contrast, do not appear to matter for patenting once controlling for government support.

79. To investigate what conditions are conducive to more patenting, regression analysis was conducted at the firm level using the cross-section of firms participating in the 2016 China Patent Survey by SIPO. The following equation was estimated:

patent $_{i}=\alpha+\beta_{1} R \& D_{i}+\beta_{2}$ researcher $_{i}+\beta_{3}$ size $_{i}+\beta_{4}$ age $_{i}+\beta_{5}$ superpatenter $_{i}+$ FE_IND $+\varepsilon_{i}$ 
80. Where patent is the ratio of effective patents to the number of employees, $R \& D$ is the ratio of average $R \& D$ spending over the past three years (as the production of patents may require research over multiple years beforehand) to sales, researcher is the share of R\&D employees in employees with higher education, size is firm size captured by the number of employees, age is the age of the firm, FE_IND is industry fixed effects and $\varepsilon$ is the standard error. The subscript $i$ indicates the company. All variables are in logarithms. The OLS estimation is applied, as the structure of the data does not leave much room for the choice of estimators. Standard errors are clustered by firm size.

81. Simultaneity is mitigated by using the average of R\&D spending over the past three years for the material input variable. For the human capital input it may be less of an issue as the number of researchers is less volatile than material inputs. The number of researchers relative to employees with a higher education does not have a multicollinearity issue with research spending, unlike the case when using the share of researchers in total employees. That may be related to using part of the R\&D spending to pay researchers' salaries, which are higher than average staff salaries but not necessarily higher than salaries of other employees with tertiary education.

82. The estimation results of equation 1 show that a higher share of researchers (in tertiary graduate employees), being a superpatenter and a smaller firm size are associated with more patenting (Table 1, column 1). R\&D spending during the past three years relative to sales and the age of the firm did not appear to be statistically significantly associated with the number of patents firms hold. The results show correlation between patenting and the explanatory variable, not causality.

83. In the next step, equation 1 was augmented with variables capturing government support. In the Patent Survey, two such variables are available: one is a variable giving the share of patents that receive government support, the median is used here as the variable is expressed as a range. The other variable is a dummy, indicating whether government support is important for the firm. Column 2 of Table 1 shows that the higher share of patents is supported by the government, the more patents firm hold (per employee). The coefficient on interaction term between government support and firm age shows that the impact of government support on patenting varies by firm age: it is larger in the case of younger firms (column 3 ). Those firms that consider government support as their major source tend to be more active patenters (column 4). The coefficient on the interaction term between firm age and the dummy variable of whether firms consider government support as a major source is again negative and statistically significant, indicating that in the case of younger firms, government support is more conducive to patenting.

84. Further, it was examined whether more expensive patenting processes are associated with more patents. The median of the questionnaire's patent process share variable, which was expressed as a range, appeared to matter for patenting (columns 5-7), even when the government support variable and its interaction with firm age were introduced into the equation. 
Table 1. Regression results - What factors determine patenting

\begin{tabular}{|c|c|c|c|c|c|c|c|}
\hline Dependent variable: patents/employees & (1) & (2) & (3) & (4) & (5) & (6) & (7) \\
\hline \multirow[t]{2}{*}{ R\&D spending } & -3.724 & -4.4 & -4.346 & -3.78 & -4.013 & -4.724 & -4.657 \\
\hline & {$[-1.297]$} & {$[-1.454]$} & {$[-1.434]$} & {$[-1.346]$} & {$[-1.434]$} & {$[-1.582]$} & {$[-1.560]$} \\
\hline \multirow[t]{2}{*}{ Researchers } & $0.210^{* *}$ & $0.246^{* *}$ & $0.245^{* *}$ & $0.212^{* *}$ & $0.210^{* *}$ & $0.245^{* *}$ & $0.245^{* *}$ \\
\hline & [2.444] & [2.558] & [2.554] & [2.461] & [2.441] & [2.546] & [2.541] \\
\hline \multirow[t]{2}{*}{ Firm size } & $0.832^{* * *}$ & $0879^{* * *}$ & $0873^{\star-}$ & $0857^{* * *}$ & $0.853^{* * *}$ & $0875^{\star * *}$ & $0869^{* * *}$ \\
\hline & {$[-5.071]$} & {$[-4.816]$} & {$[-4.821]$} & {$[-5.002]$} & {$[-5.004]$} & {$[-4.814]$} & {$[-4.819]$} \\
\hline \multirow[t]{2}{*}{ Firm age } & 0.101 & 0.0992 & $0.337^{* \star}$ & $0.212^{\star *}$ & 0.084 & 0.106 & $0.344^{* *}$ \\
\hline & {$[1.078]$} & [0.992] & [2.533] & [2.091] & [0.929] & [1.043] & [2.549] \\
\hline \multirow[t]{2}{*}{ Superpatenter dummy } & $2.486^{\star * *}$ & $2.496^{* * *}$ & $2.495^{\star * *}$ & $2.469^{* \star *}$ & $2.493^{\star \star *}$ & $2.508^{* \star *}$ & $2.507^{\star \star \star}$ \\
\hline & [4.993] & [4.765] & {$[4.762]$} & [4.997] & [4.989] & [4.765] & [4.763] \\
\hline \multirow[t]{2}{*}{ Government support: share of patents } & & $0.174^{* *}$ & $1.804^{* * *}$ & & & $0.181^{* *}$ & $1.805^{* * *}$ \\
\hline & & [2.207] & {$[3.858]$} & & & [2.303] & [3.823] \\
\hline \multirow[t]{2}{*}{$\begin{array}{l}\text { Interaction term of share of patents supported by government } \\
\text { and age }\end{array}$} & & & $0.675^{\star \star}$ & & & & $0.673^{\star * \star}$ \\
\hline & & & {$[-3.531]$} & & & & {$[-3.491]$} \\
\hline \multirow[t]{2}{*}{ Government support: major source or not } & & & & $1.837^{\star \star \star}$ & & & \\
\hline & & & & [2.691] & & & \\
\hline \multirow[t]{2}{*}{$\begin{array}{l}\text { Interaction term of whether government support is major } \\
\text { source and age }\end{array}$} & & & & $0.641^{* * *}$ & & & \\
\hline & & & & {$[-2.617]$} & & & \\
\hline \multirow[t]{2}{*}{ Patent expense to R\&D spending: median from range } & & & & & $0.460^{* *}$ & $0.432^{* *}$ & $0.421^{* *}$ \\
\hline & & & & & [2.325] & {$[2.118]$} & {$[2.070]$} \\
\hline \multirow[t]{2}{*}{ Foreign ownership dummy } & & 0.149 & 0.15 & 0.151 & 0.129 & 0.141 & 0.143 \\
\hline & & [1.132] & [1.143] & [1.245] & {$[1.053]$} & [1.059] & [1.072] \\
\hline \multirow[t]{2}{*}{ State ownership dummy } & & $0.375^{\star \star \star}$ & $0.381^{* * *}$ & $0.421^{\star * *}$ & $0.406^{\star \star \star}$ & $0.383^{* \star *}$ & $0.387^{* * *}$ \\
\hline & & [2.915] & {$[2.937]$} & [3.297] & [3.293] & [2.936] & [2.951] \\
\hline \multirow[t]{2}{*}{ Private ownership dummy } & & -0.22 & -0.212 & -0.154 & -0.171 & -0.226 & -0.218 \\
\hline & & {$[-1.378]$} & {$[-1.347]$} & {$[-1.125]$} & {$[-1.224]$} & {$[-1.394]$} & {$[-1.366]$} \\
\hline \multirow[t]{2}{*}{ Constant } & $3.765^{\star \star \star}$ & $3.958^{\star * \star}$ & $3.359^{* * *}$ & $3.492^{\star \star *}$ & $3.832^{* \star *}$ & $3.853^{* \star *}$ & $3.258^{* * *}$ \\
\hline & [5.482] & [4.992] & {$[4.879]$} & [5.102] & {$[5.280]$} & [4.915] & {$[4.818]$} \\
\hline Number of observations & 6,229 & 5,712 & 5,712 & 6,229 & 6,168 & 5,659 & 5,659 \\
\hline R-squared & 0.192 & 0.198 & 0.2 & 0.197 & 0.195 & 0.199 & 0.201 \\
\hline
\end{tabular}

Note: Standard errors are clustered by firm size. Two-digit level sector dummies are included in all equations. Superpatenters are firms holding more than 100 effective patents. Among the firm ownership dummies, the omitted one is the sum of all the other categories including joint stock, joint operation, collective and other ownership categories.

Source: Authors' analysis using the 2016 SIPO China Patent Survey.

85. To examine what factors are associated with invention, utility model and exterior design patenting, the three patent types were regressed on R\&D spending, R\&D staff, size of the firm, age of the firm and whether or not government support is important for the firm. The three equations are estimated simultaneously as very often the same firm registers more than one type of patent and there are interactions across the three patenting activities. The following system of equations was estimated:

$$
\begin{aligned}
& \text { invention }_{i}=\alpha_{\text {invention }}+\beta_{\text {invention }} R \& D_{i}+\gamma_{\text {invention }} \text { researcher }_{i}+\delta_{\text {invention }_{\text {government }}}+\theta_{\text {invention }_{\text {size }}} \\
& +\sigma_{\text {invention }} a g e_{i}+F E_{-} I N D+\varepsilon i \\
& \text { utility }_{i}=\alpha_{\text {utility }}+\beta_{\text {utility }} R \& D_{i}+\gamma_{\text {utility }} \text { researcher }_{i}+\delta_{\text {utility }} \text { government }_{i}+\theta_{\text {utility }} \text { size }_{i}+\sigma_{\text {utility }} \text { age }_{i} \\
& +F E_{I N D}+\varepsilon_{i}
\end{aligned}
$$


design $_{i}=\alpha_{\text {design }}+\beta_{\text {design }} R \& D_{i}+\gamma_{\text {design }}$ researcher $_{i}+\delta_{\text {design }}$ government $_{i}+\theta_{\text {design }}$ size $_{i}+\sigma_{\text {design }}$ age $_{i}+$ $F E_{-} I N D+\varepsilon_{i}(2)$

86. Where invention, utility and design are the number of effective invention, utility model and exterior design patens a firm holds, scaled by the number of employees, R\&D is the ratio of average R\&D spending over the past three years to sales, researcher is the share of R\&D employees in employees with higher education, government is a dummy variable, which equals to one if the firm considers government support as an important source of funding, zero otherwise, size is firm size measured by the number of employees, age is the age of the firm, FE_IND is the two-digit industry dummy and $\varepsilon$ is the error term. The subscript $\mathrm{i}$ indicates the company and the subscripts innovation, utility and design show that the coefficients in the three equations vary. All variables are in logarithms. The three-stage least squares estimation is applied to take into account three potentially different patenting processes.

87. The estimation results of equation 2 (Model 1 in the below table) show that higher R\&D spending during the past three years relative to sales is not necessary associated with more patenting, in the case of invention patents, it is even negatively associated. A higher share of researchers among collegegraduate employees appears to be associated with more patenting on all three accounts. The size of the coefficient is larger for utility patenting, that is, a large research workforce matters more in producing utility patents. Government funding is associated with more invention and utility model patents, but not necessarily with design patenting. Firm size is negatively associated with all three types of patents, but age is positively associated with invention patenting only. That is, to come up with genuine inventions, certain maturity might be needed.

88. Next, the above equation 2 was augmented by the share of tertiary graduates and the share of patent expenses in R\&D spending (Model 2 in the below table). This latter variable is measured as a range and the median of the range is used in the analysis. The share of tertiary graduates appears to matter for invention and utility patenting, but not for exterior design patents. Spending on patent registration and maintenance, using the median values of the ranges, seems to be positively associated with utility patenting only.

Table 2. Exterior design patenting differs much from invention and utility patenting Three-stage least squares estimation

\begin{tabular}{|c|c|c|c|c|c|c|}
\hline Dependent variable: patents/employees & Invention & Utility & Design & Invention & Utility & Design \\
\hline & \multicolumn{3}{|c|}{ (1) } & \multicolumn{3}{|c|}{ (2) } \\
\hline \multirow[t]{2}{*}{ R\&D spending } & $-0.736^{*}$ & 0.279 & -1.147 & $-0.859^{* *}$ & -0.364 & -1.718 \\
\hline & $(0.375)$ & $(0.915)$ & $(1.067)$ & $(0.383)$ & $(0.932)$ & $(1.089)$ \\
\hline \multirow[t]{2}{*}{ Researchers } & $0.049^{* * *}$ & $0.124^{* * *}$ & $0.050^{* * *}$ & $0.050^{* * *}$ & $0.129^{* * *}$ & $0.056^{* * *}$ \\
\hline & $(0.003)$ & $(0.008)$ & $(0.009)$ & $(0.003)$ & $(0.008)$ & $(0.009)$ \\
\hline \multirow[t]{2}{*}{ Tertiary graduates } & & & & $0.085^{*}$ & $0.400^{* \star *}$ & 0.419 \\
\hline & & & & $(0.044)$ & $(0.107)$ & $(0.125)$ \\
\hline \multirow[t]{2}{*}{ Firm size } & $-0.063^{\star * *}$ & $-0.215^{\star \star *}$ & $-0.242^{\star * *}$ & $-0.063^{\star \star *}$ & $-0.208^{\star \star *}$ & $-0.239^{* * *}$ \\
\hline & $(0.007)$ & $(0.018)$ & $(0.021)$ & $(0.007)$ & $(0.018)$ & $(0.021)$ \\
\hline \multirow[t]{2}{*}{ Firm age } & $0.029^{*}$ & -0.005 & 0.025 & $0.030^{*}$ & -0.000 & -0.028 \\
\hline & $(0.0188)$ & $(0.042)$ & $(0.049)$ & $(0.017)$ & $(0.042)$ & $(0.049)$ \\
\hline \multirow[t]{2}{*}{ Government support: major source or not } & $0.078^{* * *}$ & $0.216^{* * *}$ & 0.103 & $0.076^{* * *}$ & $0.203^{* * *}$ & 0.093 \\
\hline & $(0.024)$ & $(0.059)$ & $(0.069)$ & $(0.024)$ & $(0.059)$ & 0.069 \\
\hline \multirow[t]{2}{*}{ Patent expense to R\&D spending: median from range } & & & & 0.038 & $0.278^{\star \star *}$ & 0.136 \\
\hline & & & & $(0.043)$ & $(0.104)$ & $(0.122)$ \\
\hline \multirow[t]{2}{*}{ Constant } & 0.234 & $0.932^{* * *}$ & $1.22^{* * *}$ & 0.19 & $0.686^{*}$ & $1.014^{* *}$ \\
\hline & $(0.150)$ & $(0.367)$ & $(0.428)$ & $(0.152)$ & $(0.372)$ & $(0.434)$ \\
\hline Number of observations & 6229 & 6229 & 6229 & 6168 & 6168 & 6168 \\
\hline R-squared & 0.08 & 0.1 & 0.11 & 0.0814 & 0.103 & 0.107 \\
\hline
\end{tabular}

Note: Two-digit level sector dummies are included in all equations.

Source: Authors' estimation based on the 2016 SIPO China Patent Survey. 
89. The above results indicate that patenting is far from being a homogenous activity and in particular, design patenting differs very much from invention and utility model patenting. This is partly related to the different nature of the patent itself: in contrast to the other two patent types, exterior design patents do not necessarily need to involve new process or new technology. That is why design patenting may not require government support for R\&D spending. It does, however, need researchers, who are likely the designers of the new outlook. Design patenting in this sense may be more human-capital and less innovation-capital intensive. Patenting expenses do not appear to matter for design patenting, only for utility patenting. In this latter case, higher maintenance expenses may reflect higher quality as higher quality patents are more likely to be worth of extending their lives.

90. As the three patent types appear quite different in terms of whether or not they embed new technology and to what extent the invention needs to be genuinely new, their drivers may also differ. This warrants an investigation allowing for different impacts of the various inputs into the innovation process. The three equations are estimated simultaneously to account for possible interactions across the three types of patenting. The results suggest that there is considerable difference across invention, utility and design patenting activities. In particular, exterior design patenting does not depend much on government support, but does need researchers. Given the data structure, regressions only indicate correlation and not causality, nevertheless they allow inferring about the difference in the patenting processes across patent types.

\section{Government subsidies for R\&D and patenting}

91. The 2015 SIPO Patent Survey showed that larger patenters tend to rely more on government support for their research and patenting activities than smaller ones in both manufacturing and services industries. In electronics, transport equipment, electrical machinery and equipment manufacturing over a quarter of the very large firms (employing at least 1000 people) indicated that government support is a major source of their funding. Among services, a similar picture emerged with an even greater share of firms answering the same in scientific research, IT and software and culture and entertainment industries. A major difference between manufacturing and services patenters is among micro- and small and mediumsize enterprises. In most manufacturing industries, $10-20 \%$ of those firms mostly rely on government support, while in several services industries, such as transport and storage, education, culture, sport and entertainment, none of the firms in the smaller size categories relies on government support as the major source of funding. Furthermore, SOEs are the major beneficiaries of government support.

92. In China, the major form of government subsidies is direct support of research projects, over $80 \%$ of which is coming through province- and prefecture level projects. The high sub-national share explains the high reliance of patenters on government support for their research in wealthier provinces, which can afford more easily to subsidise their firms. In addition, accelerated depreciation and tax reduction and exemption are the two other major forms of government subsidies. The share of direct and indirect subsidies is roughly the same, but altogether much smaller than subsidies for R\&D in many OECD countries (Figure 31). Most OECD countries use tax incentives for R\&D as a major form of subsidy, though Spain and some Central and Eastern European economies use direct support overwhelmingly. Government budget allocations for R\&D at half a percent of GDP in 2018 in China also appear relatively modest compared to OECD countries (Figure 32 ). Such budget allocations are channelled to various socioeconomic objectives.

93. In China, since the 1990s local governments have been providing exemption from patent application and/or examination fees and/or offering prizes for successful patent filers. Since September 2016, individuals with an income below CNY 3500 per month and firms with pre-tax revenue below CNY 300000 per year are eligible for an exemption of up to $85 \%$ of fees related to application, examination, maintenance and re-application of a patent. 
Figure 31. In China direct and indirect subsidies for R\&D are smaller relative to GDP than in many OECD countries

Share of spending on direct and indirect subsidies as a percentage of GDP, 2016

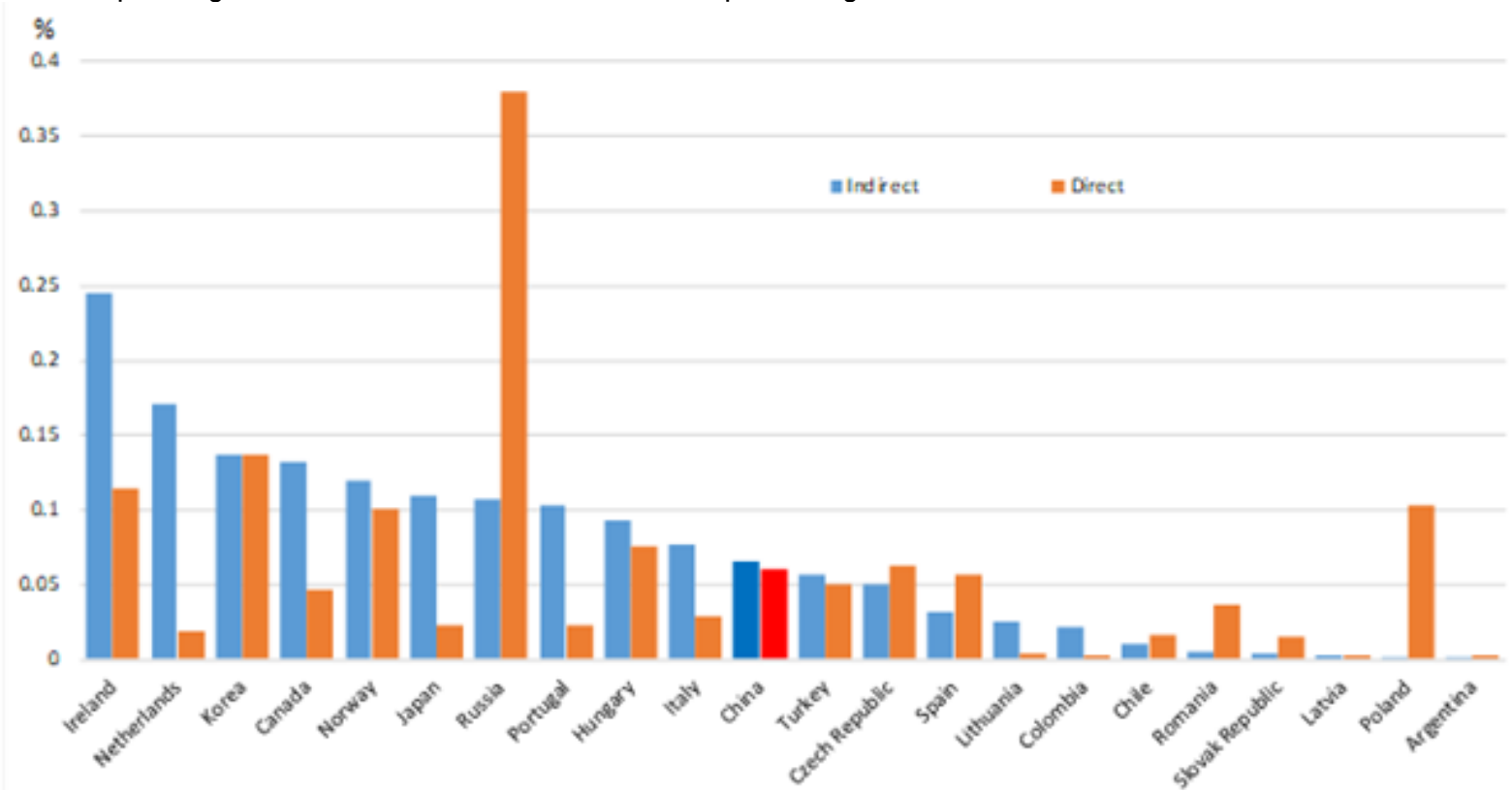

Note: Indirect spending is through R\&D tax incentives, while direct spending includes cash grant, loans and other direct financial support. Source: OECD R\&D tax expenditure dataset and OECD Main Science and Technology Indicators.

Figure 32. Government budget allocation for R\&D As a percentage of GDP, 2018

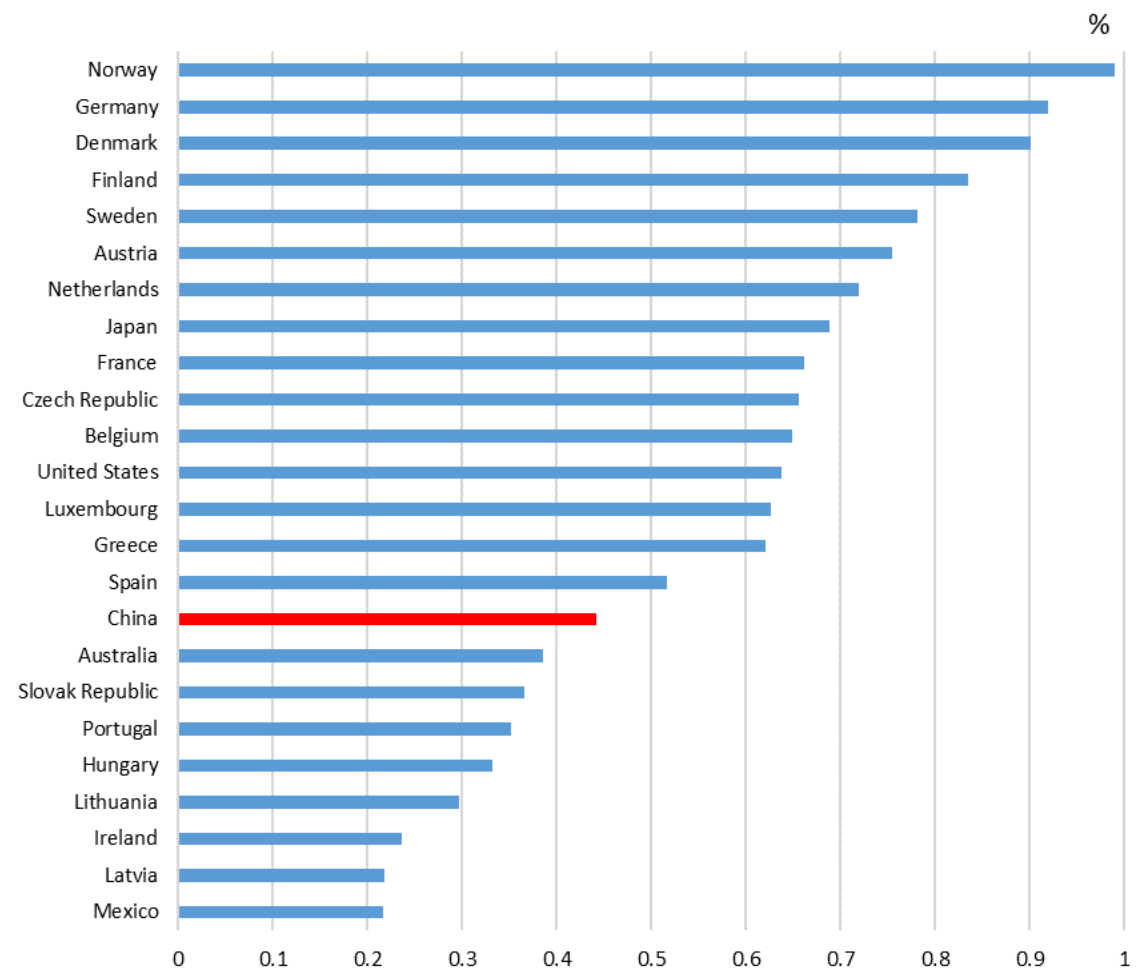

Note: Government budget allocations for R\&D socio-economic objective, using the NABS 2007 classification i.e.: Exploration and exploitation of the Earth, Environment, Exploration and exploitation of space, Transport, telecommunication and other infrastructures, Energy, Industrial production and technology, Health, Agriculture, Education, Culture, recreation, religion and mass media, Political and social systems, structures and processes, General advancement of knowledge, Defence.

Source: OECD Main Science and Technology Indicators. 


\section{Towards higher productivity through more relevant and higher quality patenting}

94. Patenting activity has been thriving in China, supported by an enabling policy environment and generous subsidies coupled with a "petit patent" system with more emphasis on diffusion than protection of intellectual property. Such a combination has been favourable for incremental innovation. Indeed, most patents are utility model patents. Also, it has been favourable for technology diffusion, in particular to smaller firms. The market, however, appears to have reached a more mature stage, where the majority of inventors demand a stronger protection of IPRs, which would encourage them to invest in innovation and register their inventions.

95. Most patent holders, regardless of their size, consider IPR protection insufficient (Figure 33). When it comes to having experienced patent infringement, the largest firms (with more than 1000 employees) are more likely to face this problem (Figure 34 ), around $40 \%$ in both modern and traditional manufacturing. In Heilongjiang and Guangdong similar shares of micro firms have such experience, but in general, micro firms do not appear to be the major targets. Micro firms in modern industries are even less likely to have experienced patent infringement than in traditional manufacturing. Probably these are fast movers in newly emerging industries with less threat of copycats. Foreign firms more often report patent infringement than SOEs or private firms. In some provinces such as Hunan, $60 \%$ of foreign firms have such experience, while in Guangdong, Shanghai and Fujian around $40 \%$. Such firms are likely to have superior technology and may operate in industries where it is hard to protect products or processes from imitators.

\section{Figure 33. Most firms, regardless of firm size, consider IPR protection insufficient}

Share of firms replying IPR protection is insufficient

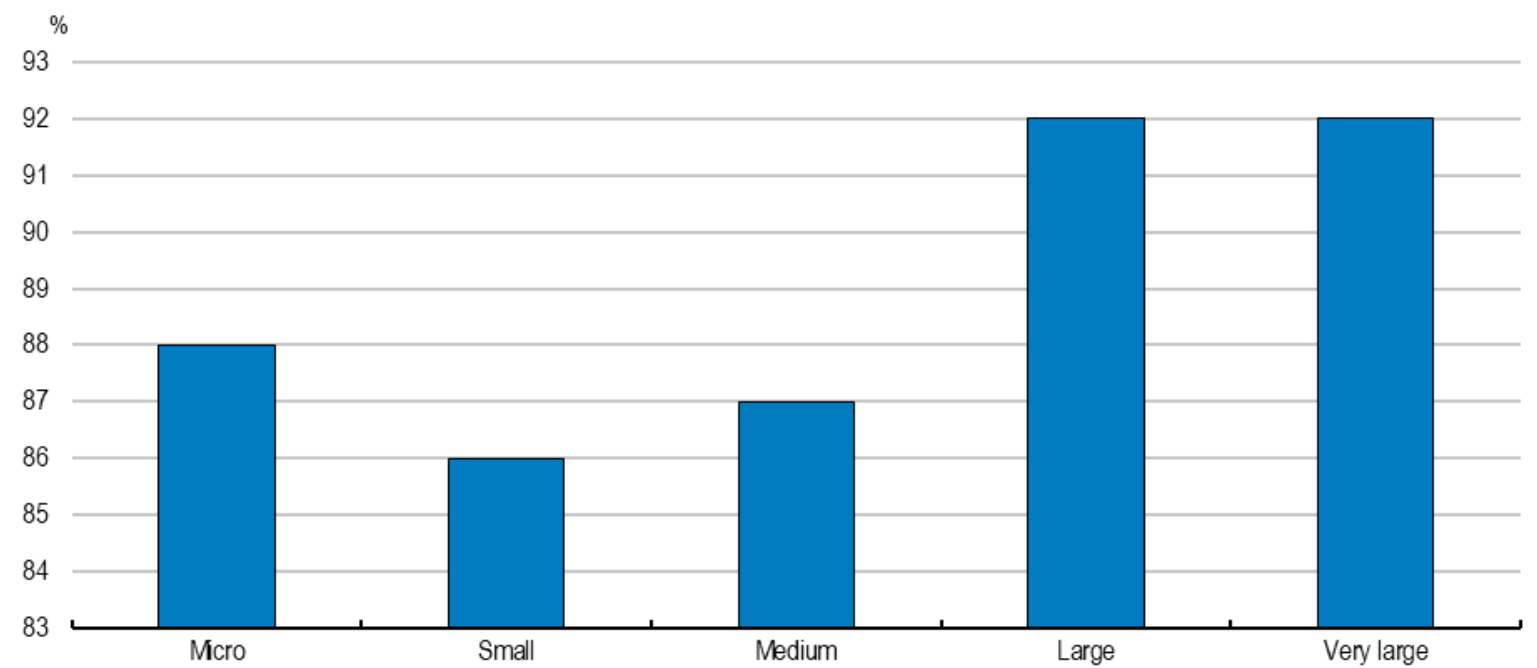

Note: Size categories are defined using the definition of up to 19 employees for micro firms, 20-49 for small, 50-245 for medium, 250-999 for large and at least 1000 employees for very large firms.

Source: Authors' calculation based on the 2016 SIPO China Patent Survey. 
Figure 34. Very large firms are more likely to have experienced patent infringement

Share of firms experiencing patent infringement by firm size

A. Modern manufacturing

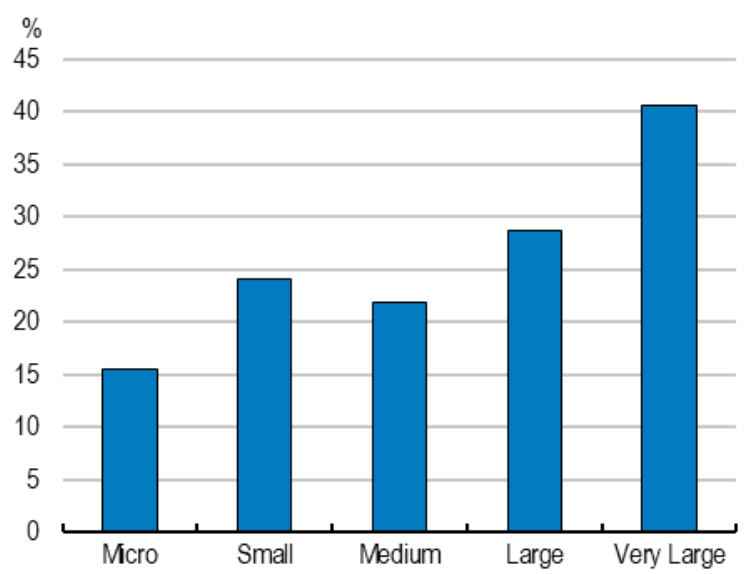

B. Traditional manufacturing

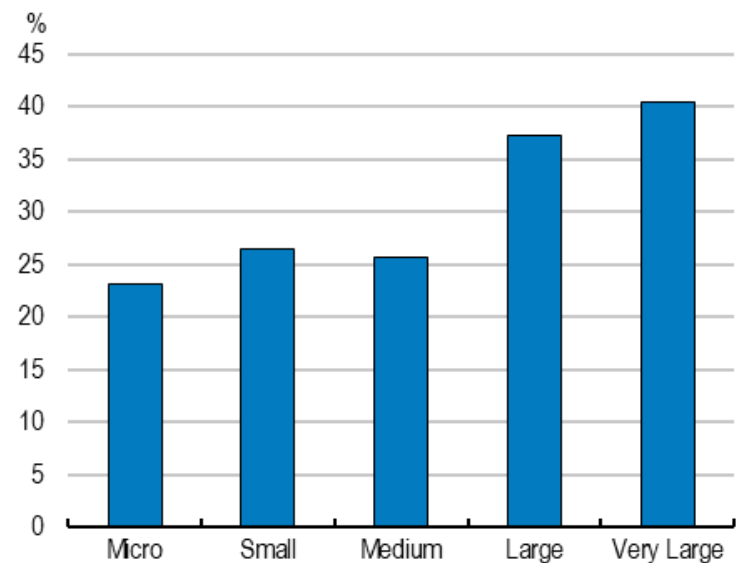

Note: Based on the official classification of industries into new/modern and traditional (National Bureau of Statistics, 2012). Size categories are defined using the definition of up to 19 employees for micro firms, 20-49 for small, 50-245 for medium, 250-999 for large and at least 1000 employees for very large firms.

Source: Authors' calculation based on the 2016 SIPO China Patent Survey.

96. Smaller firms are less affected by patent infringement and a relatively large share $--15-20 \%$ depending on the sub-industry -- think that IPR protection is too high. These firms may prefer benefiting from innovation results of other - most likely larger -- firms instead of protecting inventions. In light industries and transport equipment manufacturing the share of micro firms preferring lower protection of IPR is particularly high (Figure 35). In the former, this may be related to the large number of small firms in the sector and in the latter to high fixed costs of patenting, as discussed above in the section on the sectoral dimension of patenting firms. 
60 | ECO/WKP(2019)53

Figure 35. Some smaller firms consider IPR protection too high

Share of firms replying IPR protection is too stringent
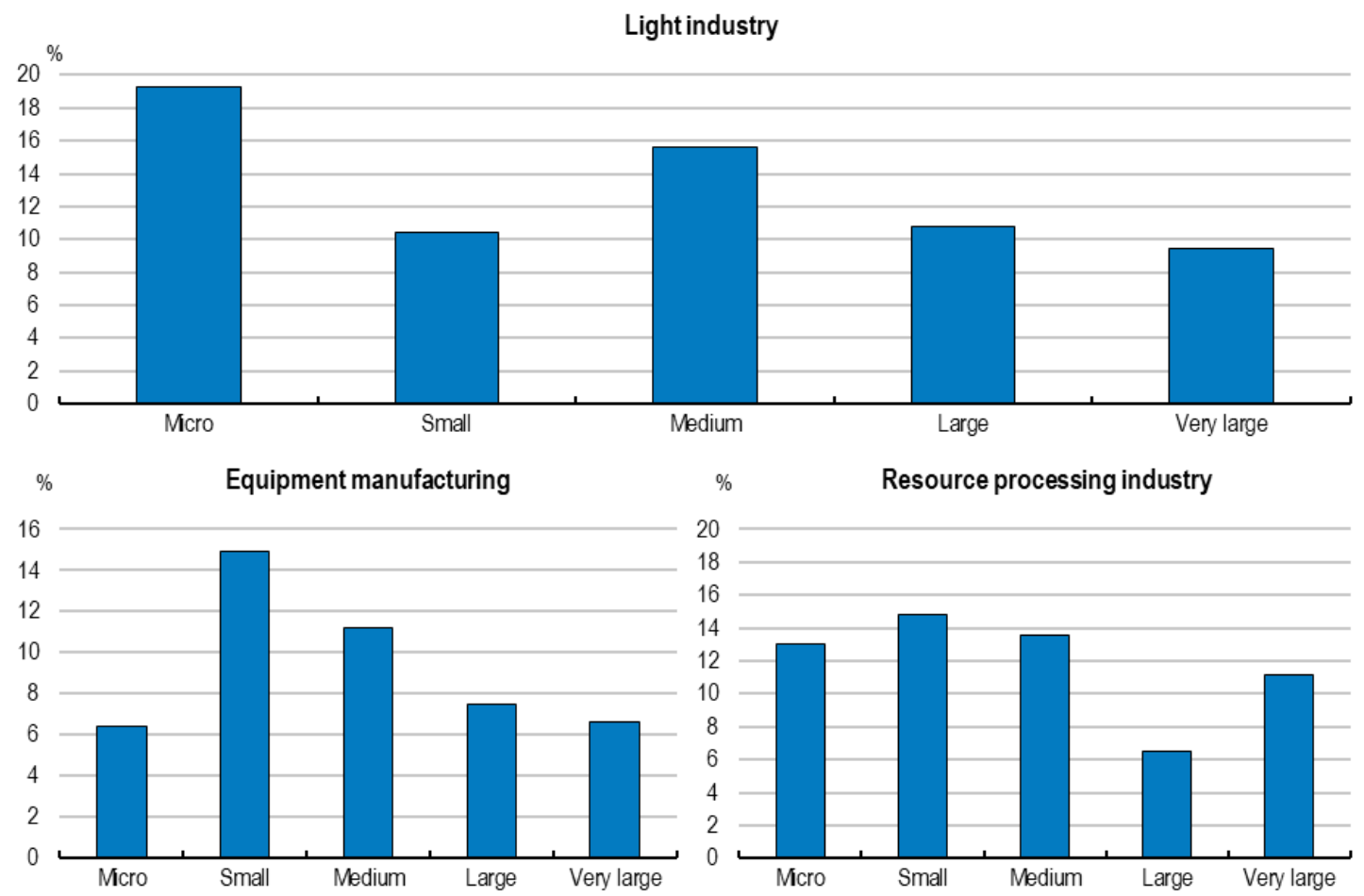

$\% \quad$ Resource processing industry
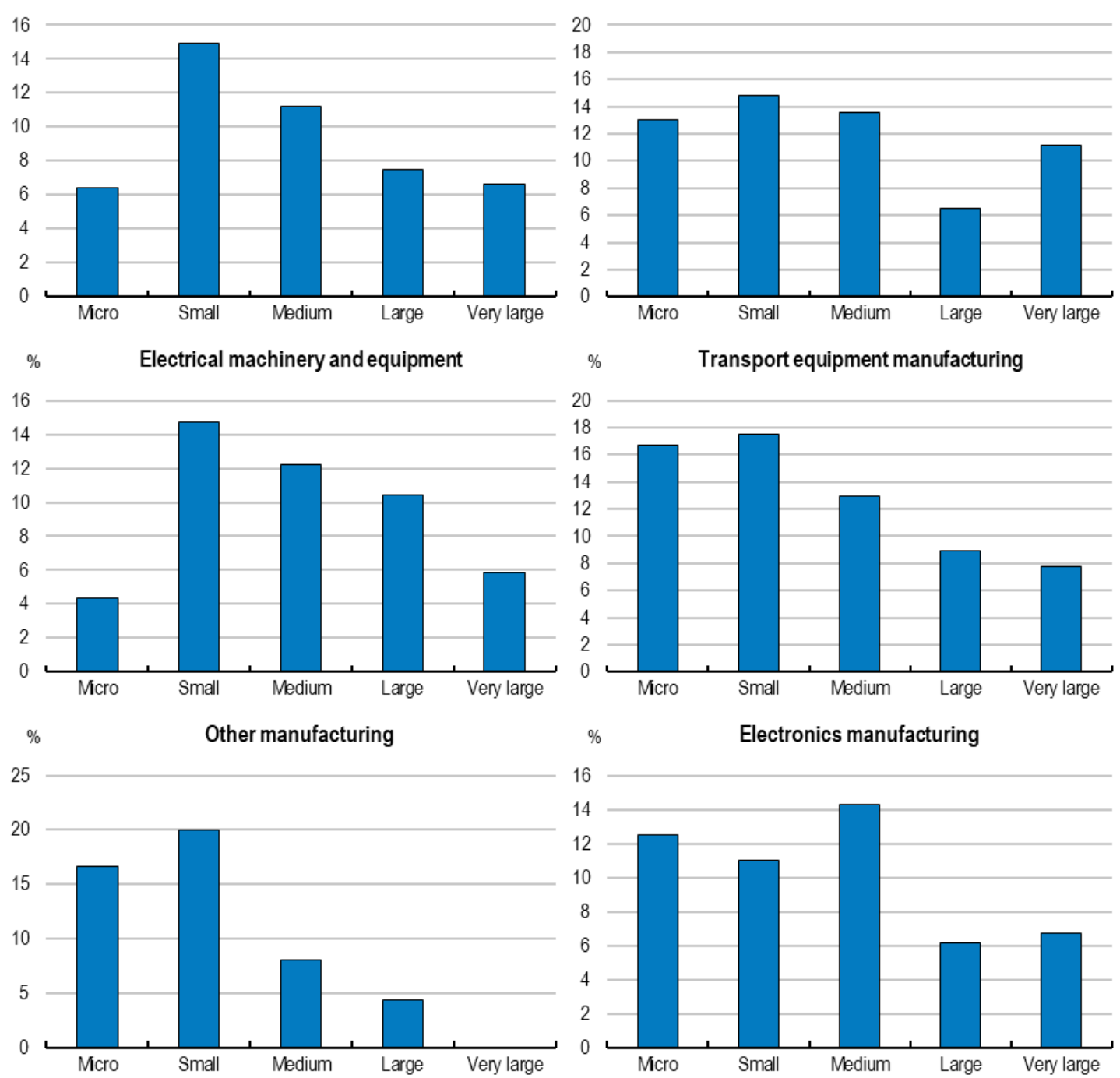

Note: Size categories are defined using the definition of up to 19 employees for micro firms, 20-49 for small, 50-245 for medium, 250-999 for large and at least 1000 employees for very large firms.

Source: Authors' estimation based on the 2016 SIPO China Patent Survey. 
97. Most firms prefer stronger IPR protection, many experience infringement of their patent rights and again a large share of them do not do anything once their rights are infringed as they do not expect effective remedy. Instead of patenting (Figure 36), which may not provide sufficient protection from imitators, they adopt other strategies like reaping the first mover advantage to market their goods or sign confidentiality agreements with their staff or contracts on commercial secrets (SIPO, 2015).

Figure 36. Several firms prefer not to register patents

Share of firms with non-registered product innovation

A. Eastern provinces

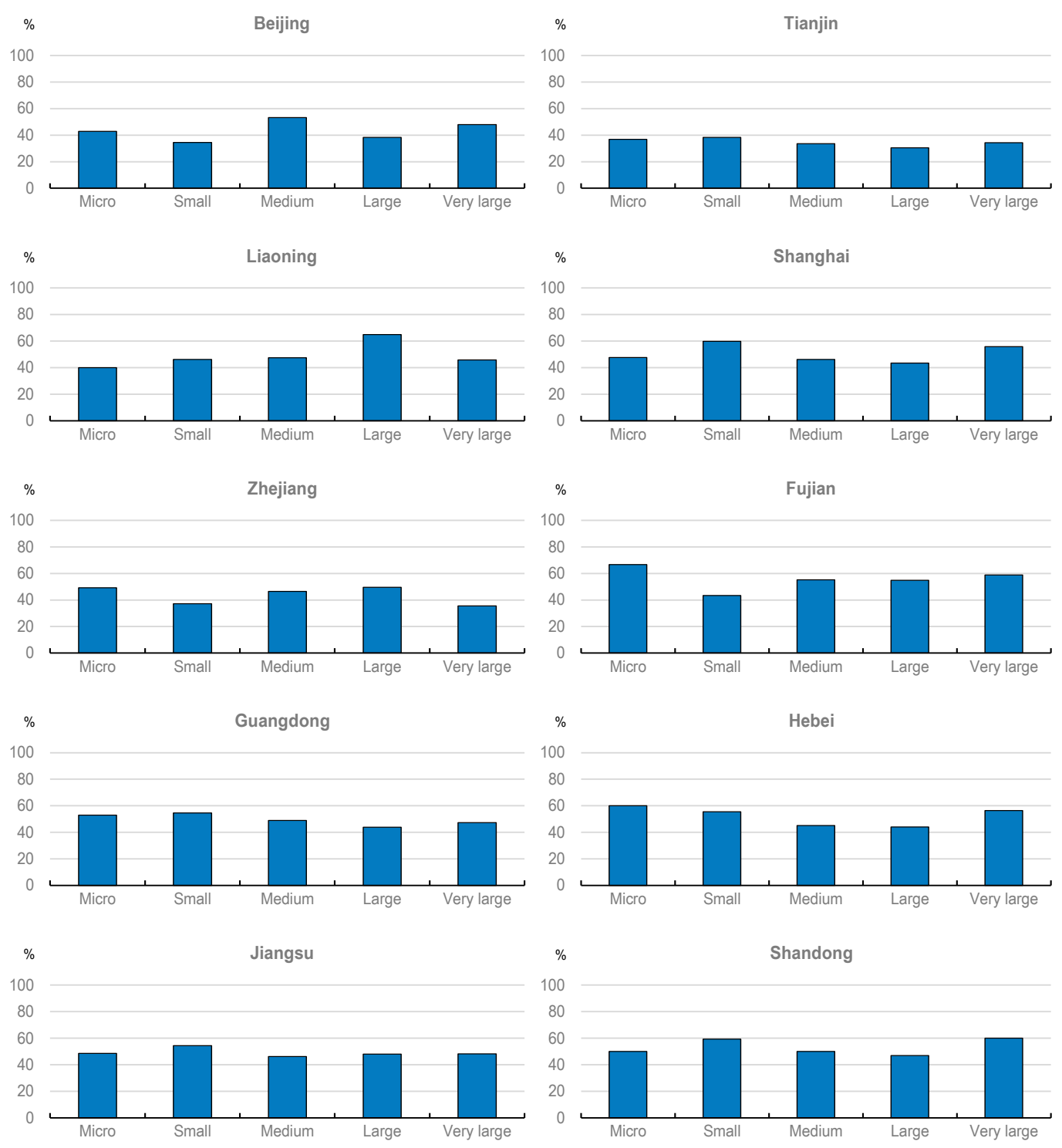


62 | ECO/WKP(2019)53

B. Central provinces

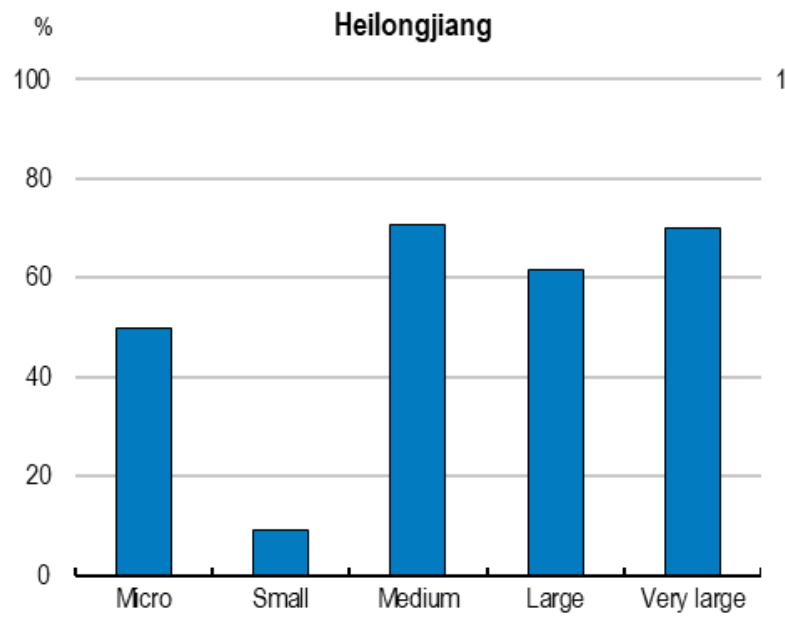

$\%$ Henan

100

80

60

40

20
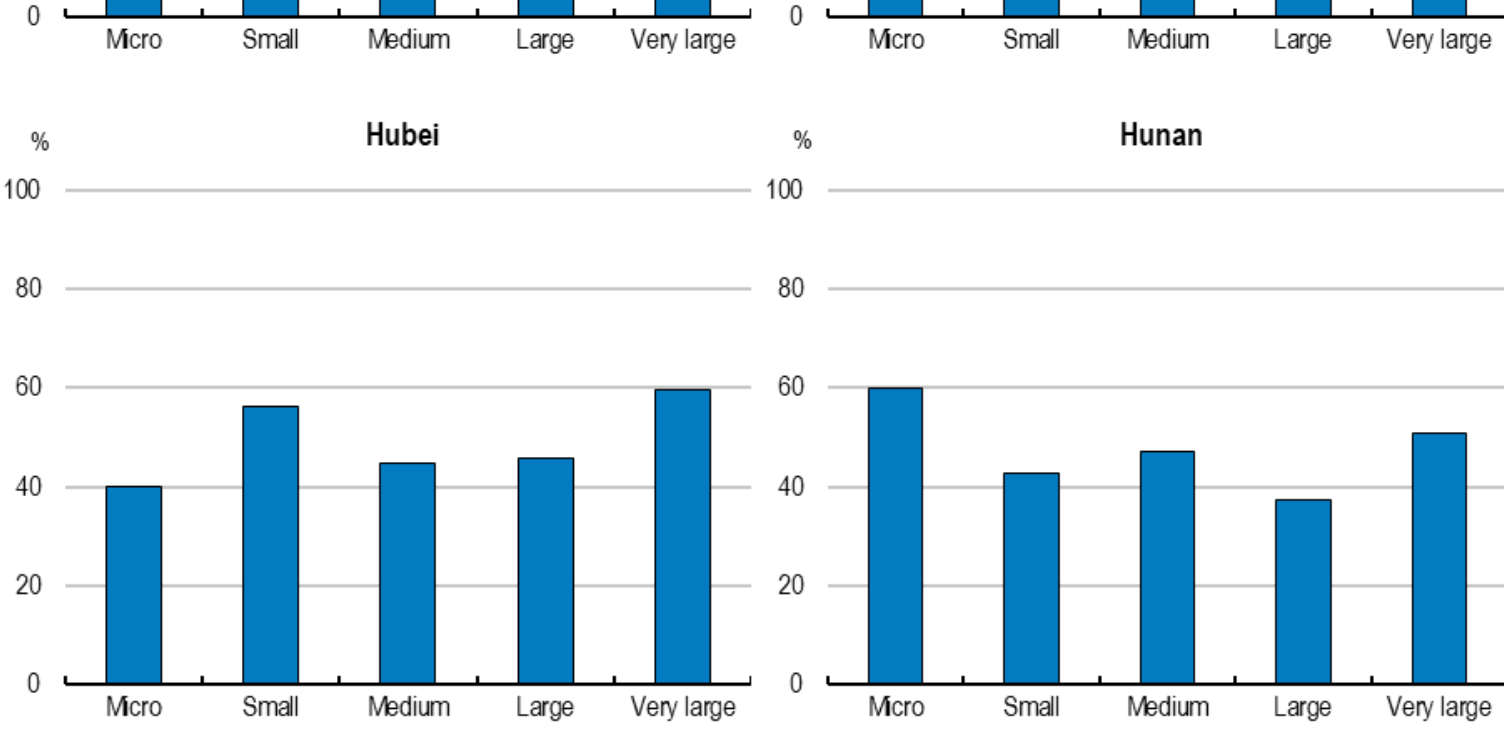

$\%$

Hunan

100

80

60
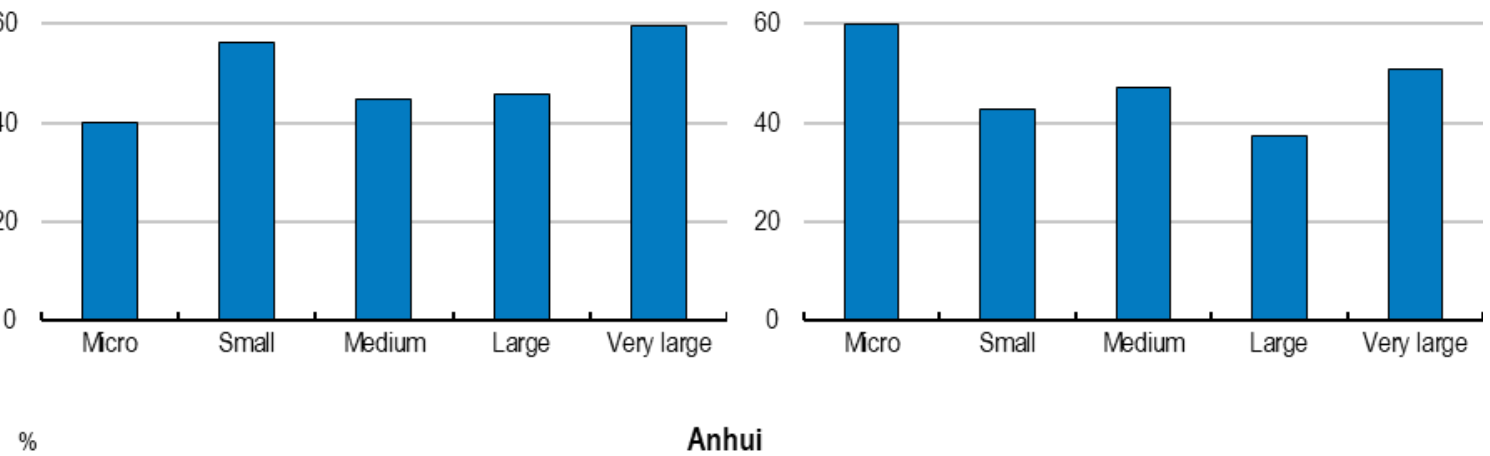

100

80

60

40

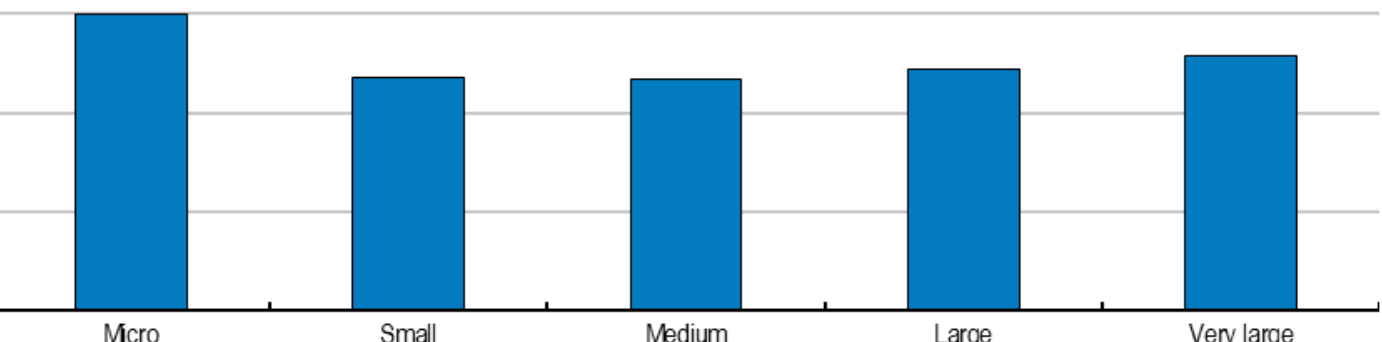



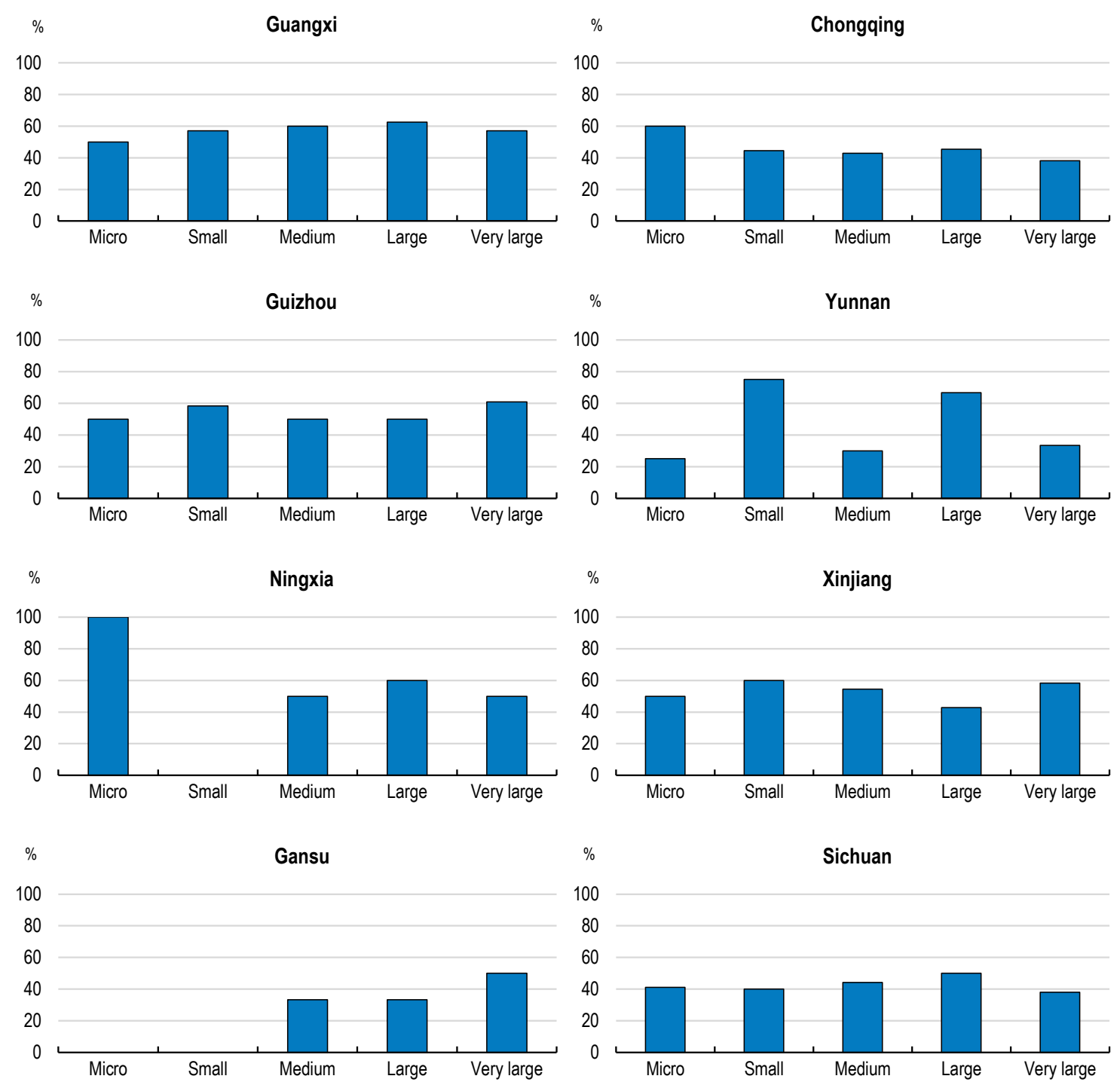

Note: According to the definition by China's National Bureau of Statistics, Eastern provinces include Beijing, Tianjin, Hebei, Liaoning, Shanghai, Jiangsu, Zhejiang, Fujian, Shandong, Guangdong and Hainan, Central provinces comprise Shanxi, Jilin, Heilongjiang, Anhui, Jiangxi, Henan, Hubei and Hunan and Western provinces cover Inner Mongolia, Guangxi, Chongqing, Sichuan, Guizhou, Yunnan, Tibet, Shaanxi, Gansu, Qinghai, Ningxia and Xinjiang Size categories are defined using the definition of up to 19 employees for micro firms, 20-49 for small, 50-245 for medium, 250-999 for large and at least 1000 employees for very large firms.

Source: Authors' calculation based on the 2016 SIPO China Patent Survey.

98. Such inventions protected by commercial secret agreements or confidentiality contracts to some extent represent foregone patents. With a stronger protection of IPRs, such potential patenters would not be deterred from registering their inventions by the threat of imitation. Stronger IPR protection would also likely raise patent quality as potential patenters would be willing to invest more in research should they be surer that they will be able to reap the benefits from their future inventions. The Chinese government is putting increasing emphasis on IPR protection, since 2014 specialised IPR courts are being set up. The courts set up in Beijing, Shanghai and Guangzhou together, dealt with around $8 \%$ of all concluded IPR cases in 2015 . Of the 120000 cases, $62 \%$ were related to copyrights, $22 \%$ to trademarks, $10 \%$ to patents and the remaining $6 \%$ to technology contracts, unfair competition and other disputes (Supreme People's 
Court of the PRC, 2016). Specialisation is justified on effectiveness and efficiency grounds. An important pitfall to avoid is interest-group capture, as seen elsewhere (Dourado and Tabarrok, 2015).

99. Both quality and relevance of patents could be boosted by more streamlined subsidy policies, which are now being adjusted. Sub-national governments since long have been providing exemptions from patent application and examination fees and/or offering prizes for patentees. Subsidies at the filing and examination phase tend to be particularly harmful as the former encourage filing non-patentable or lowquality/low-value inventions and the latter hinder the filtering effect of examination fees and overload patent examiners, imposing a congestion externality on other applicants. Grant-contingent subsidies may be the least harmful, though they may still boost low-value and/or low-quality patents (OECD, 2017). Patent application screening could be enhanced to avoid perverse incentives and congestion costs at handling institutions.

\section{References}

Acs, Z. J. and D. B. Audretsch (1991), “R\&D, firm size and innovative activity”, in Z. J. Acs and D. B. Audretsch, (eds.), Innovation and Technological Change: An International Comparison, New York, NY: Harvester Wheatsheaf.

Boeing, P., E. Mueller and P. Sandner (2016), “China's R\&D explosion - Analysing productivity effects across ownership types and over time", Research Policy, Vol. 45.

Coad, A., A. Segarra and M. Teruel (2016), "Innovation and firm growth: Does firm age play a role?", Research Policy Vol. 45.

Cohen, W. M. and S. Klepper (1996a), "Firm size and the nature of innovation within industries: The case of process and product R\&D", Review of Economics and Statistics Vol. 78 (2).

Cohen, W. M. and S. Klepper (1996b), "A Reprise of size and R\&D", Economic Journal, Vol. 106(437).

Criscuolo, P. N. Nicolaou and A. Salter (2012), "The elixir (or burden) of youth? Exploring differences in innovation between start-ups and established firms", Research Policy Vol. 41.

Dang, J. and K. Motohashi (2015), "Patent statistics: A good indicator for innovation in China? Patent subsidy program impacts on patent quality", China Economic Review, Vol. 35.

Dourado, E. and A. Tabarrok (2015), "Public choice perspectives on intellectual property", Public Choice, Vol. 163.

Feldman, M. P., and D. B. Audretsch (1999), "Innovation in cities: Science-based diversity, specialization, and localized competition", European Economic Review, Vol. 43.

Fritsch, M. and H. Brezinski (eds.) (1999), Innovation and Technological Change in Eastern Europe: Pathways to Industrial Recovery. Edward Elgar.

Griliches, Z. (1990), "Patent statistics as economic indicators: A survey”, Journal of Economic Literature Vol. 28.

Guo, D., Y. Guo and K. Jiang (2016), "Government-subsidised R\&D and firm innovation: Evidence from China”, Research Policy, Vol. 45.

Hong Kong Shanghai Banking Corporation (2017), China's Smart Move - Climbing the technology ladder.

Hu, A. (2014), "Propensity to patent, competition and China's foreign patenting surge", in S. Ahn, B.H. Hall and K. Lee (eds) Intellectual Property for Economic Development. Korea Development Institute and Edward Elgar.

Jaffe, A.B., M. Trajtenberg and R. Henderson (1993), "Geographic localisation of knowledge spillovers as evidenced by patent citations", Quarterly Journal of Economics Vol. 434.

Liang, Z. and L. Xue (2011), "A Tale of Two Cities: A Comparison of Patent-based Innovative 
Performance of Domestic and Multinational Companies in China", Journal of International Commerce and Economics Vol. 3(1).

Liang, Z. and L. Xue (2010), "The evolution of China's IPR system and its impact on the patenting behaviours and strategies of multinationals in China", International Journal of Technology Management Vol. 51 (2/3/4).

Molnar, M. and J. Lu (2019), "State-owned firms behind China's corporate debt", OECD Economics Department Working Papers No. 1536, OECD Publishing.

Molnar, M. and W. Wang (2015), "A Snapshot of China's Service Sector", OECD Economics Department Working Papers No. 1217, OECD Publishing.

National Bureau of Statistics (2012), Zhanlüexing Xinxing Chanye Fenlei 2012.

OECD (2019), Economic Survey of China. OECD Publishing, Paris.

OECD (2017), Economic Survey of China. OECD Publishing, Paris.

OECD (2015), The Innovation Imperative - Contributing to productivity, growth and well-being. OECD Publishing, Paris.

State Intellectual Property Office (SIPO) (2016a), 2016 Nian quanguo zhuanli diaocha jichu shuju baogao, in Chinese (2016 National patent survey basic data report) SIPO Development Research Centre.

State Intellectual Property Office (SIPO) (2016b), 2016 Nian quanguo zhuanli diaocha shuju baogao, in Chinese, (2016 National patent survey report), SIPO Development Research Centre.

State Intellectual Property Office (SIPO) (2016c), Zhongguo zhuanli mijixing chanye zhuyao tongji shuju baogao 2015, in Chinese (2015 Statistical data report on China's patent-intensive industries).

State Intellectual Property Office (SIPO) (2015), 2014 Nian Zhongguo zhuanli diaocha baogao, in Chinese (2014 China patent survey report).

Supreme People's Court of the PRC (2016), The Work of China's Courts 2015.

Usai, S. (2011), "The geography of inventive activity in OECD regions", in Regional Studies, Taylor \& Francis Journals, Vol. 45(6).

Wang, E.C. (2010), "Determinants of R\&D investment: The extreme-bounds-analysis approach applied to 26 OECD countries", Research Policy Vol. 39. 


\section{Annex A. Definition of manufacturing sector sub- groups}

100. For the sake of easier assessment of patenting activity across manufacturing sub-sectors, the following re-classification is used throughout the paper. This classification groups the 312-digit industries into 7 sub-groups by placing industries with common features in the same group.

\section{Table A.1. Manufacturing sub-groups}

Light industry (13-24)

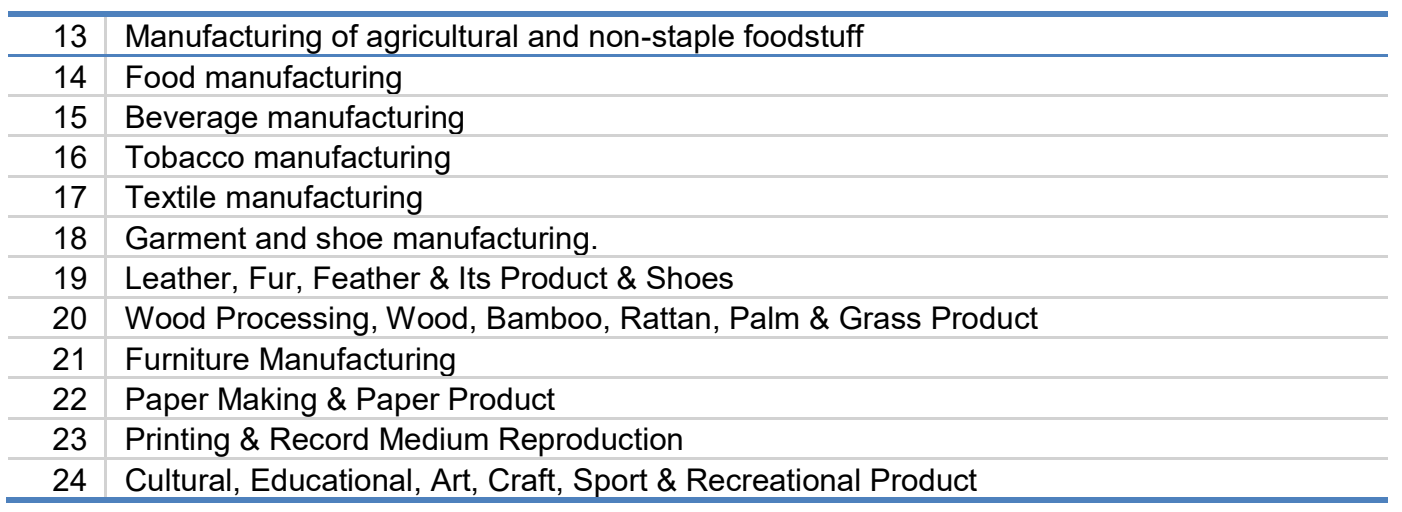

Resource processing industry (25-33)

\begin{tabular}{r|l}
\hline 25 & Petroleum, Coking \& Nuclear Fuel \\
\hline 26 & Chemical Material \& Product \\
\hline 27 & Medical \& Pharmaceutical Product \\
\hline 28 & Chemical Fibre \\
\hline 29 & Rubber \& Plastic Product \\
\hline 30 & Non Metallic Mineral Product \\
\hline 31 & Ferrous Metal Smelting \& Pressing \\
\hline 32 & Non Ferrous Metal Smelting \& Pressing \\
\hline 33 & Fabricated Metal Product \\
\hline
\end{tabular}

Equipment manufacturing (34-35)

\begin{tabular}{l|l}
34 & General Equipment \\
35 & Special Equipment
\end{tabular}

Transport equipment manufacturing (36-37)

36 Automobile Manufacturing

37 Rail, Ship, Aircraft, Spacecraft \& Other Transport Equipment

Electrical machinery and equipment (38)

38 Electrical Machinery \& Equipment 
Electronics manufacturing (39-40)

39 Computer, Communication \& Other Electronic Equipment

40 Instrument \& Meter

Other manufacturing (41-43)

41 Other Manufacturing

42 Comprehensive Utilization of Resource Waste

43 Fabricated Metal Product, Machine \& Equipment Repair 


\section{Annex B. Definition of modern and traditional industries}

101. The grouping used in this report follows the official classification of industries into new/modern and traditional (National Bureau of Statistics, 2012), for both services and manufacturing industries. As the official classification is at the 4-digit level of the Chinese industry classification, while data in the Patent Survey are at the 2-digit level, the following classification is applied, based on the majority principle (i.e. if the majority of the sub-industries at the 4-digit level are classified as strategic new industries, then their 2digit level industry is classified as new, otherwise as traditional).

\section{Table B.1. New and traditional industries}

\begin{tabular}{|c|c|c|}
\hline & Modern & Traditional \\
\hline \multirow[t]{18}{*}{ Manufacturing } & Beverage manufacturing & $\begin{array}{l}13 \text { Manufacturing of agricultural and non-staple } \\
\text { foodstuff }\end{array}$ \\
\hline & Textile manufacturing & 14 Food manufacturing \\
\hline & Leather manufacturing & 16 Tobacco manufacturing \\
\hline & Paper manufacturing & 18 Garment and shoe manufacturing \\
\hline & Petroleum processing and coking & 20 Wood processing \\
\hline & Chemical manufacturing & 21 Furniture manufacturing \\
\hline & Medicine manufacturing & 23 Printing and recording \\
\hline & Chemical fibre manufacturing & $\begin{array}{l}24 \quad \text { Culture, education and sports goods } \\
\text { manufacturing }\end{array}$ \\
\hline & Non-metallic minerals manufacturing & Rubber manufacturing \\
\hline & $\begin{array}{l}31 \quad \text { Ferrous metals smelting and } \\
\text { processing }\end{array}$ & Metal product manufacturing \\
\hline & $\begin{array}{l}32 \quad \text { Non-ferrous metal smelting and } \\
\text { processing }\end{array}$ & General-purpose equipment manufacturing \\
\hline & $\begin{array}{l}35 \quad \text { Special-purpose equipment } \\
\text { manufacturing }\end{array}$ & Car manufacturing \\
\hline & $\begin{array}{l}37 \quad \text { Railroad, ship and airplane equipment } \\
\text { manufacturing }\end{array}$ & Other manufacturing \\
\hline & Electric machinery manufacturing & Metal and machine repairing \\
\hline & $\begin{array}{l}39 \text { Computer, telecommunications and } \\
\text { other electronics equipment manufacturing }\end{array}$ & \\
\hline & Measurement equipment manufacturing & \\
\hline & Recycling & \\
\hline & & \\
\hline
\end{tabular}




\begin{tabular}{|c|c|c|c|c|}
\hline & & Modern & & Traditional \\
\hline \multirow[t]{42}{*}{ Services } & 63 & Telecommunications & 51 & Wholesale \\
\hline & 64 & Internet and related services & 52 & Retail \\
\hline & 65 & Software and IT services & 53 & Rail transport \\
\hline & 76 & Water production and supply & 54 & Road transport \\
\hline & & & 55 & Water transport \\
\hline & & & 56 & Air transport \\
\hline & & & 57 Pipelir & ne transport \\
\hline & & & 58 & Container transport \\
\hline & & & 59 & Storage \\
\hline & & & 60 & Posts \\
\hline & & & 61 & Accommodation \\
\hline & & & 62 & Catering \\
\hline & & & 66 & Financial services \\
\hline & & & 67 & Capital market services \\
\hline & & & 68 & Insurance \\
\hline & & & 69 & Other financial industries \\
\hline & & & 70 & Real estate \\
\hline & & & 71 & Leasing \\
\hline & & & 72 & Business services \\
\hline & & & 73 & $R \& D$ \\
\hline & & & 74 & Professional technical services \\
\hline & & & $\begin{array}{l}75 \\
\text { services }\end{array}$ & Technology dissemination and application \\
\hline & & & $\begin{array}{l}77 \\
\text { governance }\end{array}$ & $e^{\text {Ecological protection and environmental }}$ \\
\hline & & & 78 & Public facilities management \\
\hline & & & 79 & Resident services \\
\hline & & & $\begin{array}{l}80 \\
\text { repairing }\end{array}$ & Electric vehicles, electronics and daily goods \\
\hline & & & 81 & Other services \\
\hline & & & 82 & Education \\
\hline & & & 83 & Health \\
\hline & & & 84 & Social work \\
\hline & & & 85 & Newspaper and publishing \\
\hline & & & 86 & Broadcasting, tv and video recording \\
\hline & & & 87 & Cultural art services \\
\hline & & & 88 & Sport \\
\hline & & & 89 & Entertainment \\
\hline & & & 90 & Party organisation \\
\hline & & & 91 & Government bodies \\
\hline & & & 92 & People's consultation, democratic party \\
\hline & & & 93 & Social security \\
\hline & & & 94 & Mass and social organisations \\
\hline & & & 95 & Grassroots self-governing organisations \\
\hline & & & 96 & International organisations \\
\hline
\end{tabular}

